\title{
Electrochemical Reactions of Quinones at Conducting Polymer Electrodes
}

\section{Canyan Che}

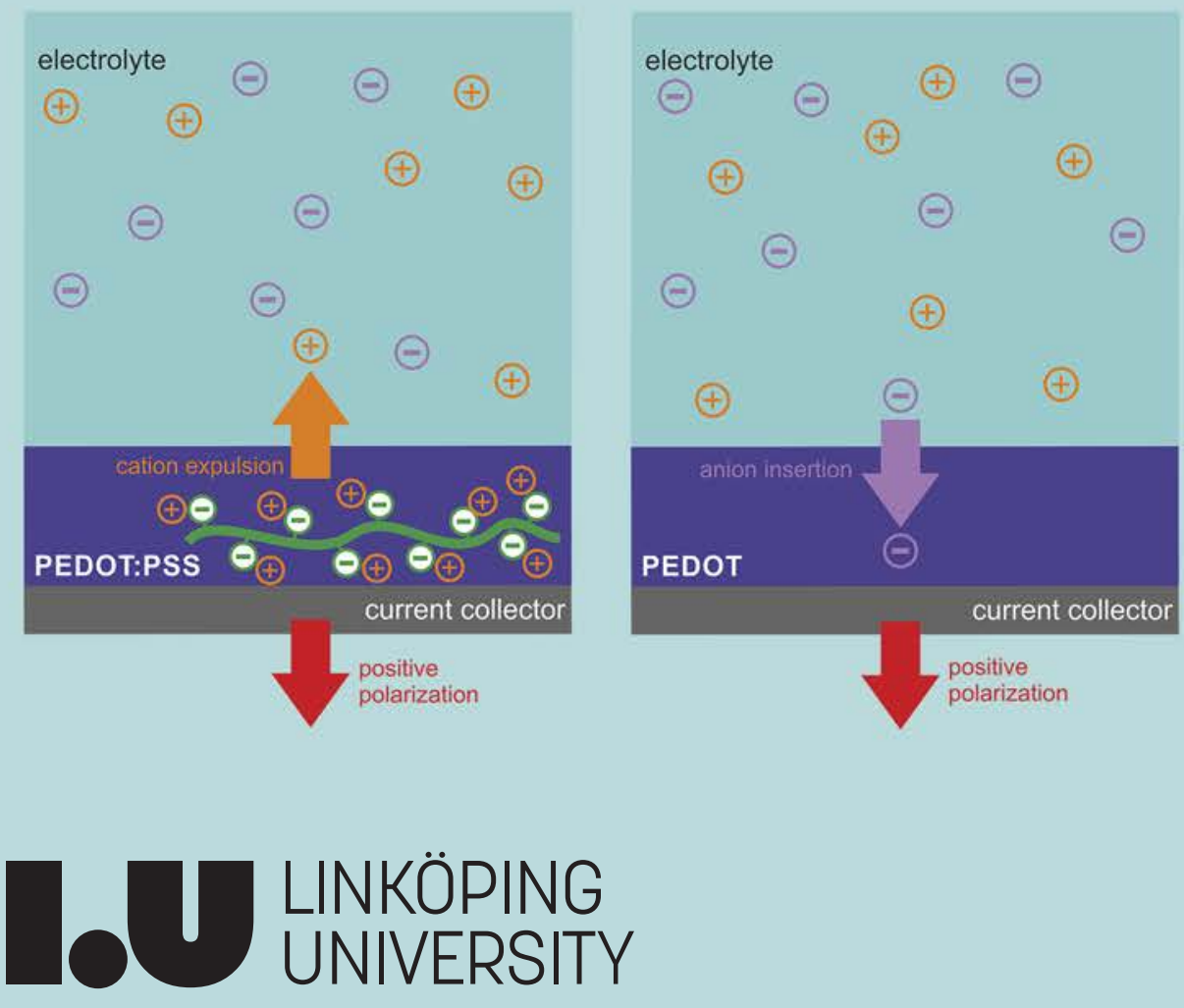




\section{Electrochemical Reactions of Quinones at Conducting Polymer Electrodes}

Canyan Che

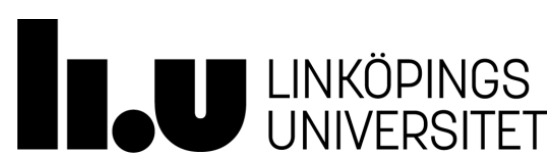

Department of Science and Technology

Linköping University, Sweden

Norrköping 2019 


\section{Description of the cover image:}

The illustration of the cover represents the congruent and non-congruent ion transport at PEDOT:PSS and PEDOT:Tos electrode designed by Canyan Che and Mikhail Vagin.

Electrochemical Reactions of Quinones at Conducting Polymer Electrodes

(C) Canyan Che, 2019

During the course of the research underlying this thesis, Canyan Che was enrolled in Agora Materiae, a multidisciplinary doctoral program at Linköping University, Sweden.

Printed by LiU-Tryck, Linköping, Sweden, 2019

ISBN 978-91-7929-958-3

ISSN 0345-7524 


\section{Abstract}

Proton-coupled multielectron transfer reactions are of great abundance in Nature. In particular, two-proton-two-electron transfers in quinone/hydroquinone redox couples are behind oxidative phosphorylation (ADP-to-ATP) and photosystem II. The redox processes of neurotransmitters, as a platform for brain activity read-out, are two-proton two-electron transfers of quinones. Moreover, humic acids, which constitute a major organic fraction of soil, turf, coal, and lignin, which forms as a large-scale surplus product from forest and paper industry, contain a large quantity of polyphenols, which can undergo the exchange of two electrons per aromatic ring accompanied with transfers of two protons. This makes polyphenol-based biopolymers, such as lignin, promising green-chemistry renewable materials for electrical energy storage or generation. The application of intact or depolymerized polyphenols in electrical energy devices such as fuel cells and redox flow batteries requires appropriate electrode materials to ensure efficient proton-coupled electron transfer reactions occurring at the solid-liquid interface. Moreover, investigation of the biological quinones reaction calls for porous, soft, biocompatible materials as implantable devices to reduce the rejection reaction and pain.

At common electrode materials such as platinum and carbons, quinone/hydroquinone redox processes are rather irreversible; in addition, platinum is very costly. Conducting polymers (CPs), poly(3,4-ethylenedioxythiophene) (PEDOT) in particular, offer an attractive option as metal-free electrode material for these reactions due to their molecular porosity, high electrical and ionic conductivity, solution processability, resistance to acid media, as well as high atomic abundance of their constituents.

This thesis explores the possibility of utilizing CPs as electrode materials for driving various quinone redox reactions. Firstly, we studied the electrocatalytic activity and mechanism of PEDOTs for the generic hydroquinone reaction and their application in a fuel cell. Secondly, the mechanism of integrating lignosulfonate (LS) into CP matrices and optimization strategies were explored in order to boost energy storage capacity. Thirdly, we attained mechanistic understanding of the influence of ionic transport and proton management on the thermodynamics and kinetics of the electrocatalysis on CPs, thereby providing steps towards the design of quinone-based electrical energy storage devices, such as organic redox flow batteries (ORFB). 


\section{Sammanfattning}

Proton-kopplade multielektronöverföringsreaktioner är vanligt förekommande i naturen. Exempelvis ligger två-proton-två-elektronöverföringar i kinon/hydrokinon-redoxpar bakom oxidativ fosforylering (ADP-till-ATP) och fotosystem II. Redoxprocesserna för neurotransmittorer, som en plattform för avläsning av hjärnaktivitet, är två-proton tvåelektronöverföringar av kinoner. Dessutom innehåller huminsyror, som utgör en stor organisk fraktion av mark, torv och kol och lignin, och som också är en överskottsprodukt från skogs- och pappersindustrin, en stor mängd polyefenoler, som kan genomgå utbyte av två elektroner per aromatisk ring åtföljt av överföringar av två protoner. Detta gör polyfenolbaserade biopolymerer, såsom lignin, lovande som förnybara material för lagring eller produktion av elektrisk energi. Applicering av intakta eller depolymeriserade polyfenoler i elektriska energianordningar såsom bränsleceller och redoxflödesbatterier kräver lämpliga elektrodmaterial för att säkerställa effektiva protonkopplade elektronöverföringsreaktioner som sker vid gränsytan mot vätska.

Vid vanliga elektrodmaterial, såsom platina och kol, är kinon / hydrokinon-redox-processer i stort sett irreversibla; dessutom är platina mycket kostsamt. Ledande polymerer (CP, akronymer på engelska), och särskilt poly (3,4-etylendioxytiofen) (PEDOT) erbjuder ett attraktivt alternativ som metallfritt elektrodmaterial för dessa reaktioner på grund av deras molekylära porositet, höga elektriska och joniska ledningsförmåga, processerbarhet i lösningsform, motståndskraft mot syror, samt överflöd av deras beståndsdelar.

I denna avhandling undersöks möjligheten att använda CP som elektrodmaterial för att driva olika kinonredoxreaktioner. För det första studerar vi den elektrokatalytiska aktiviteten och mekanismen för PEDOT mot den generiska hydrokinonreaktionen och dess tillämpning i en bränslecell. För det andra undersöks mekanismen för lignosulfonat (LS) -integration i CPmatris och optimeringsstrategier för att öka energilagringskapaciteten. För det tredje uppnådde vi mekanistisk förståelse för jontransportens och protonhanteringens effekter på termodynamiken och kinetiken för elektrokatalys på $\mathrm{CP}$, vilket är värdefullt för design av kinonbaserade enheter för lagring av elektrisk energi, till exempel organiska redoxflödesbatterier (ORFB). 


\section{Acknowledgements}

Time flies, the memories of how I started my $\mathrm{PhD}$ studies and how was the first day when I stepped into Sweden remain fresh. During the past few years, the exciting, peaceful, enjoyable life here were embedded with tough moments such as confusing, depressing, hesitating, struggling, anxious, etc. Now, the PhD journey almost comes to the end, an end filed with scientific results, knowledge, friendships, fun, love and my first baby! I understand from the bottom of my heart that this amazing ending will not be possible without the encouragement, support, guidance, inspiration and sharing of the people around. For that, I would like to express my sincere gratitude to all of them. In particular, I would like to thank:

Xavier Crispin, my main supervisor, for giving me the great opportunity to work in this fantastic, international research group, for being kind and willing to share your life story, dreams beyond science, and for all the patient explanations, creative ideas, inspiring discussions and continuous supports along the projects and for being the "matchmaker" between me and Shaobo.

Mikhail Vagin, one of my co-supervisors, for being my technician teacher, standing by firmly and guiding me on electrochemistry from experimental operations to theoretical analysis throughout the whole $\mathrm{PhD}$ life. Your passions towards electrochemistry and vivid teaching is so impressive that I would benefit for a very long time.

Magnus Jonsson, one of my co-supervisors for the first 2-3 years, for the magic quinone molecules that you introduced to my $\mathrm{PhD}$ projects, and all the instant responses whenever I have doubts and asked for help as well as for all the input on manuscripts and thesis.

Viktor Gueskine, one of my co-supervisors for the last 1-2 years, for the effort in sustaining the electrochemistry group; for the active involvement and patience in my project, and particularly, for the hard work on refining the manuscripts as well as thesis.

Magnus Berggren, senior of the seniors in LOE, for leading and maintaining such a fantastic environment of LOE and for being an impressively kind and energetic scientist as well as for the help in polishing the manuscripts.

Daniel Simon, for sharing all the cool stuff and updating information related to LOE, and for the introduction on presentation techniques. Igor Zozoulenko, for organizing the cool ITN conferences and keeping track of the study plans. Isak Engquist, Simone Fabiano, Eleni 
Stavrinidou, Eric Glowacki, Klas Tybrandt and Valerio Beni, for the interesting conversations during lunch, fika or Friday beers.

Anna Malmström, Lars Gustavsson, Thomas Karlsson, and Meysam Karami Rad, for their tremendous help with technical issues in the lab.

Evangelia (Elina), my elegant mentor, and lab guider Kosala, for their introduction in the start, help and advices throughout the $\mathrm{PhD}$ study. Ioannis (Yiannis), Ziyauddin, Nadia and Josefin, for the help with thesis correction and translating. Gábor, Jaywant, Jesper, Magdalena, Robert, Roger, Ujwala, Wing Cheung Mak, for scientific discussions, advices, help or collaborations.

Anna H, Mina, Dan, Xiaoyan, for the happy times during mushroom picking, walking, cooking and gossips in life.

Ahmadou, Andrea, Anton, Arman, Ayesha, Chiyuan, Chuanfei, Dagmawi, David, Deyu, Divyaratan, Donata, Donghyun, Ellen, Eliot, Eni, Evan, Fareed, Fei, Felipe, Gang Wang, Gwennael, Hamid, Hengda, Hongli, Iwona, Jennifer, Jiu, Johannes, Kai, Lixin, Maciej, Makara, Maria, Marie, Mert, Mehmet, Miriam, Nara, Naveed, Nitin, Lorenz, Penghui, Renbo, Saeed, Samim, Samuel, Sanna, Sergi, Shangzhi, Silan, Skomantas, Suhao, Tran, Tero-Petri, Tobias, Vasileios, William, Xiane, Xenofon, Yusuf, Zia...... all the old and new colleagues and friends in LOE, for sharing knowledge, offering helps and for the happy times during parties, fika as well as sharing cakes and cookies.

The administrative team: Åsa Wallhagen, Katarina Swanberg, Lesley G Bornhöft, Kattis Nordlund, Annelie Westerberg and Jenny Joensuu, for the help on many activities beside research.

The leaders of Agora Marteriae, Per-Olof, Caroline and all the members, for organizing seminars, study visit and conferences, and for the cakes, fika, and interesting discussions.

My whole family in China for their remote encouragement, support and love, and of course to my colleague, friend as well as husband: Shaobo, for the accompany, tolerance, support in life and fun in exploring the nature of Sweden.

In the end, I would like to thank all the Fundings includes China Scholarship Council (CSC), Swedish foundation strategic research etc., for the financial supports during this $\mathrm{PhD}$ study. 


\section{List of Included Papers}

Paper I: Conducting Polymer Electrocatalysts for Proton-Coupled Electron Transfer Reactions: Toward Organic Fuel Cells with Forest Fuels. Advanced Sustainable Systems, 2018. 1800021. Canyan Che, Mikhail Vagin, Kosala Wijeratne, Dan Zhao, Magdalena Warczak, Magnus P. Jonsson and Xavier Crispin*

Contribution: performed most of the experiments and characterization of the materials, wrote the first draft and contributed to the final editing of the manuscript.

Paper II: Twinning Lignosulfonate with a Conducting Polymer via Counter-ion Exchange for Large-scale Electrical Storage. Advanced Sustainable Systems, 2019. 1900039.

Canyan Che, Mikhail Vagin, Ujwala Ail, Viktor Gueskine, Jaywant Phopase, Robert Brooke, Roger Gabrielsson, Magnus P. Jonsson, Wing Cheung Mak, Magnus Berggren, Xavier Crispin* Contribution: performed most of the experiments and characterization of the materials, wrote the first draft and contributed to the final editing of the manuscript.

Paper III: Ion-selective electrocatalysis of quinones on conducting polymer electrodes for redox flow batteries (Manuscript).

Canyan Che, Mikhail Vagin, Viktor Gueskine, ..., Magnus Berggren, Xavier Crispin

Contribution: performed most of the experiments and characterization of the materials, wrote parts of the draft and contributed to the final editing of the manuscript.

Paper IV: Proton management in electrochemical conversion of quinones with implantable poly(3,4-ethylenedioxythiophene) electrodes (Manuscript).

Canyan Che, Mikhail Vagin, Viktor Gueskine, ..., Magnus Berggren, Xavier Crispin

Contribution: performed most of the experiments and characterization of the materials, wrote parts of the draft and contributed to the final editing of the manuscript.

Patent application: Electrode System with Polymer Electrode, EP3447836A1. 2019.

Xavier Crispin, Canyan Che, Mikhail Vagin, Magnus Jonsson

Contribution: performed most of the experiments and characterization of the materials, contribute to the final editing of the patent. 


\section{Contents}

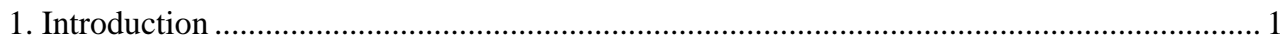

1.1. Motivation and Research Background ........................................................................ 1

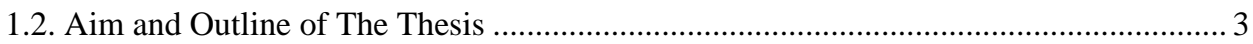

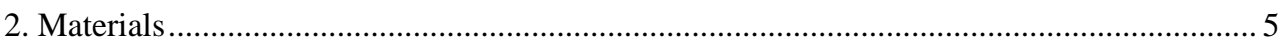

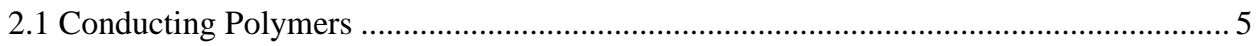

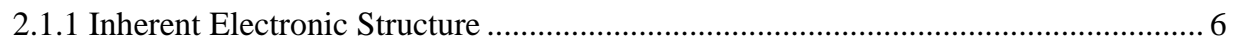

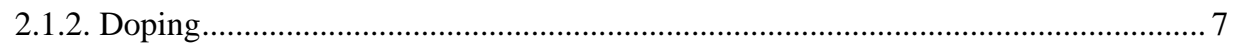

2.1.3. Electrochemical Properties of Conducting Polymers ........................................... 11

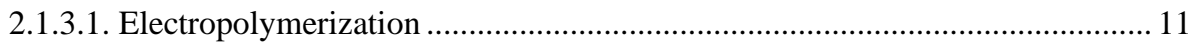

2.1.3.2. Electrochemical Charge and Discharge of The Conducting Polymers ............ 12

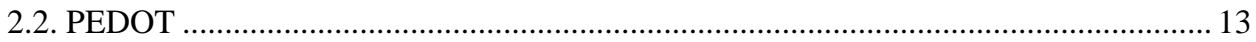

2.3. Lignin and Lignosulfonate and quinone/hydroquinone Redox Systems ...................... 15

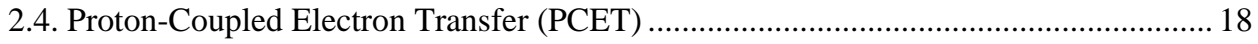

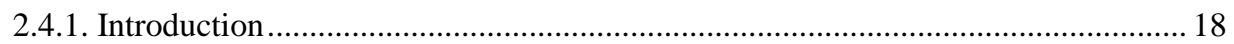

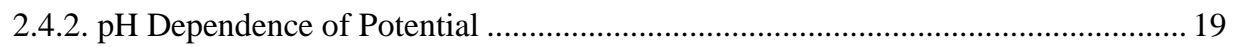

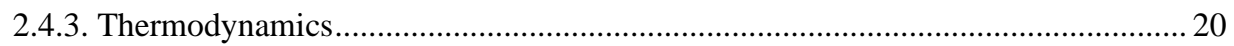

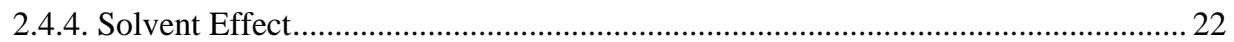

3. Principles of Characterization Methods and Devices......................................................... 23

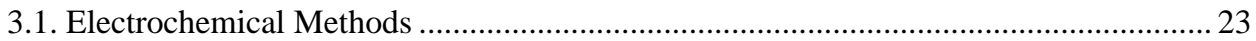

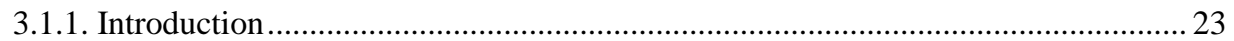

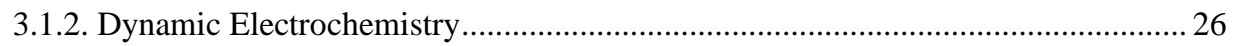

3.1.3. Factors Affecting Electrode Reaction Rate and Current....................................... 29

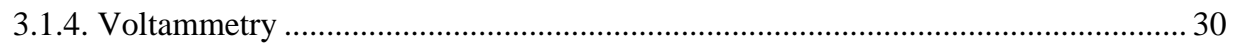

3.1.4.1. Linear sweeping Voltammetry and Cyclic Voltammetry ................................ 30

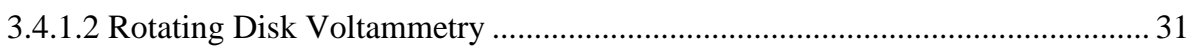

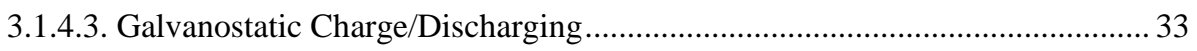

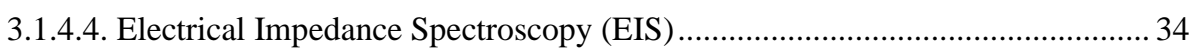

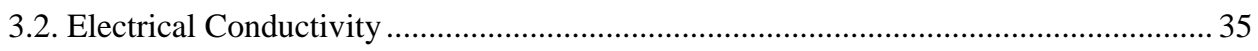

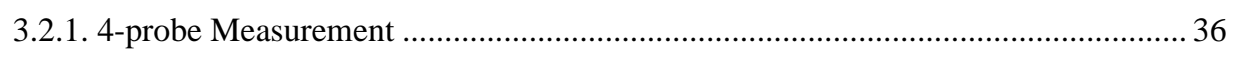

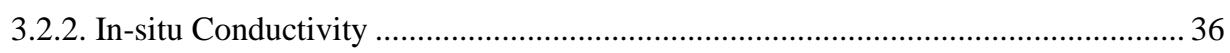




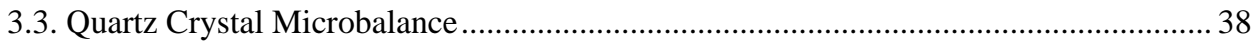

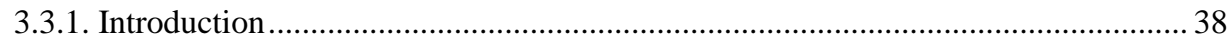

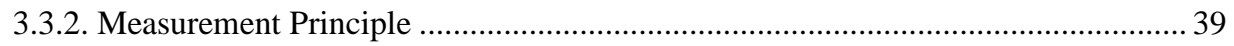

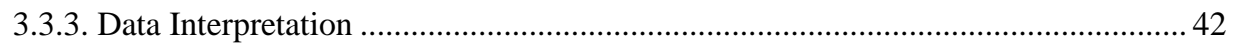

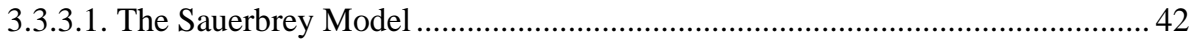

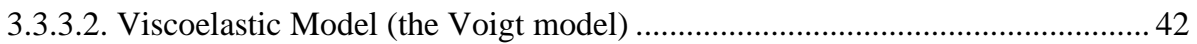

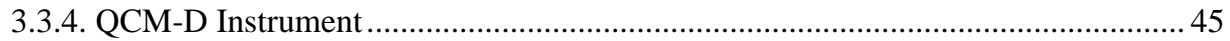

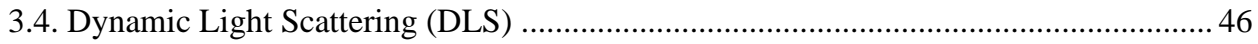

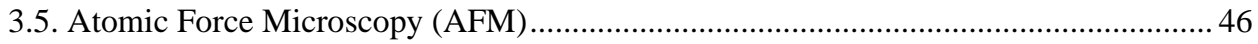

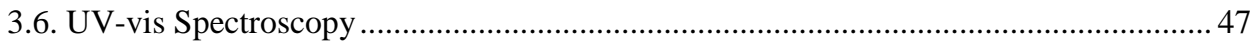

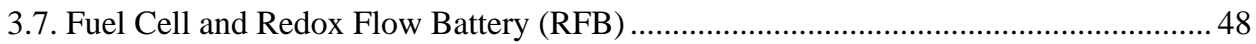

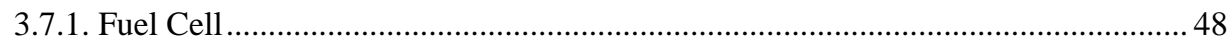

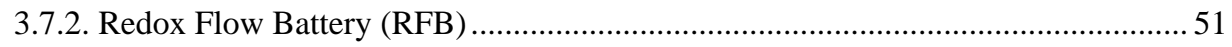

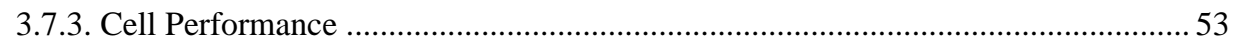

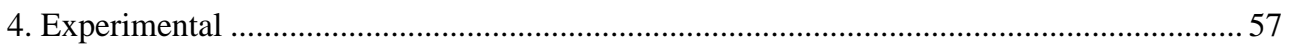

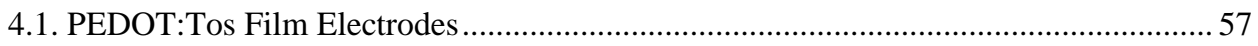

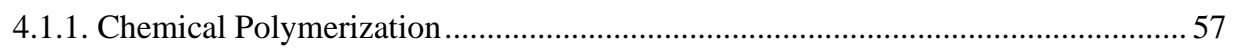

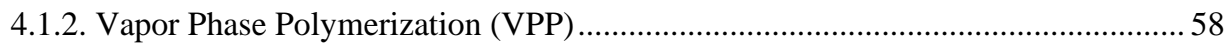

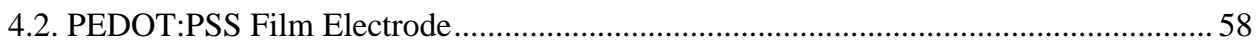

4.3. PEDOT and PEDOT: Lignosulfonate (PEDOT:LS) Nanoparticles ............................. 59

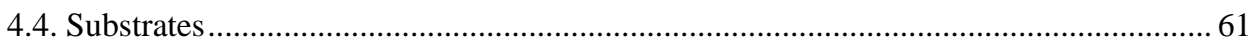

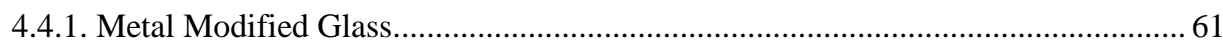

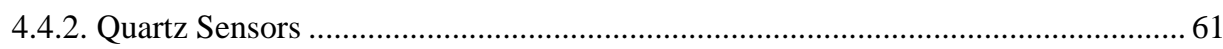

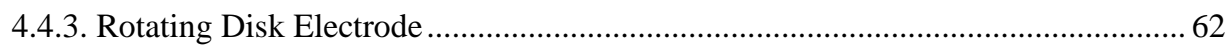

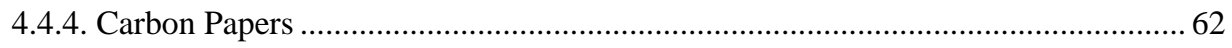

4.5. Hydroquinone-Oxygen Fuel Cell and ARS-Tiron Redox Flow Battery .......................... 62

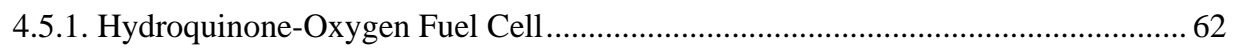

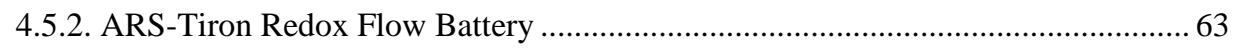

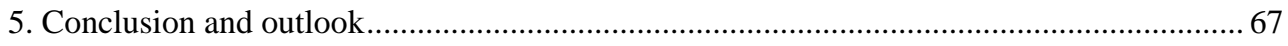

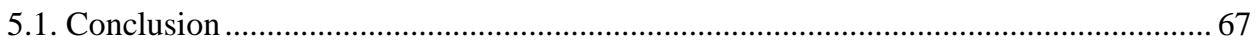

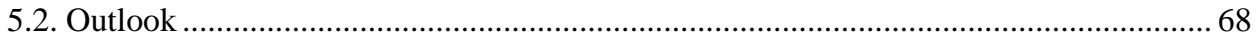

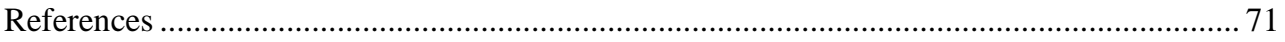




\section{Introduction}

\subsection{Motivation and Research Background}

Biomass englobes organic materials from plants to animal materials. Among its multiple applications, we single out biomass is an renewable energy source ${ }^{[1]}$. Indeed, biomass contains the energy from the sun, as plants collect the luminous radiation and convert it into chemical energy via photosynthesis and store it in the form of glucose. Then animals take in lots of plants and condense their chemical energy further storing it in varieties of proteins and fats. Upon combustion, the stored chemical energy is released as heat when biomass is burned directly. Such conversion of biomass into thermal energy dates back 1.7 to 0.2 million years ago, when Homo erectus got to master fire from wood for cooking, keeping warm and protection ${ }^{[1]}$. Biomass can also be fermented to convert into liquid biofuels like ethanol and biodiesel or decomposed and processed in digesters or in high temperature reactors into biogas like methane, and then be burned for energy used in vehicles.

Nowadays, the pulp and paper industry have the largest woody biomass utilization system which is also an important user and producer of bioenergy ${ }^{[2]}$. Yet it is characterized with low efficiency of raw materials and energy utilization. Indeed, the pulp and paper making process extract cellulose and hemicellulose (65-80\% of a tree) for papermaking but release lignin-rich products called black liquor ( $\sim 170$ million tons per year) as waste. Gasification of the ligninrich waste into biogas was one solution in operation to further burn it to produce heat ${ }^{[3]}$.

However, combustion of the fossil fuels (coal, oil and natural gas), as well as burning plantderived biomass, causes adverse effects to the environment, such as global warming because of 
the rapid emissions of $\mathrm{CO}_{2}$, acid rain caused by $\mathrm{NO}_{x}$ and $\mathrm{SO}_{x}$, and air pollutions caused by fine suspended particles, thus posing severe problems for mankind because of rapidly increasing consumption of the fossil fuels in industries, transportation, and everyday life. Therefore, new methods of clean and renewable biomass conversion need to be explored for the sustainable development of the society. Recently utilization of the lignin and lignin-derived quinone moieties materials in electrochemical energy devices, such as fuel cells ${ }^{[4][5]}$, redox flow batteries $^{[6][7][8][9]}$, and supercapacitors ${ }^{[10][11][12]}$ have attracted attention.

Unlike combustion, the energy conversion from chemical energy stored in lignin-based biomass into electricity via these devices involves no $\mathrm{CO}_{2}$ emission, as the electroactive sites in lignin and lignin-derived hydroquinone moieties can exchange electrons and protons by transformation into quinones and vice versa. Furthermore, the utilization of lignin-based biomass fuels in the electrochemical energy devices such as fuel cells and redox flow batteries, is advantageous from the conversion efficiency viewpoint, because the conversion of chemical energy to electricity in these devices occurs without any intermediate steps, unlike thermal power plants where the chemical energy of fuels is first converted into thermal energy, then mechanical energy and then electricity comprising the losses on each conversion steps. Also, electrochemical energy conversion in these devices are also continuous and on demand, unlike solar, wind and hydroelectric energy devices, which are intermittent as solar irradiation, wind and water flow are not constant in time, calling for extra storage devices in order to supply electricity in pace of human's demand.

However, for the application of lignin and lignin-derived hydroquinone moieties in electrochemical energy device like fuel cells, the choice of the electrode materials remains an issue. Even at the benchmark Pt electrocatalyst, the redox interconversions of benzenediols such as hydroquinone and catechol show an irreversible character ${ }^{[13]}$. Introduction of nanopores in Pt may help to recover reversibility but cost of this noble metal is another huge barrier preventing the upscaling of the electrochemical energy devices with it. Recently, various porous carbon papers were used as electrode materials in quinone-based redox flow batteries ${ }^{[7][14][15][16]}$, without any independent study of their electrocatalytic activity towards quinones. The reversibility of carbon electrodes was reported to be improved by various surface modification layers, such as $\mathrm{TiO}_{2}$ nanoparticles ${ }^{[17]}$, carbon nanotubes ${ }^{[18]}$ or a thin poly-(p-aminobenzoic acid) film $^{[19]}$. For the first two, the proposed improvement mechanism involves the increased adsorption of reactants and their confinement due to increased porosity close to the electrode surface. In the third case, as the polymer is an electrical insulator but proton conductor, it is 
suggested that it is proton transfer that also plays a key role, in addition to the confinement effect of increased porosity, for the redox reversibility.

Electrically conducting polymers form an attractive class of electrode materials for lignin and lignin-derived quinone moieties, because they are electrically conductive, based on abundant atomic elements, can be processed at low temperature and in solution, easy to scaling up and demonstrate electrocatalysis in various reactions ${ }^{[20][21][22][23]}$. Moreover, conducting polymers, such as poly(3,4-ethylenedioxythiophene) (PEDOT), polypyrrole (Ppy), polyaniline (PANI)

were also reported to be good scaffold materials for lignin derives or other quinones ${ }^{[11][24][25]}$ and are capable to enhance the electron transfer rates for simple benzenediols such as catechol

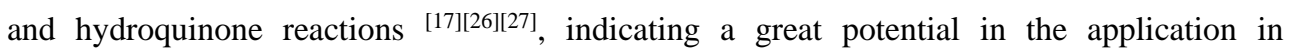
electrochemical energy devices based on lignin or lignin-derived quinone moieties.

In addition to the potential applications in electrical energy devices, investigation of the quinone reactions on conducting polymer electrodes also shed light on the studies related to implantable devices as the quinones redox are significant processes in biological systems. The controllable electrical, ionic charge transfer as well as buffer capacity of the porous, soft conducting polymer offer unique electrochemical interfaces, that are not reachable by the planar, rigid metal or inorganic electrodes.

\subsection{Aim and Outline of The Thesis}

Our intention is to study and evaluate the electrocatalysis of conducting polymers, in particular PEDOTs on quinone reactions, further to explore the possibility to use them as fuels for electrical power source in fuel cell, or as charge storage molecules in a redox flow battery as well as to reveal the redox facts relevant to biological mechanism. Meanwhile, the current understanding of electrochemistry of the quinone/hydroquinone redox reaction is mainly based on platinum, carbon electrodes, rarely on conducting polymers. Thus, we first studied in this thesis the electrochemistry of the generic quinone reaction at conducting polymer PEDOT in order to evaluate the electrocatalytic performance of the system. Then, the incorporation mechanism of the macro lignosulfonate molecule into conducting polymer PEDOTs was investigated and the synthesize routes of the PEDOT-lignosulfonate composite was optimized for the largest charge capacity. Next, we explored the effect of ion transport direction on redox kinetics of ortho-quinones, or catechols (catechol itself, and its sulfonated analog iron) in aqueous solution at two types of PEDOT-based electrodes interfaces, namely, balanced by 
mobile counter ions: tosylate ion $\left(\mathrm{Tos}^{-}\right)$or immobile poly(styrene sulfonate) ion $\left(\mathrm{PSS}^{-}\right)$) counterions. Finally, the proton management of the two PEDOT electrodes towards the catechols reaction are evaluated electrochemically in buffered and unbuffered electrolytes. A hydroquinone fuel cell and an all-quinone redox flow battery were also structured in order to demonstrate the practical application of the concepts revealed during fundamental electrochemistry study.

The first part of the thesis gives the basic background information to understand the motivation, theory, methodology and results of the thesis. Chapter 1 presents the state-of-the-art knowledge, goals and main work of the thesis. Chapter 2 introduces the relevant materials and theories of conducting polymer and proton coupled electron transfer reaction; Chapter 3 describes the basics of electrochemistry and electrochemical analysis methods, as well as other relevant characterization methods. In Chapter 4, various electrode preparation methods used through the thesis were presented. Chapter 5 explains the principles of the devices constructed in the thesis. Chapter 6 gives a summary of the original scientific work and outlook to the future developement.

The second part presents the main results of the thesis in the form of papers and manuscripts. Paper I deals with the hydroquinone/benzoquinone reaction at conducting polymer PEDOTs electrode and the demonstration of hydroquinone-oxygen fuel cell. Paper II treats the lignosulfonate adsorption on conducting polymer PEDOTs and its incorporation mechanism via ion exchange as well as up-scale synthesis strategies. In paper III and Paper IV, we developed the concept of ionic selective electrocatalysis of PEDOTs electrodes on the catechols oxidation: study in Paper III revealed the effect of ionic transport direction on the oxidation kinetics of catechols at PEDOTs electrodes. While the kinetic investigation about the same reactants at the PEDOTs electrodes in Paper IV conducted in buffered and unbuffered electrolyte revealed a different proton management ability of the two PEDOTs electrodes towards the catechol oxidation. 


\section{Materials}

This chapter will introduce the main materials utilized throughout the scientific work, including conducting polymers, particularly poly(3,4-ethylenedioxythiophene) (PEDOT). The electrical conductivity, conducting mechanism, electrochemical performance of PEDOT will be illustrated in depth. Basic information on the other materials such as lignosulfonate, hydroquinone, catechol, tiron and alizarin red $\mathrm{S}$ will also be presented.

\subsection{Conducting Polymers}

Polymers are macromolecules, composed of many repeated units, often made of carbon and hydrogen and sometimes oxygen, nitrogen, sulfur, fluorine, phosphorous and silicon. Polymers have long been thought to be insulators. Even though conducting polymers were theoretical predicted as early as in the middle of $20^{\text {th }}$ century ${ }^{[28]}$, it is only in 1977 that, Alan Heeger, Alan MacDiarmid, Hideki Shirakawa (Nobel Prize in chemistry,2000) discovered the first of a new class of polymer, chemically doped polyacetylene (PA) with iodine, presenting surprisingly high electronic conductivity up to $10^{3} \mathrm{~S} \mathrm{~m}^{-1}$ at room temperature ${ }^{[29][30]}$. Though PA is not stable and easily to degrade in air, various other and more stable conducting polymers were reported, including polypyrrole (PPy), polyaniline (PANi), polythiophene (PTh), poly(p-phenylene vinylene) (PPV), polyfluorenes (PF) and poly(3,4-ethylenedioxythiophene) (PEDOT) as listed in Figure 2.1. The conductivity of this type of polymers spans the semiconducting and metallic range as shown in Figure 2.2. Nowadays, conducting polymers are well developed and investigated as efficient materials for (opto)electronics. In the following text, the electronic structure, doping, electrochemical properties of conducting polymers will be introduced. 


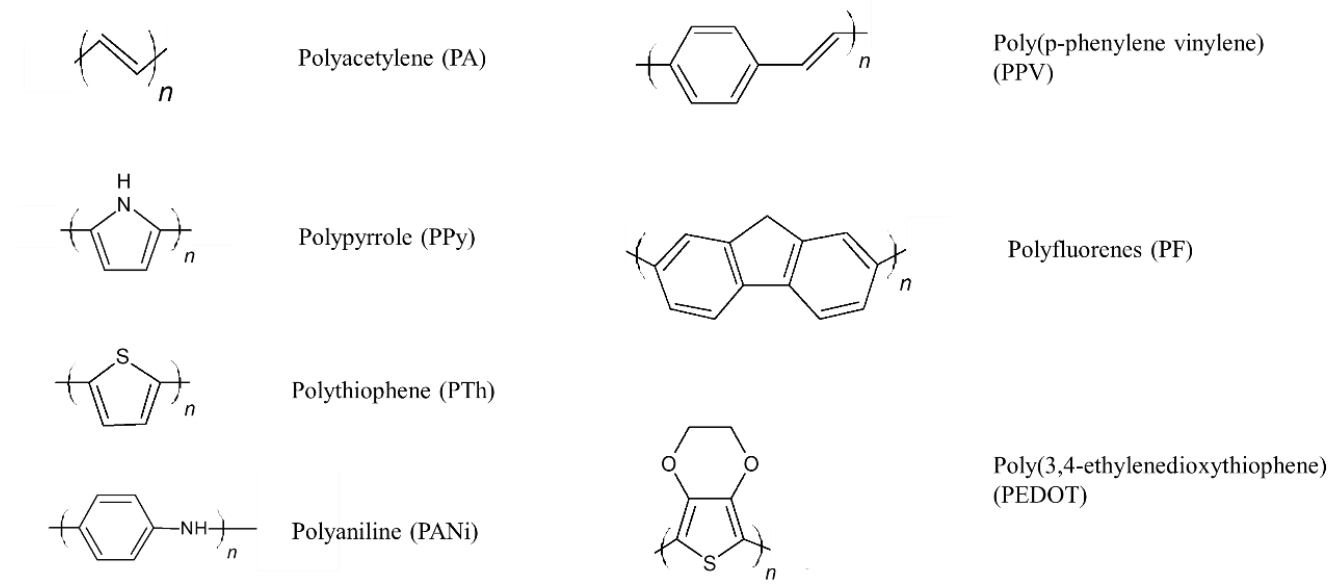

Figure 2.1. Examples of conductive polymers ${ }^{[31][32]}$.

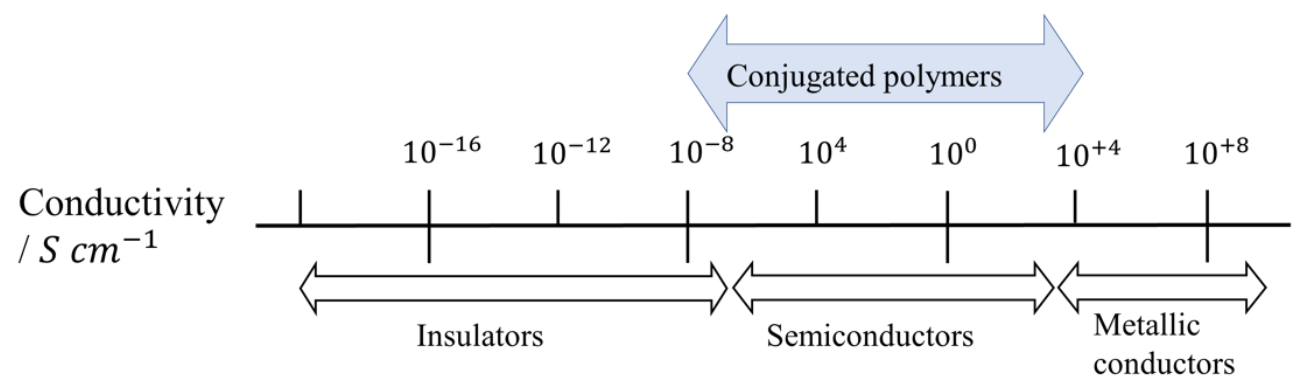

Figure 2.2. Electrical conductivities of conjugated polymers compared to other materials ${ }^{[33]}$.

\subsubsection{Inherent Electronic Structure}

The electrical conductivity of the material is mainly determined by its electronic structure. Conventional polymer insulators have a saturated chemical structure as polyethylene shown in Figure 2.3. Every carbon atom binds to other adjacent atoms by single bonds. In this case, the molecular orbitals are formed by an overlap of many $s p^{3}$ hybridized atomic orbitals, resulting in a bonding $\sigma$-band and anti-bonding $\sigma^{*}$-band consisting of many discrete energy levels and separated with a large bang gap in the order of $8 \mathrm{eV}^{[34]}$. But conducting polymers such as transpolyacetylene shown in Figure 2.3, possess alternating single and double bonds, so that the carbon atom is in the $s p^{2}$ hybridized state and each has an unhybridized p orbital, which can form a $\pi$ bond with an unhybridized $p$ orbital of the adjacent carbon. The $\pi$ conjugated system allows delocalization of $\pi$ electrons throughout multiple atoms, resulting in a smaller band gap 
about $1.5-3 \mathrm{eV}$, which puts such conjugated systems into the class of semiconductors and is the origin of the inherent electrical/electronic, optical and electrochemical properties.

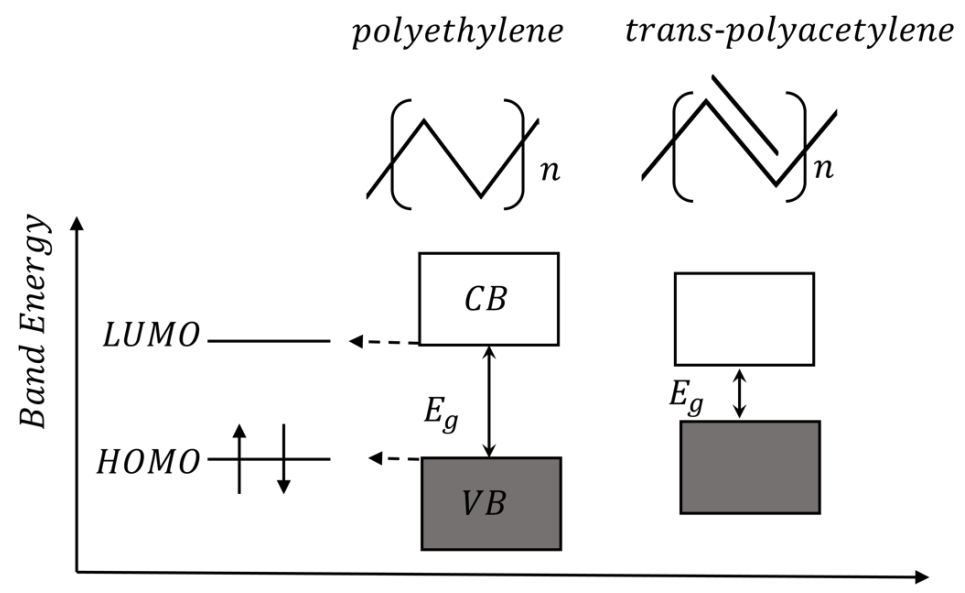

Figure 2.3. Energy diagram of polyethylene and trans-polyacetylene ${ }^{[35]}$.

\subsubsection{Doping}

Still, the conductivity of intrinsic conjugated polymer is very low, in the range of $10^{-9}-10^{-6} \mathrm{~S}$ $\mathrm{cm}^{-1[32]}$. It is because their band gap is still too large to allow the electrons to be thermally excited from the valence to the conduction band thus creating appreciable concentration of charge carriers. The electrical conductivity, however, can be tuned chemically either via redox reaction or electrochemically via charge transfer with an electrode, this process is called doping. For example, the electrical conductivity of trans-polyacetylene before and after doping can be increased by 5 to 6 orders magnitude ${ }^{[29]}$.

The term "doping" was used originally in solid state physics for introduction of foreign neutral atoms into a host lattice. But in the research field of conducting polymers, it means chemical or electrochemical oxidation or reduction, involving electron transfer between a dopant or electrode and the polymer. Chemical doping is efficient and straightforward, but it is difficult to control and to achieve homogeneous dopant distribution with it. Electrochemical doping, on the contrary, allows for precise control of the dopant distribution and of the doping level through the control of the electrode potential. Doping serves to introduce charges into the backbone of conjugated polymers, while charge compensating counterions are drawn from surrounding medium. Removing electrons (oxidation) results in a p-doped polymer, such as Poly(3,4-ethylenedioxythiophene)(PEDOT), as the charge carriers (holes) are positively charged, while adding electrons (reduction) process produces n-doped polymers, such as 
Poly(benzimidazobenzophenanthroline) $(\mathrm{BBL})^{[36]}$, as the charge carriers (electrons) are negatively charged. In general, $\mathrm{n}$-doped polymers are not as environmentally stable as p-doped polymers, and as a result, p-doped polymers are more popular in academic research as well as in industrial applications ${ }^{[36]}$.

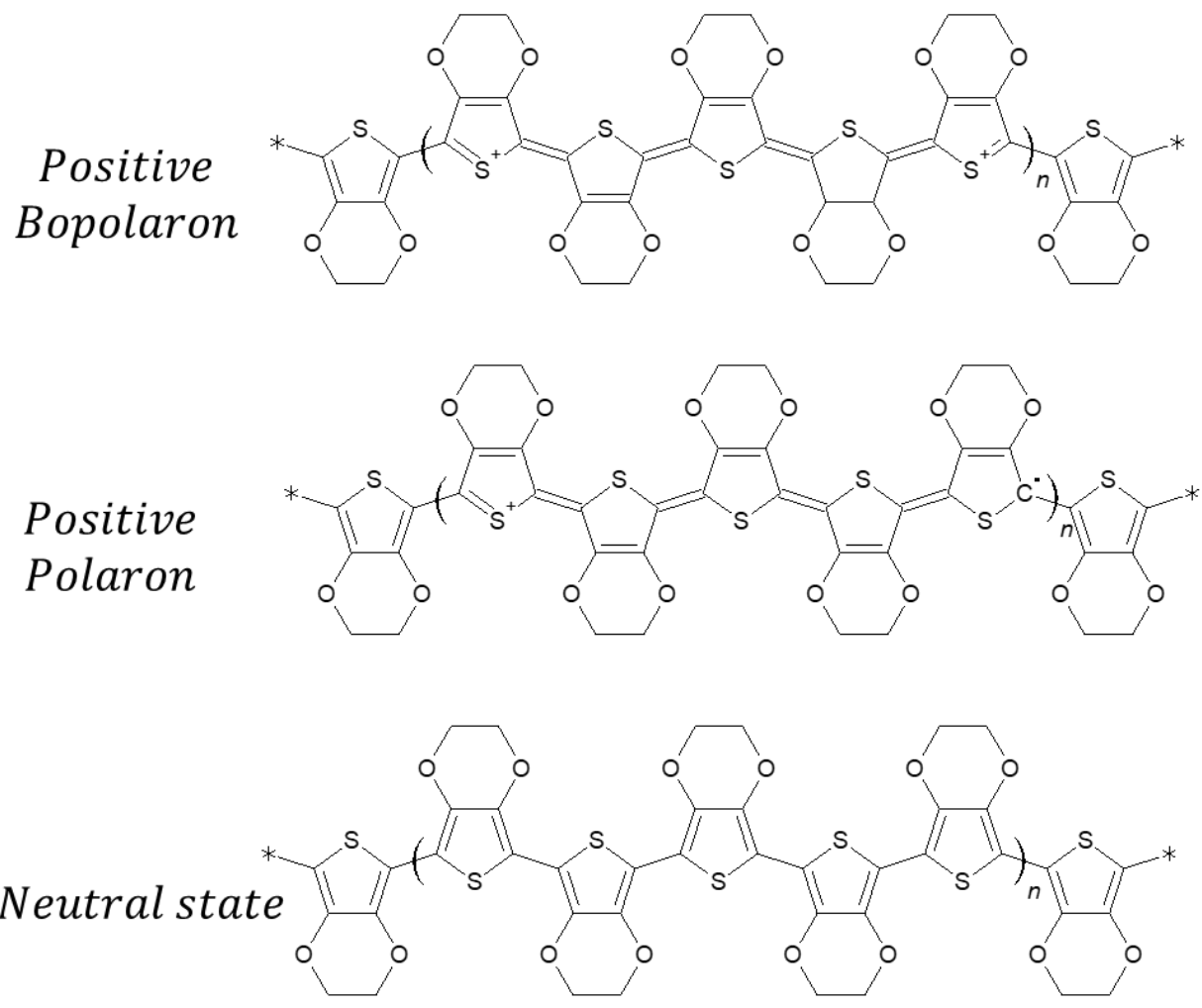

Figure 2.4. Chemical structures of Poly(3,4-ethylenedioxythiophene) (PEDOT) at neutral state or with polaron, bipolaron ${ }^{[37]}$.

Charges introduced by doping process bring about changes to the polymer's electronic structures (shift of electron levels) and created associated lattice distortion, resulting in formation of different charged carrier species: polarons, bi-polarons and solitons in the doped conjugated polymers. A polaron is formed when a $\pi$-electron is added (electron polaron) or removed (hole polaron) from the conjugated polymer chain, accompanied by a local deformation and change in energy level structure. One electron level with its two electrons move from the valence band into the band gap and an additional level is moved from the conduction band into the band gap. In the case of electron polaron, the added electron is stored 
in the newly formed energy level drawn from the conduction band. While in the case of hole polaron, an electron is removed from the newly formed level drawn from the valence band. When a second electron is added or removed, a stronger deformation occurs, resulting in a doubly charged system, the so called bi-polaron. The polaron and bipolaron chemical structures of PEDOT are shown in Figure 2.4. Bi-polarons have two levels in the energy gap ${ }^{[33]}$. There are positively charge polaron and bi-polaron and negatively charged polaron and bipolaron in conducting polymers. If a polymer is further oxidized or reduced, an overlap between bi-polarons will occur. The presence of polaron or bi-polaron introduced two states in the energy gap and the unpaired electron occupies the two new bonding states, i.e., its energy lies between the conduction band and valance band. The geometrical distortion caused by polaron and bi-polaron has a similar width, but the bond length modification of the later is larger so that the two states in polaron are further away from the band edges. Soliton is another type of excited species, that can exist only in degenerate polymers where interchange of single and double carbon-carbon bonds along the chain result in the same structure ${ }^{[33][38]}$. The presence of a soliton causes a localized electronic level in the center between the valance band and conduction band. For a non-degenerate conjugated polymer, such as Poly $(3,4-$ ethylenedioxythiophene) (PEDOT), only polarons and bi-polarons are accountable for the electrical conductivity.

The energy band diagrams of PEDOT with varying doping levels is shown in the schematic diagram in Figure 2.5 ${ }^{[39][40]}$, together with UV-Vis-NIR spectroscopy which allows qualitative evaluation of the charge carrier concentration in polythiophenes ${ }^{[41]}$. The absorption around 480nm in UV-Vis-NIR spectroscopy refers to neutral PEDOT films. The absorption around $900 \mathrm{~nm}$ and $1250 \mathrm{~nm}$ are assigned to polaronic and bi-polaronic structures in the most recent DFT calculations differ from the pre-DFT calculation which the former refers to polaron and the latter refers to bi-polaron. And it is pointed out that the main features of the electronic band structure and electron transport remain similar even through when the PEDOT chain undergoes a transition between polaronic and bipolaronic states due to oxidation level changes. 
low oxidation level

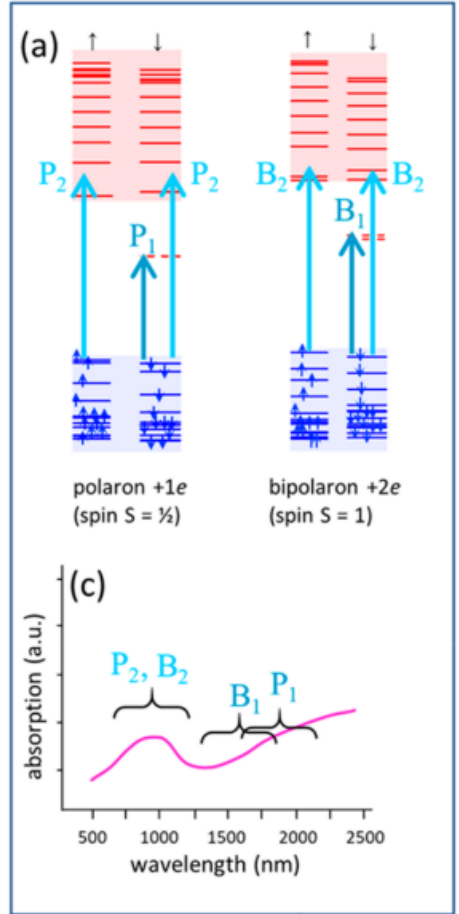

high oxidation level

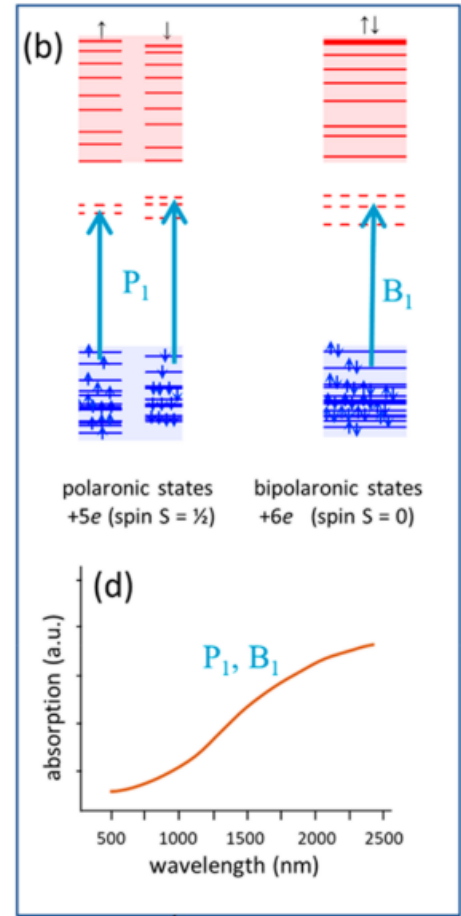

Figure 2.5. (a, b) Schematics of energy band diagrams and main optical transitions of PEDOT for (a) low oxidation level and (b) high oxidation level. $\mathrm{P}_{1}$ represents the absorption peaks due to the transition valence band to the polaronic level, $\mathrm{P}_{2}$ for valence band to conduction band, $\mathrm{B}_{1}$ refers to valence band to the bi-polaron levels, and $\mathrm{B}_{2}$ is assigned to valence band to conduction band ${ }^{[40]}$. (Reprinted with permission from ref 40. Copyright 2019 American Chemical Society).

The charge-transport mechanism in conducting polymers is different from that operating in metals where electrons can move freely in energy bands. In conducting polymers, the charge carriers are localized or belong to narrow energy bands between the conduction band and valance band. While the charge carriers can easily move along a single polymer chain (intrachain transport), hopping between chains (interchain transport) is more hindered as the activation energy for hopping transport is much higher. Therefore, interchain transport is the limiting factor of the conductivity of conducting polymers ${ }^{[32]}$. Indeed, the electrical conductivity of conducting polymers exhibits a thermal activated behavior, which is an indication of the hopping transport. In addition to temperature, doping levels, and morphology are also the levers to tune the electronic structure, thus to alter the conductivity ${ }^{[42][43]}$. High 
temperature, doping level and crystallinity would, in general, result in high conductivity in conducting polymers.

\subsubsection{Electrochemical Properties of Conducting Polymers}

Electrochemistry plays a very important role in the preparation and characterization of conducting polymers. Furthermore, conducting polymers are inherently electroactive, that is, they can be reduced and oxidized in an electrolytic solution upon application of potential, and these changes are usually reversible. Electroactivity is accompanied by changes in their electronic conductivity due to doping/dedoping. Electrochemical properties of conducting polymers are interesting for electrochemists as a means for the detailed study of underlying phenomena of such processes and important for electrical energy related applications. In the following text, the electropolymerization and typical characterization will be introduced briefly.

\subsubsection{Electropolymerization}

First of all, the synthesis of conducting polymer via electrochemistry is the process of interest. The anodic electropolymerization of conducting polymers, such as polypyrroles, polythiophenes, and polyanilines, is an anodic oxidation and coupling process. The mechanism of electropolymerization from its monomer was first proposed by Diaz in 1981 and is still widely accepted $^{[44]}$. As illustrated in of Figure 2.6, monomers dimerize at the $\alpha$-position after loss two electrons, forming a doubly charged dimer, then proton elimination occurs resulting in a neutral aromatic $\sigma$-dimer. The dimer is easier to be oxidized compared to its monomer due to higher conjugation, thus it can be oxidized immediately to its cation and undergo the next coupling with new monomeric radical cation as well as next proton elimination, so that the polymer chain propagates. However, with the increase of the chain length, the tendency of coupling between oligomers and a monomer radical cation decreases, forming conjugated oligomers as the main products rather than infinite polymer chains ${ }^{[45]}$. Importantly, electropolymerization normally results in a conducting polymer film adherent to the electrode. 


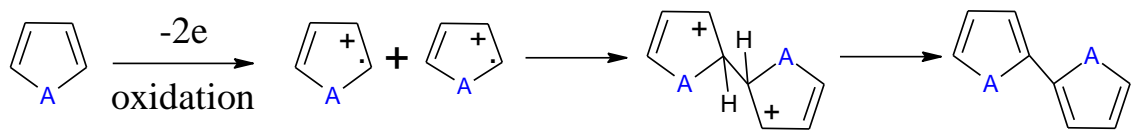

oxidation

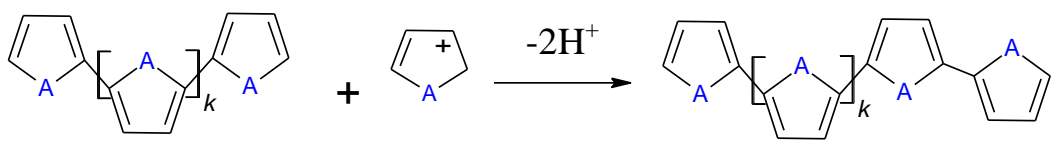

Figure 2.6. Classical formation mechanism of conducting polymers ${ }^{[46]}$. A represents $\mathrm{NH}$ or $\mathrm{S}$.

There are also some conducting polymers can be synthesized via cathodic electropolymerization, such as poly(p-xylylenes) (PPXs) and poly(p-phenylenevinylenes) (PPVs), which can be obtained via the electrochemical reduction of $R, R, R^{\prime}, R^{\prime}$-tetrahalo-pxylenes, with the bromo-compounds ${ }^{[47]}$.

\subsubsection{Electrochemical Charge and Discharge of The Conducting Polymers}

Electrochemical mechanism of charge and discharge processes of conducting polymers with a highly delocalized $\pi$-system consist in the oxidation and the reduction, including an electron transfer at the polymer-metal interface, as well as an accompanying ionic charge transfer at the polymer-solution interface: therefore, it involves three phases. The conductivity of the polymer is variable due to doping and de-doping during charge and discharge. Cyclic voltammetry (CV) is a popular way to monitor this electrochemical process. Consider PEDOT:PSS as an example, its $\mathrm{CV}$ in sulfuric acid (Figure 2.7) shows a stable capacitive background current in a wide potential window of $-0.4 \mathrm{~V}$ to $1.0 \mathrm{~V}$ vs $\mathrm{Ag} / \mathrm{AgCl}$, indicating its high conductivity in this range. The transition of the polymer from neutral state to oxidized state during doping and de-doping is accompanied by a color change from dark blue to transparent or light blue. Extending the negative limit results in decrease of the capacitive current with little effect on the stability, due to conductivity loss caused by full de-doping of the conjugated backbone, while applying voltage over the positive limit $(1.2 \mathrm{~V})$ causes progressive loss of the capacity and destroys the electroactive behavior of the film due to overoxidation ${ }^{[48][44]}$. Another example is polypyrrole, whose $\mathrm{CV}$ manifests broad peaks near $-0.15 \mathrm{~V}$ vs. $\mathrm{Ag} / \mathrm{AgCl}$, and a large capacitive background current in the anodic potential region $+0.25 \mathrm{~V}$ to $+0.85 \mathrm{~V}$ vs. $\mathrm{Ag} / \mathrm{AgCl}$. Polypyrrole is stable in 
the range of $-0.75 \mathrm{~V}$ to $+0.85 \mathrm{~V}$ vs. $\mathrm{Ag} / \mathrm{AgCl}$, at higher positive potential, it is also overoxidized irreversibly.

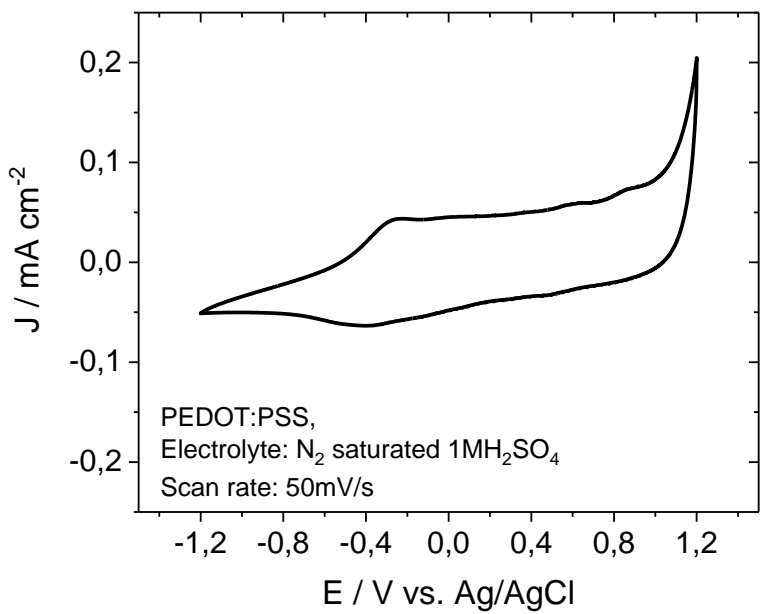

Figure 2.7. cyclic voltammogram at conducting polymer PEDOT:PSS electrode. Electrolyte: $1 \mathrm{M}$ nitrogen saturated sulfuric acid; scan rate: $50 \mathrm{mV} / \mathrm{s}$.

\subsection{PEDOT}

This section provides some general information about Poly(3,4-ethylenedioxythiophene) (PEDOT). PEDOT was developed in 1980s by the Bayer company, and became the most successful commercial conducting polymer due to its high conductivity, transparency in doped state, and high chemical stability in air at room temperature due to the oxygenated bicyclic structure.

PEDOT can be easily synthesized via chemical or electrochemical polymerization from its monomer EDOT, with the chain length of PEDOT to be estimated to consist of 5-20 monomer units. The polymerized, pristine PEDOT is typically already at oxidized state, and it can be tuned with electrochemical means or control the polymerization temperature to an oxidation level about 33\%[33][40][49] . The positively charge on PEDOT backbone is balanced by negatively charged counterions. A wide range of counterions can be introduced ${ }^{[33]}$, and the choice of counterions depends on their solubility and stability under the reaction condition. The tosylate ion $\left(\mathrm{Tos}^{-}\right)$and poly(styrene sulfonate) ion $\left(\mathrm{PSS}^{-}\right)$shown in Figure 2.8 are of interest for us and thus will be discussed in more detail in the following text. 
The doping agent PSSH or PSSNa, as a polyelectrolyte, has a large molecular weight and size, still it is soluble in water. By using this dopant, stable water soluble PEDOT:PSS suspension can be obtained containing the excess of nonconductive PSS around the conductive PEDOT:PSS rich domains ${ }^{[42]}$. This suspension is very attractive for large scale printing electronics due to the solution processability. However, the conductivity of pristine PEDOT:PSS prepared simply from the $1.3 \mathrm{wt} \%$ dispersion in water is rather low, below $1 \mathrm{~S} / \mathrm{cm}$. But the conductivity can be enhanced easily by up 2 to 4 orders of magnitude by mixing the aqueous PEDOT:PSS suspension with the high boiling, high-dielectric-constant co-solvent like dimethylsulfoxide (DMSO) or ethylene glycol (EG), which is called secondary doping, or by a post treatment of the film by solvents, e.g. immersing the polymerized PEDOT:PSS in $\mathrm{H}_{2} \mathrm{SO}_{4}$ ${ }^{[50][51]}$ or methanol ${ }^{[52]}$, or by exposing the cast film to the solvent vapors with subsequent thermal annealing ${ }^{[53]}$. The mechanism of conductivity improvement depends on the treatments. In general, secondary doping results in morphology changes showing larger grain size and better interchain hopping connection, while film treatment brings about both morphological change and removal of the excess PSS from the film surface. The conductivity of PEDOT:PSS treated with DMSO can thus reach $1000 \mathrm{~S} / \mathrm{cm}^{[54]}$. Other additives are mixed with PEDOT:PSS suspension in order to improve film stability in water such as (3glycidyloxypropyl)trimethoxysilane (GOPS ${ }^{[55]}$, or improve its mechanical strength by adding cellulose, or increase its plasticity by adding glycerol ${ }^{[56]}$.

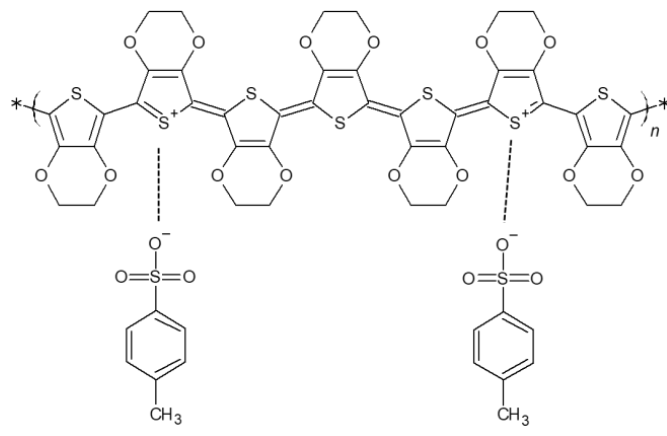

PEDOT:Tos

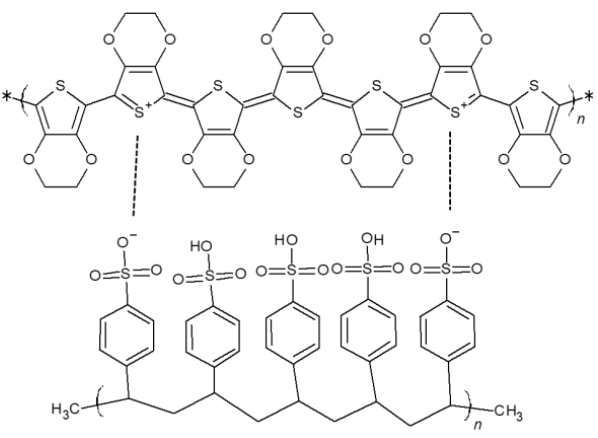

PEDOT: PSS

Figure 2.8. Molecular structure of PEDOT:Tos (left), PEDOT:PSS (right) with a bi-polaron ${ }^{[57]}$.

Another common dopant agent for PEDOT is tosylate (Tos), which is, on the contrast, a smaller counterion. PEDOT:Tos is insoluble in water. High level of crystallinity can be reached via structure-directed growth by using tri-block polymer poly(ethylene glycol-propylene glycol- 
ethylene glycol) (PEG-PPG-PEG) in the oxidant solution of vapor phase polymerization (VPP), also resulting in a high electronic conductivity of $2500 \mathrm{~S} / \mathrm{cm}^{[58]}$.

PEDOT:PSS and PEDOT:Tos are the focused electrodes in this thesis not only because of their electrical conductivity, but also due to their special ionic conductivity brought by the counterions. PEDOT:PSS film is a two-phase blend, comprising a PEDOT rich phase insuring electrical conductance, and a polyanionic PSSH phase. On one hand, the polyanionic acid is a good proton conductor and thus able to facilitate fast proton transfer within the porous electrode which makes PEDOT:PSS superior to PEDOT:Tos in this respect. On the other hand, PSS is an immobile polyanion because of the large molecular size and the crosslinking brought by GOPS $^{[55]}$, which hinders the absorption of negative ions into the bulk of the materials via ion exchange, by virtue of Donnan exclusion ${ }^{[59]}$.

\subsection{Lignin and Lignosulfonate and quinone/hydroquinone Redox Systems}

Lignin forms important structure material in supporting tissues of vascular plants and some algae, which is a complex cross-linked macromolecule with molecular weights more than $5000 \mathrm{~g} / \mathrm{mol}$. As an abundant biomaterial on Earth, lignin embodies $25-30 \%$ of the total mass of woods, exceeded only by cellulose $(40-45 \%)^{[60]}$. The major building blocks of this biopolymer are three hydroxycinnamyl acohol monomers, including p-coumaryl alcohol(H), coniferyl alcohol (G), and sinapyl alcohol (S) (see in Figure 2.9), differing in the degree of methoxylation. The types of lignin are determined by $\mathrm{pH}$ and extraction process, includes lignosulfonate as byproducts of the sulfite process and kraft lignin obtained in kraft pulping process. Kraft lignins are only soluble in alkaline solution at $\mathrm{pH} 10$, they are mainly used in gasification to produce carbon monoxide, hydrogen and carbon dioxide. Lignosulfonate is typically used in additives, dispersant agents, complexing agents and emulsifying agents as well as to produce oriented strands, fiber and particle boards. Lignosulfonate comprises sulfonate groups which enables its solubility in water. We suppose that, due to these sulfonate groups, lignosulfonate could as well as act as dopant akin to PSS. The intrinsic dissociation constant $\left(\mathrm{pK}_{0}\right)$ has a value close to 4.5 at ionic strength of $0.1 \mathrm{M}$, and is ionic strength dependent ${ }^{[61]}$, which may contribute to the buffer capacity of the electrolyte due to large amount of sulfonate groups.

Lignin and Lignosulfonate are also electroactive molecules, the main electroactive unit is the substituted phenylpropane $\left(C_{9}\right)$ group, corresponding to functional groups: $\mathrm{G}, \mathrm{S}$, which can be oxidized and give o-quinone upon initial irreversible oxidation; the generated quinone moieties 
can be transformed into its dihydroxy form reversibly during reduction and oxidation as shown in Figure 2.10 ${ }^{[62]}$.

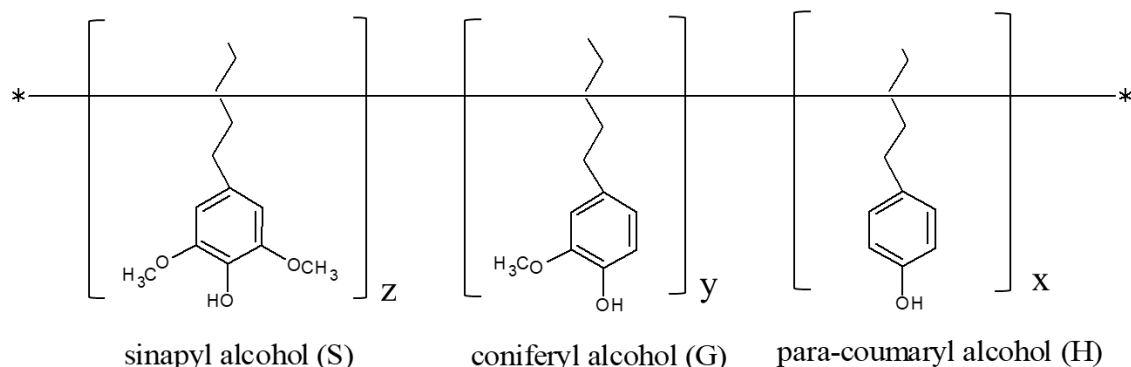

Figure 2.9. The three functional phenolic groups: Sinapyl alcohol (S), coniferyl alcohol $(G)$ and P-coumaryl alcohol $(H)$ in lignin macromolecule ${ }^{[25]}$.

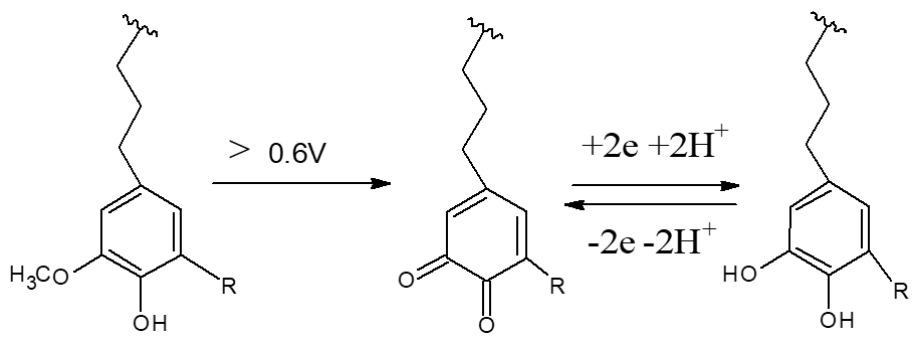

Figure 2.10. Electrochemical activity of lignosulfonate ${ }^{[62]}$.

Today, as the prime surplus material of the forest and paper industries, lignin-rich black liquor is released as waste that reach ca. 170 million tons per year world-wide, as its heating values is relatively low due to high inorganic content ${ }^{[3]}$. However, lignin-rich black liquor may become a key source of renewable fuels due to the electroactive phenol moieties within it. Moreover, by depolymerization of Kraft lignin, mono ligno-fuel can be obtained with a yield of phenolic monoaromatics up $21.5 \mathrm{wt} \%$ with a content of catechol up to $7 \%$, in particular ${ }^{[5]}$. This operation makes the phenol moieties in lignosulfonate attractive chemical intermediates and potential fuels. As a renewable resource, it is thus attracting to it lots of interest in the countries with a large pulp and paper industry, including Sweden.

Lignosulfonate is not conductive, so it has to be employed with conductive materials, such as gold $^{[63]}$ or glassy carbon ${ }^{[62]}$ or activated carbon ${ }^{[10]}$. The planar conducting interfaces limit the charge capacity or adsorption amount of lignin derives. Recently, incorporating lignin derives with porous conducting polymers, such as polypyrrole ${ }^{[24][25]}, \operatorname{PEDOT}^{[11]}$ is popular, the resulting composite enables the redox reaction of the generated quinone/hydroquinone moieties 
as well as the electrical transport within the electrode, showing great potential in energy harvesting and storage devices without carbon dioxide emission.

As mentioned, the phenol moieties in lignin derives can undergo two-electrons redox reactions coupled with proton transfer, this is indeed the inherent properties of all quinones molecules. The typical reaction is shown in Figure 2.11 for the simplest quinone. A more detailed introduction to such proton coupled electron transfer (PCET) reactions follows.

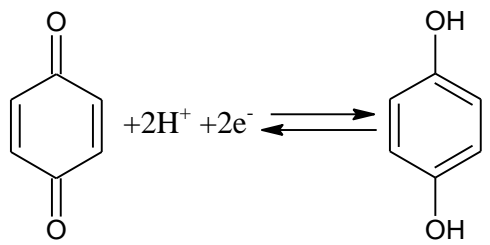

Figure 2.11. Typical hydroquinone/quinone reaction involving two electrons and two protons ${ }^{[64]}$.

Figure 2.12 shows the structures of a few important hydroquinones and quinones. The generic ones are hydroquinone or benzoquinone. The redox behaviors of hydroquinone and isomers have been studied intensively on different electrodes materials ${ }^{[65][64][66]}$, mainly planar electrodes like Au, Pt, glassy carbon, or porous carbon as well as carbon nanotube modified glass carbon electrode, however, very few on polymer modified metal electrodes, which, on the contrary, is the focus of this thesis.<smiles>Oc1ccc(O)cc1</smiles>

Hydroquinone<smiles>Oc1ccccc1O</smiles>

Catechol<smiles>O=S(=O)(O)c1cc(O)c(O)c(S(=O)(=O)O[Na])c1</smiles>

Tiron<smiles>NOS(=O)(=O)c1cc2c(c(O)c1O)C(=O)c1ccccc1C2=O</smiles>

Alizarin res S<smiles>O=C1c2ccc(S(=O)(=O)O)cc2C(=O)c2ccc(S(=O)(=O)O)cc21</smiles>

AQDS

Figure 2.12. Chemical structures of Hydroquinone, Catechol, Tiron, Alizarin red s and AQDS. 
Hydroquinone and catechol remain neutral molecules in aqueous solution, as their acidity is very weak (hydroquinone: $p K_{1}=9.85, p K_{2}=11.4^{[67]}$; catechol: $p K_{1}=9.45, p K_{2}=12.8^{[68]}$ ). By adding sulfonate groups to the catechol, a derivative such as 4,5-dihydroxybenzene-1,3disulfonic acid (Tiron) can be obtained. The two hydrophilic sulfonate groups make the quinone more soluble in water, and it ionizes easily in aqueous solution resulting in an aromatic anion. In this thesis, we make a detailed comparison of the electrochemical behavior of catechol and tiron redox at the electrodes based on conducting polymer PEDOT balanced by mobile or immobile counterion, Tos $^{-}$and $P S S^{-}$.

The electrochemical potential of the hydroquinone, catechol and tiron redox are located at quite positive values in acidic electrolyte, which makes them natural candidates as the redox component of the positive electrolyte (posolyte) in an organic energy device. On the other hand, Alizarin Red S, namely, 3,4-Dihydroxy-9,10-dioxo-2-anthracenesulfonic acid sodium salt, a water-soluble analog of an organic dye Alizarin, has a relatively much negative electrochemical potential as a derivative of anthraquinone, making it a possible component of the negative electrolyte (negolyte). Interestingly, only a few of quinones are, at the same time, soluble in acidic aqueous solution and show a relatively high negative oxidation potential. This allows to use them in organic redox flow batteries. Both the redox potential gap between posolyte and negolyte, and their solubility are important parameters in the design of the flow battery, large potential gap and high solubility is the key challenge to obtain high-energy density and highpower density redox flow battery.

\subsection{Proton-Coupled Electron Transfer (PCET)}

\subsubsection{Introduction}

The concept of Proton-coupled electron transfer (PCET) was first introduced by Thomas Meyer and his colleagues in $1981^{[69]}$, and refers initially only to the reactions where a proton and electron are transferred in a single, concerted step. But it now embraces a broader definition and includes reactions in which both protons and electrons are transferred, either in concertedly or stepwise. The electrons are exchanged with the electrode, while the protons with the solution, which separates PCET from hydrogen atom transfer, supposing that electron and proton are transferred from the same bond ${ }^{[70][71]}$. PCET can proceed through different mechanisms as shown in Figure 2.13. In the stepwise mechanisms, when electron transfer (ET) and proton transfer (PT) occur sequentially via pathways involving stable intermediates, namely PT-ET and ET-PT. In the concerted process, for which Savéant and coworkers coined the term CPET 
${ }^{[72]}$, protons and electrons are transferred in a single step. PCET is important and attractive as it is ubiquitous in chemical and biological reactions such as carbohydrate formation by light induced $\mathrm{CO}_{2}$ reduction by water in photosynthesis ${ }^{[73]}$, oxidation of glucose by oxygen in respiration, nitrogen fixation in nitrogenase, DNA repair in photolyase ${ }^{[74]}$, quinone redox transformations in lignin derivatives ${ }^{[24]}$, as well as in fuel cells ${ }^{[7][15]}$, therefore, it has been intensively investigated during the past 40 years ${ }^{[71][75]}$. In this thesis, our focus on PCET reactions goes to benzoquinone/hydroquinone type redox.

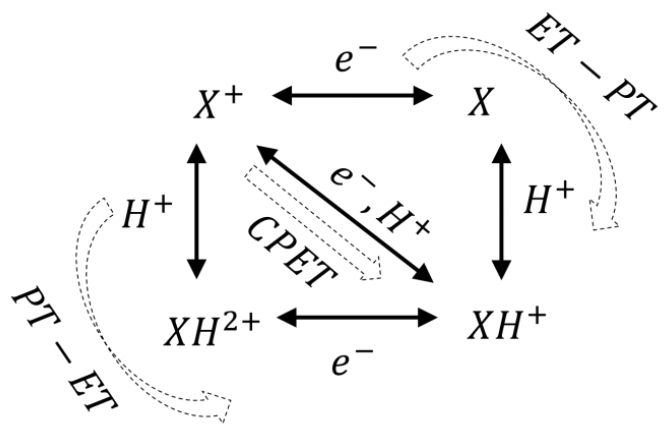

Figure 2.13, Three possible mechanisms in PCET reactions: the stepwise mechanisms including electron transfer followed by proton transfer (ET-PT) and PT-ET; the concerted proton-electron transfer $(\mathrm{CPET})^{[76]}$.

\subsection{2. $\mathrm{pH}$ Dependence of Potential}

As PCET reactions involve protons in redox transformations, it is useful to remind here how the equilibrium potential $E$ of the reaction depends on $\mathrm{pH}$ dependence according to Nernst equation:

$$
\begin{gathered}
Q+n e^{-}+m H^{+}=H_{m} Q^{(m-n)} \\
E=E^{0}-\frac{R T}{n F} \ln \frac{C_{H_{m} Q^{(m-n)}}}{C_{Q} * C_{H^{+}}^{m}} \\
E=E^{0}-\frac{R T}{n F} \ln \frac{C_{H_{m} Q^{(m-n)}}}{C_{Q}}-\frac{m R T 1 n 10}{n F} p H
\end{gathered}
$$

Note that $\frac{R T 1 n 10}{F}=59 \mathrm{mV}$ at room temperature. Therefore, taking a 2-electron-2-proton $(m=n=2)$ reaction as an example, at constant concentration of the redox component, the plot of electrode potential vs $\mathrm{pH}$ gives the slope of about $59 \mathrm{mV} / \mathrm{pH}$. 


\subsubsection{Thermodynamics}

An equilibrium potential - $\mathrm{pH}$ thermochemical map called Pourbaix diagram represents possible stable thermodynamic phases of an aqueous electrochemical system. Potentials are usually plotted at the vertical axes, and $\mathrm{pH}$ values horizontally. The vertical boundary lines thus separate the species in protonation/deprotonation equilibrium, when no electrons are transferred, such lines are located at specific $\mathrm{pH}$ values corresponding to the $p K_{a}$ of this equilibrium. The horizontal (zero slope) boundary lines separate the species in purely electron transfer equilibrium, with no protons involved in the reaction, these lines are located at the standard or formal potential of such a reaction. The boundaries with finite slopes describe PCET equilibria. The Pourbaix diagrams p-benzoquinones/1,4-hydroquinone $\left(Q / Q H_{2}\right)$ and obenzoquinone/catechol in the $\mathrm{pH}$ range of 1 and 15, according to literature of and has been summarized or introduced in literatures as shown in Figure 2.14 ${ }^{[77][78][79]}$. Note multiple equilibria involve quinone/hydroquinone, quinone/semiquinone and semiquinone/quinone.

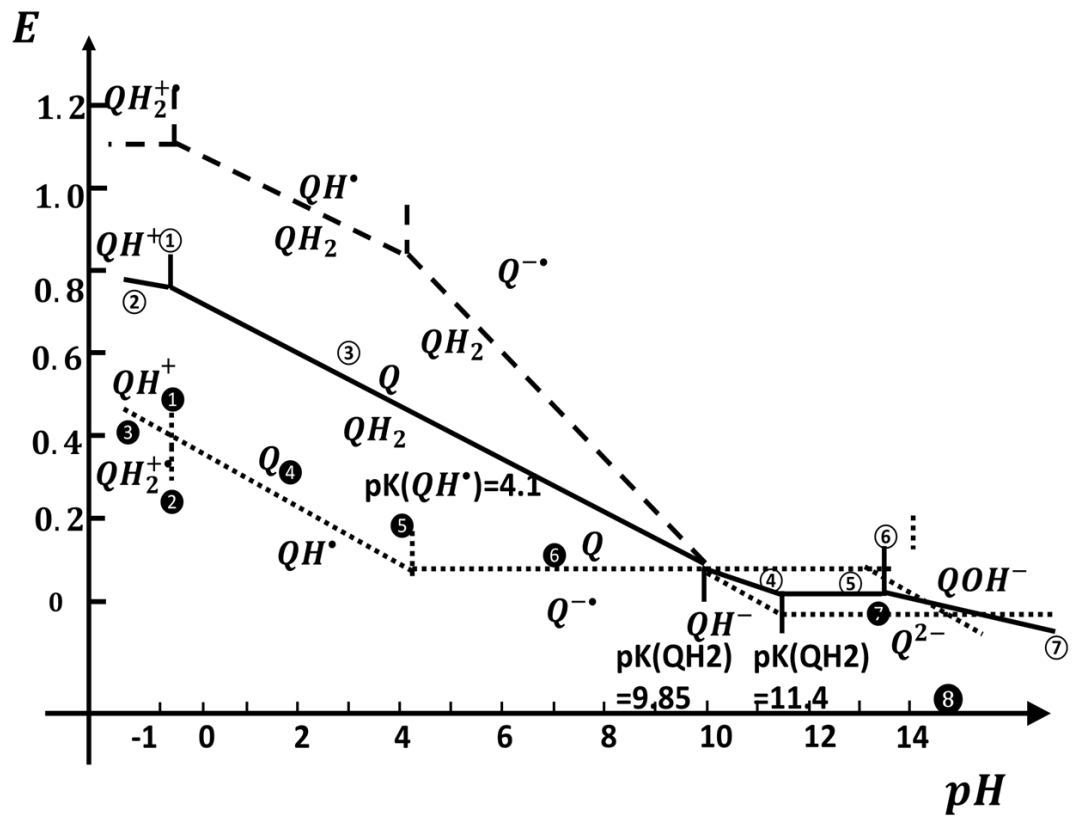

Figure 2.14. The Pourbaix diagram for 1,4-benzoquinone/hydroquinone ${ }^{[77]}$. (Reproduced from Ref. 77 with permission from the Royal Society of Chemistry).

Quinone-hydroquinone equilibrium reactions (solid line):

1. $Q H^{+} \leftrightarrow Q+H^{+}$, verticle line at $p K=-1$ 
2. $Q H^{+}+H^{+}+2 e^{-} \leftrightarrow Q H_{2},-0,0296 V / p H$

3. $Q+2 e^{-}+2 H^{+} \leftrightarrow Q H_{2},-0.059 \mathrm{~V} / \mathrm{pH}$

4. $Q+H^{+}+2 e^{-} \leftrightarrow Q H^{-},-0,0296 V / p H$

5. $Q+2 e^{-} \leftrightarrow Q^{2-}, 0 V / p H$

6. $Q+O H^{-} \leftrightarrow Q O H^{-}$, verticle line at $p K=-13.1$

7. $Q O H^{-}+2 e^{-} \leftrightarrow Q^{2-}+O^{-},-0,0296 V / p H$

Quinone-semiquinone equilibrium reactions (dot line):

(3) $\mathrm{OH}^{+}+\mathrm{e}^{-}+\mathrm{H}^{+} \leftrightarrow \mathrm{QH}_{2}^{+\bullet},-0.059 \mathrm{~V} / \mathrm{pH}$
4 $\mathrm{Q}^{+} \mathrm{e}^{-}+\mathrm{H}^{+} \leftrightarrow \mathrm{QH}^{\bullet},-0.059 \mathrm{~V} / \mathrm{pH}$
(6 $\mathrm{Q}^{-} \mathrm{e}^{-} \leftrightarrow \mathrm{Q}^{-}, 0 \mathrm{~V} / \mathrm{pH}$
(7) $2 \mathrm{Q}^{-\bullet} \leftrightarrow \mathrm{Q}+\mathrm{Q}^{2-}$, disproportion
(8) $\mathrm{QOH}^{-}+\mathrm{e}^{-} \leftrightarrow \mathrm{Q}^{+\bullet}+\mathrm{OH}^{-},-0.0592 \mathrm{~V} / \mathrm{pH}$

Semiquinone-quinone equilibrium reaction (dashed line):

$$
Q^{-\bullet}+e^{-}+2 H^{+} \leftrightarrow Q H_{2},-0.118 V / p H
$$

The microscopic pathways for the PCET of quinones in aqueous electrolyte were established and summarized in the framework of nine-member square scheme, which are shown in Figure 2.15 for $Q / Q H_{2}$ and $C / \mathrm{CH}_{2}$ redox couples ${ }^{[75][79][80] \text {. }}$
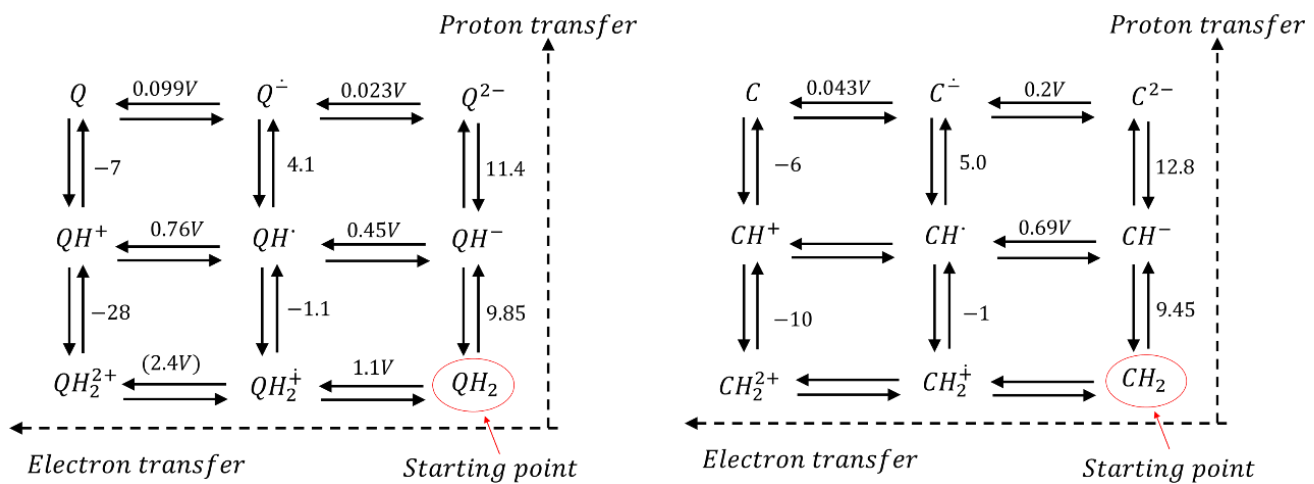

Figure 2.15. The nine-element square scheme for 1,4-benzoquinone/hydroquinone $\left(Q / Q H_{2}\right)$ and catechol/1,2-benzoquinone $\left(\mathrm{C} / \mathrm{CH}_{2}\right)$ redox ${ }^{[75 \mid 179]}$.

Note that $\mathrm{QH}_{2}^{2+}, \mathrm{QH}_{2}^{+}$and $\mathrm{QH}^{+}$are not actually involved in typical PCET reactivity because they are rather dissociated under normal conditions. 


\subsubsection{Solvent Effect}

Voltammetry studies involve PCET are usually conducted in buffered solution and in excess presence of supporting electrolyte. However, it is also interesting to carry electrochemical studies in unbuffered solution: 1) to eliminate the possible interference of the buffer capacity in electroanalysis in vivo; 2) to evaluate the role of the buffer components as proton donor or accepter in mechanistic pathways ${ }^{[70]}$.

Protic media such as water, water may act as the proton acceptor along with $\mathrm{OH}^{-}$and the basic components of any buffers used, or act as a proton donor along with $\mathrm{H}_{3} \mathrm{O}^{+}$and the acidic components of any buffers used. Proton transfers are fast and often assumed to be at equilibrium in water. In nonaqueous solvents such as alcohols, proton transfer is unfavorable. Therefore, the $E^{0} / p K_{a}$ properties of a compound can be altered, same as the PCET mechanism. The role of proton transfer and hydrogen bonding in the unbuffered aqueous electrochemistry of quinones was addressed in literatures ${ }^{[81][82][83]}$. 


\section{Principles of Characterization}

\section{Methods and Devices}

Various characterization methods have been utilized for the electrode materials, redox reactants, and the devices throughout the thesis work, including electrochemical methods, Quartz Crystal Microbalance (QCM), Dynamic Light Scattering (DLS), Atomic Force Microscopy (AFM), UV-vis spectroscopy. This chapter will give a detailed introduction to the electrochemical methods, QCM and the devices, from the basic concept, principles to data analysis. The other characterization methods will be introduced briefly instead.

\subsection{Electrochemical Methods}

In this section, basic electrochemistry concepts and rules, voltammetry techniques including linear sweep voltammetry, cyclic voltammetry, rotating disk electrode, charge and discharge, electrical impedance spectroscopy and in-situ conductivity and electrical conductivity by 4 probes will be introduced.

\subsubsection{Introduction}

Electrochemistry is a branch of chemistry dealing with the interrelation of electrical and chemical effects. The field of electrochemistry includes study of the chemical changes caused by the electrical current and the electrical energy produced by chemical reactions. In other words, electrochemistry involves the chemical phenomena associated with charge separation across the interface between the chemical phases ${ }^{[84][85]}$. 
When a conductive electrode is placed in contact with an electrolyte, a potential difference occurs at the interface due to the different chemical potentials of the two species, which drives the charge transfers including electron transport in the electronic conductor and ion movement in the ionic conductor at the junction to reach an equilibrium state, where, due to net charge separation, a potential difference $\varphi_{\text {electrode/electrolyte }}$ is developed,

$$
\varphi_{\text {electrode/electrolyte }}=\varphi_{\text {electrode }}-\varphi_{\text {electrolyte }}
$$

However, one electrode-electrolyte interface is not sufficient to get an experimental access to the potential, a second electrode is required, which forms a complete electrochemical cell of at least two electrodes separated by electrolyte. In general, electrode potential drop can be measured with respect to a standardized reference electrode made up of constant composition and high input impedance so the current flowing through is negligible. The international accepted reference electrodes include standard hydrogen electrode (SHE, 0V), standard calomel electrode (SCE, $0.242 \mathrm{~V}$ vs. SHE), silver-silver chloride electrode $[\mathrm{Ag} / \mathrm{AgCl} /(\mathrm{KCl}$, saturated in water), $0.197 \mathrm{~V}$ vs. SHE $]^{[86]}$. Thus, the voltage $E$ of the questioned electrode/electrolyte would be measured as:

$$
E=\varphi_{\text {electrode } / \text { electrolyte }}+\text { const }
$$

Where the constant is determined by the reference.

Two types of processes can take place at an electrode-electrolyte interface. In a so-called Faradaic process, charges are transferred across the electrode-electrolyte interface, the corresponding Faradaic current is due to the reduction or oxidation of some chemical substance $^{[87]}$. The other kind is non-faradaic process involving no charge transfer across the interface, such as adsorption and desorption ${ }^{[85]}$, showing a property of capacitance. 


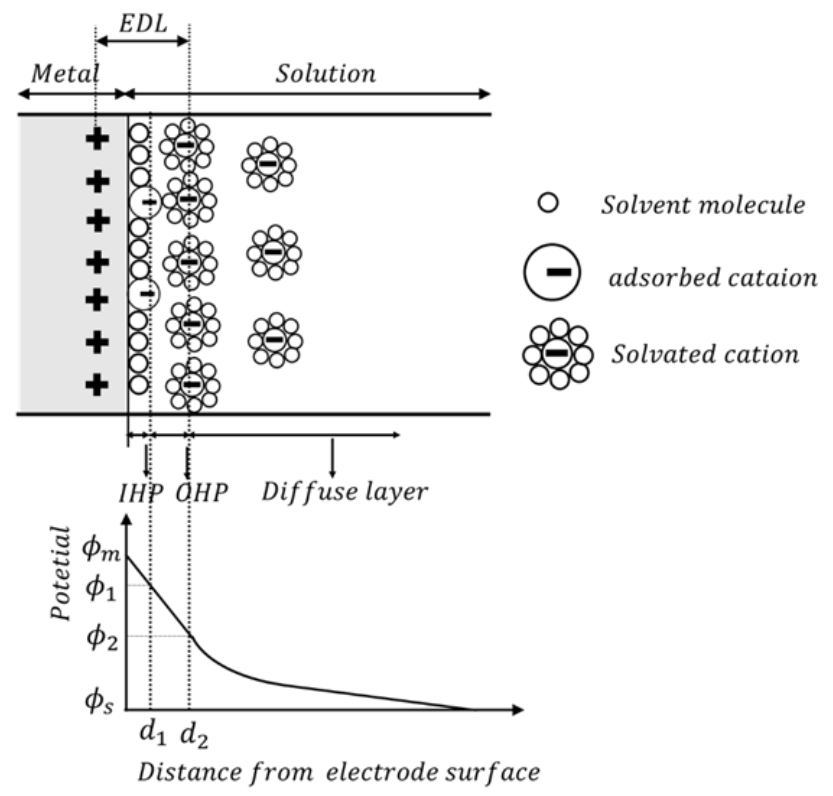

Figure 3.1. Electrified interface between electrode and solution and the potential drop as a function of distance ${ }^{[84]}$. (Reprinted with permission from ref 84. Copyright (C) 2000 John Wiley and Sons).

The formation of electrical double layer is a typical non-faradaic process. Electrical double layer (EDL) is the structure formed by charged species and the originated dipoles existing at the interface. As shown in Figure 3.1, at given potential, there is a charge on the metal electrode $\phi_{m}$ and the opposite charge in solution $\phi_{s}, \phi_{m}=-\phi_{s}$. At the solution side, the inner layer which contains mostly solvent molecules and some other species is called compact, Helmholtz, or stern layer, corresponding the electrical center of the dipoles is called inner Helmholtz plane (IHP). Solvated ions plane located at a distance $d_{2}$ is called outer Helmholtz plane (OHP), while the region extended from OHP into the bulk solution is called diffuse layer. Corresponding potential profile across the electrical double layer is shown in Figure 3.1. The EDL capacitance is $C_{d}$, and is dependent on the potential applied onto the electrodes and the concentration of electroactive species adsorbed.

For a simple one electron faradic process, the electron transfer takes place at the electrodeelectrolyte interface,

$$
O+e^{-} \rightleftarrows R^{-}
$$

Here, $O$ represents the reactant (oxidized species) and $R$ represents the product (reduced species). 
In equilibrium, i.e., when oxidation and reduction reaction have the same rate, so that there is no net flux of reactants and the overall circuit has zero current flow, the equilibrium electrode potential is given by Nernst equation:

$$
E_{e q}=E^{0}+\frac{R T}{F} \ln \frac{C_{O}^{*}}{C_{R}^{*}}
$$

$C_{O}^{*}$ and $C_{R}^{*}$ are the initial concentrations of the reactants, and $E^{0}$ is defined as the formal potential for the half-reaction involving them, formal potential describes the potential of a couple at equilibrium in a system where the oxidized and reduced forms are present an unit formal concentration ${ }^{[84][85]}$.

\subsubsection{Dynamic Electrochemistry}

Equilibrium state is fundamental in electrochemistry, but very often, the system departure from the equilibrium and undergoes a dynamic electrochemical process. Kinetics and thermodynamics are two main aspects in the evaluation of the electrode reaction.

Kinetics illustrate the evolution of mass flow in the system, including the approach to equilibrium and dynamic maintenance of that state. The reactions $O \rightarrow R$ and $R \rightarrow O$ are active at all times, the forward and backward currents $i$ are a function of reaction rate $v$, which, in turn, is a function of the rate constant $k$ and the surface concentration $C$ :

$$
\begin{gathered}
i_{c}=F A v_{f}=F A k_{f} C_{O}(0, t) \\
i_{a}=F A v_{b}=-F A k_{b} C_{R}(0, t)
\end{gathered}
$$

The overall reaction current $i$ can be given then,

$$
i=i_{c}+i_{a}=F A\left[k_{f} C_{O}(0, t)-k_{b} C_{R}(0, t)\right]
$$

The rate constant $k$ of the reaction can be expressed with activation enthalpy $\Delta H$, activation entropy $\Delta S$ (or free activation Gibbs energy $\Delta G$ ) and temperature $T$ :

$$
k=A e^{-(\Delta H-T \Delta S) / R T}=A e^{-\Delta G / R T}
$$

Potential $E$ relative to the formal potential $E^{0}$ applied to the electrode can be reflected by the change in Gibbs free energy. For a reduction reaction which accept electrons from the electrode,

$$
\Delta G_{c}=\Delta G_{c, 0}+a F\left(E-E^{0}\right)
$$

And for an oxidation which gives electrons to electrode,

$$
\Delta G_{a}=\Delta G_{a, 0}-(1-a) F\left(E-E^{0}\right)
$$


$\Delta G_{f, 0}$ or $\Delta G_{b, 0}$ is the standard free energy of activation for anodic or cathodic reaction. $a$ is defined as fraction of the electrostatic potential energy affecting the reaction rate and called transfer coefficient.

So, the rate constant can be expressed as:

$$
\begin{gathered}
k_{f}=A_{f} e^{\left[-\Delta G_{c, 0}-a F\left(E-E^{0}\right)\right] / R T} \\
k_{b}=A_{b} e^{\left[-\Delta G_{a, 0}+(1-a) F\left(E-E^{0}\right)\right] / R T}
\end{gathered}
$$

Each contains a parameter that is independent to potential and equals to the rate constant at $E=$ $E^{0}$. This corresponds to a solution of $C_{O}^{*}=C_{R}^{*}$ at the equilibrium state, the reaction rate $k_{f} C_{O}^{*}=k_{b} C_{R}^{*}$, so that $k_{f}=k_{b}$. That is, $E^{0}$ is where the forward and backward rate constant is the same value, so-called standard rate constant, expressed as $k^{0}$. So,

$$
\begin{gathered}
k_{f}=k^{0} e^{-a F\left(E-E^{0}\right) / R T} \\
k_{b}=k^{0} e^{(1-a) F\left(E-E^{0}\right) / R T}
\end{gathered}
$$

Hence, the total current can be rewritten as the well-known Butler-Volmer equation ${ }^{[84][85] \text { : }}$

$$
i=F A k^{0}\left[C_{O}(0, t) e^{-a F\left(E-E^{0}\right) / R T}-C_{R}(0, t) e^{(1-a) F\left(E-E^{0}\right) / R T}\right]
$$

Where, $E-E^{0^{\prime}}$ refers the extent of the applied potential departure from the equilibrium potential, it is termed with overpotential, usually represented by $\eta$, so,

$$
i=F A k^{0}\left[C_{O}(0, t) e^{-a F \eta / R T}-C_{R}(0, t) e^{(1-a) F \eta / R T}\right]
$$

At equilibrium, the net current is zero, the balanced faradaic activity can be expressed in terms of exchange current $i_{0}$.

$$
\begin{gathered}
i_{0}=i_{c}=F A k^{0} C_{O}^{*} e^{-a F \eta / R T} \\
i_{0}=-i_{a}=F A k^{0} C_{R}^{*} e^{(1-a) F \eta / R T}
\end{gathered}
$$

The Butler-Volmer equation can be rewritten as the current-potential equation embedded with exchange current:

$$
i=i_{0}\left[\frac{C_{O}(0, t)}{C_{O}^{*}} e^{-a F \eta / R T}-\frac{C_{R}(0, t)}{C_{R}^{*}} e^{(1-a) F \eta / R T}\right]
$$

If the solution is well stirred or the currents are kept very low, the surface concentration $C_{O}(0, t)$ does not differ too much from the bulk value $C_{O}^{*}$, the current-potential equation embedded with exchange current will become:

$$
i=i_{0}\left[e^{-a F \eta / R T}-e^{(1-a) F \eta / R T}\right]
$$




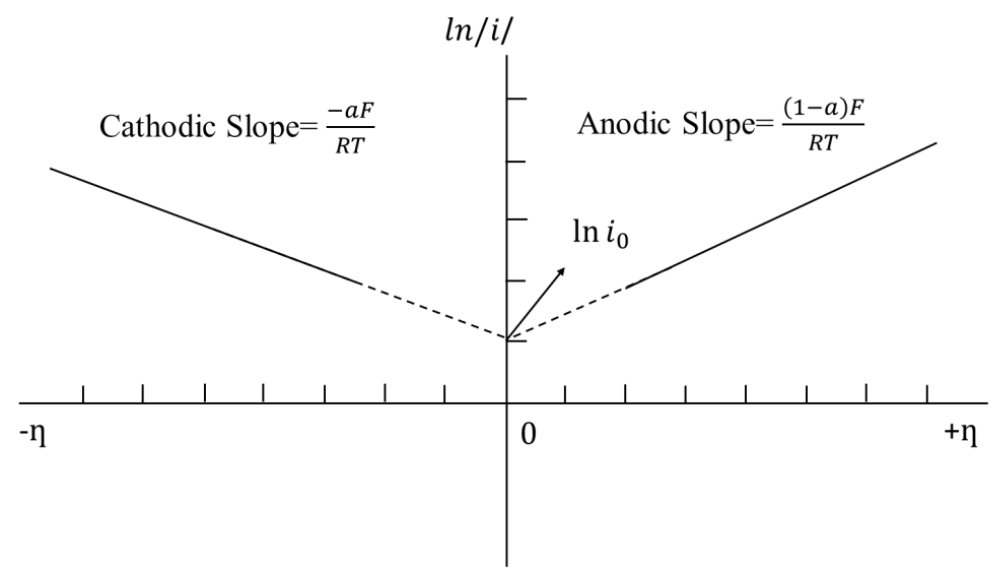

Figure 3.2. Tafel plot for anodic and cathodic branches of the current-overpotential curves for

$$
O+e^{-} \rightleftarrows R^{-[84]} .
$$

(Reprinted with permission from ref 84. Copyright (C) 2000, John Wiley and Sons).

A plot of $\ln i$ vs $\eta$, can be obtained and is called "Tafel plot" and displayed in Figure 3.2. At large overpotentials, the branches tend to linear relationship as the other reaction is negligible. In general, the anodic branch is with a slope of $\frac{(1-a) F}{R T}$, while the cathodic branch is with a slope of $\frac{-a F}{R T}$, thus the transfer coefficient can be obtained from the slope of $\frac{d \ln / j_{a} /}{d E}$.

In history, the definition of the transfer coefficient $a_{a}$ and $a_{c}$ for a reaction involves n electrons, has been defined as $-\frac{R T}{n F} \frac{d l n / j_{a} /}{d E}$ or $-\frac{R T}{n F} \frac{d l n / j_{c} /}{d E}$. However, it was pointed out few years ago that this definition applies only to an electrode reaction that consists of a single elementary step involving simultaneous uptake or release of $\mathrm{n}$ electrons from or to the electrode. However, in practice, many reactions consist of multistep process with multi-electron uptake or release. To process with n electrons reaction with unknow mechanism, Rolando Guidelli, Richard G. Compton and their colleagues proposed a mechanism-independent definition of the transfer coefficient $^{[88][89]}$.

For anodic reaction,

$$
a_{a}=-\frac{R T}{F} \frac{d \ln / j_{a} /}{d E}
$$

For cathodic reaction,

$$
a_{c}=-\frac{R T}{F} \frac{d \ln / j_{c} /}{d E}
$$

And, 


$$
a_{a}+a_{c}=n / v
$$

Where $v$ is the numbers of occurrence of rate-determining step in the electrode reaction ${ }^{[88]}$. Moreover, both linear segments of the Tafel branches extrapolate to an intercept of $\ln i_{0}$. Apparently, exchange current corresponds to overpotential free current, where the current is very small. The ratio of $-\frac{\eta}{i}$ has a unit of resistance and is often called the charge transfer resistance, $R_{c t}$.

$$
R_{c t}=\frac{R T}{n F i_{0}}
$$

The values can be used as one of kinetic indices, the smaller the exchange current, the higher the charge transfer resistance, and more sluggish the kinetics.

\subsubsection{Factors Affecting Electrode Reaction Rate and Current}

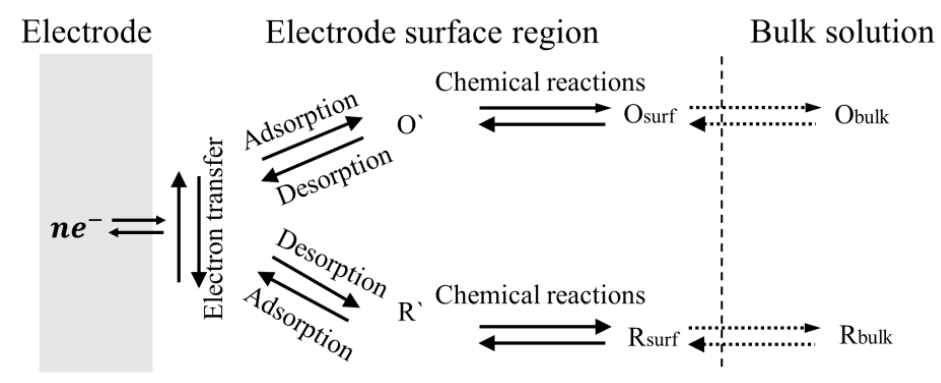

Figure 3.3 Pathway of a general electrode reaction ${ }^{[84]}$. (Reprinted with permission from ref 84 . Copyright (C) 2000 John Wiley and Sons).

The pathway of a general electrode reaction:

$$
O+e^{-} \rightleftarrows R^{-}
$$

is shown in Figure 3.3. Reactants approach the electrode surface from the bulk under concentration and electrical gradient, can experience a chemical transformation and be adsorbed prior to undergoing the electron transfer reaction. Thus, factors affecting the electrode reaction rate and current include:

1) Mass transfer, e.g., $O$ from the bulk to the electrode surface and $R$ from the electrode surface to the bulk.

2) Homogeneous chemical reactions before or after the electron transfer.

3) Heterogeneous electron transfer at the electrode surface. 
4) Other reactions such as adsorption/desorption.

The simplest reactions involve mass transfer and electron transfer only. Mass transfer includes three modes: i) Migration: movement of a charged body under an electrical potential gradient. ii) Diffusion: movement of a charged body under a concentration gradient. iii) Convection: Stirring or hydrodynamic transport.

When the electrode process involves only fast electron transfer and reversible, rapid chemical reactions, then the electrochemical reaction can be considered being at equilibrium and the concentrations of species in the faradic process are related to the electrode potential according to Nernst equation. The net electrode reaction rate will be then controlled by the mass transfer rate.

\subsubsection{Voltammetry}

\subsubsection{Linear sweeping Voltammetry and Cyclic Voltammetry}

Linear sweep voltammetry (LSV) is a method in which the potential is controlled to vary linearly with time, from $E_{i}$ to $E$, and the resulting current $i$ as a function of time and potential is recorded. If the potential is swept forward and backward between $E$ and $E_{i}$, the method is known as cyclic voltammetry (CV), the sweeping rate $v$ is scan rate, as shown in Figure 3.4.

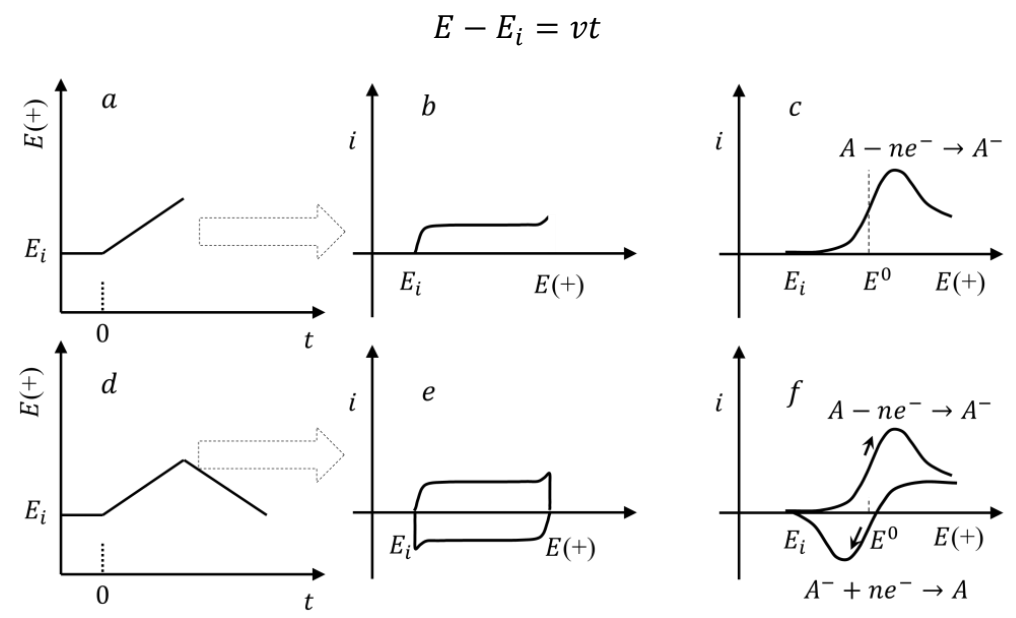

Figure 3.4. a) Variation of applied potential with time in Linear sweep voltammetry and resulting $i \sim E$ curve for b) a capacitive process and c) faradaic process; d) Variation of applied potential with time in in cyclic voltammetry and resulting $i \sim E$ curve for e) a capacitive process and f) faradaic process.

Quantitative analysis can be carried with cyclic voltammogram. 
For a capacitive process, the current rise from zero as the scan starts and attains a steady state current (Figure 3.4b\&e), which depends on the scan rate and the capacitance C:

$$
i=v C=\frac{d E}{d t} C
$$

For a pure faradaic process (Figure $3.4 \mathrm{~d} \& \mathrm{f}$ ), the $i \sim E$ curve during a single CV cycle figured with characteristic peaks, which is relative to the oxidation and reduction of the electroactive species. The position of the peaks at the potential axis, and the intensity of the current provides basic diagnosis.

For a reversible reaction, the peak current $\left(i_{p}\right)$ is directly proportional to reactant concentration and the square root of the scan rate, follow the so-called Randle-Sevcik equation:

$$
i_{p}=0.4463 n F A C\left(\frac{n F v D}{R T}\right)^{\frac{1}{2}}
$$

Where $\mathrm{n}$ is the numbers of the electrons transferred, the Faraday constant in $\mathrm{C} \mathrm{mol}^{-1}, \mathrm{~A}$ is the electrode area in $\mathrm{cm}^{2}$, $\mathrm{R}$ is the gas constant in $\mathrm{J} \mathrm{K}^{-1}$, T is the temperature in $\mathrm{K}, \mathrm{D}$ is the diffusion coefficient in $\mathrm{cm}^{2} \mathrm{~s}^{-1}, \mathrm{C}$ is the concentration of the reactant in $\mathrm{mol} \mathrm{cm}^{-3}$.

So, at $25^{\circ} \mathrm{C}$, the derivation as follow can be obtained:

$$
i_{p}=269000 n^{3 / 2} A D^{1 / 2} C v^{1 / 2}
$$

The position of the oxidation and reduction peaks is related to the formal potential $\left(E^{0}\right)$ of the redox process, which is centered between the two peaks for reversible reactions:

$$
E^{0}=\frac{E_{p, a}+E_{p, c}}{2}
$$

And the peak separation for a reversible reaction gives the number of electrons transferred:

$$
\Delta E=E_{p, a}-E_{p, c}=\frac{0.059}{n} V
$$

In addition, according to the criterion of Nernst equation for an ideal reversible reaction, the oxidation/reduction peak current shall be symmetrical, that is $\frac{i_{p, a}}{i_{p, c}}=1$, it shall also be independent to the scan rate, so as the peak separation $\Delta E^{[84][90]}$.

\subsubsection{Rotating Disk Voltammetry}

Rotating disk voltammetry is a hydrodynamic voltammetry technique. The core component rotating disk electrode (RDE) is composed of a conductive disk embedded in a rod of inert insulator, the electrode was connected to an electrical motor to make the assembly rotate at a controllable and constant angular velocity $\omega$. The advantage of RDE in comparison to stationary electrode is that the thickness of the diffusion layer decreases as electrode rotating 
speed increases. The reaction products at the electrode vicinity can be continuously swept away from the electrode to the bulk solution, while the reactant can be transported to the electrode vicinity continuously from the bulk. This results in the peak current in CV for RDE with a plateau, as governed by Levich equation.

Levich equation is applied to the totally mass-transfer-limited condition in a reversible reaction at the RDE, predicts that the limiting current $i_{l}$ is proportional to the bulk concentration $C^{*}$ and the square root of sweep rate $\omega^{1 / 2}$, the current- potential curve follows ${ }^{[84][90]}$ :

$$
\begin{gathered}
i_{l, c}=0.62 n F A D_{O}^{2 / 3} \omega^{1 / 2} v^{-1 / 6} C_{O}^{*} \\
i_{l, a}=-0.62 n F A D_{R}^{2 / 3} \omega^{1 / 2} v^{-1 / 6} C_{R}^{*}
\end{gathered}
$$

The potential obtained from the Nernst equation and above current relation is:

$$
\begin{gathered}
E=E^{0}+\frac{R T}{n F} \ln \left(\frac{i_{l, c}-i}{i-i_{l, a}}\right) \\
E^{0}=E^{0^{\prime}}+\frac{R T}{n F} \ln \left(\frac{D_{R}}{D_{O}}\right)^{2 / 3}
\end{gathered}
$$

Where $n$ is the electron numbers transferred in the reaction, $F$ is the Faradic constant $(96485$ $\mathrm{C} / \mathrm{mol}$ ), $\mathrm{A}$ is the electrode area, $D$ is the diffusion coefficient of the electroactive species, $v$ is the kinematic viscosity of the solution and $C^{*}$ is the bulk concentration of the electroactive species.

Koutecky-Levich equation describes the current-potential relation relative to both the kinetic activity and the mass transport ${ }^{[84]}$ :

$$
\frac{1}{i}=\frac{1}{i_{K}}+\frac{1}{i_{l, c}}=\frac{1}{F A k_{f}(E) C_{O}^{*}}+\frac{1}{0.62 n F A D_{O}^{2 / 3} \omega^{1 / 2} v^{-1 / 6} C_{O}^{*}}
$$

where $i_{l, c}$ is the Levich current, $i_{K}$, called kinetic current, and is the current at the given potential in the absence of mass transport restriction, $k_{f}(E)$ is the kinetic rate of the electron transfer at potential $E$.

The kinetic current, can be obtained from the Koutecky-Levich plot $i^{-1}$ vs $\omega^{-1 / 2}$ by extrapolating the intercept of infinite $\omega$. The kinetic rate constant $k_{f}$ could be calculated from $i_{K}$. In addition, the effective diffusion constant at a given potential can be calculated from the and slope of $i^{-1}$ vs $\omega^{-1 / 2}$. 


\subsubsection{Galvanostatic Charge/Discharging}

Galvanostatic charge/discharging (GCD) is a common technique used to test the performance of capacitors and batteries. GCD is conducted at a constant current until a desired voltage is reached. Numerous cycles of GCD are usually done to test the stability or cycle-life of capacitors and batteries.

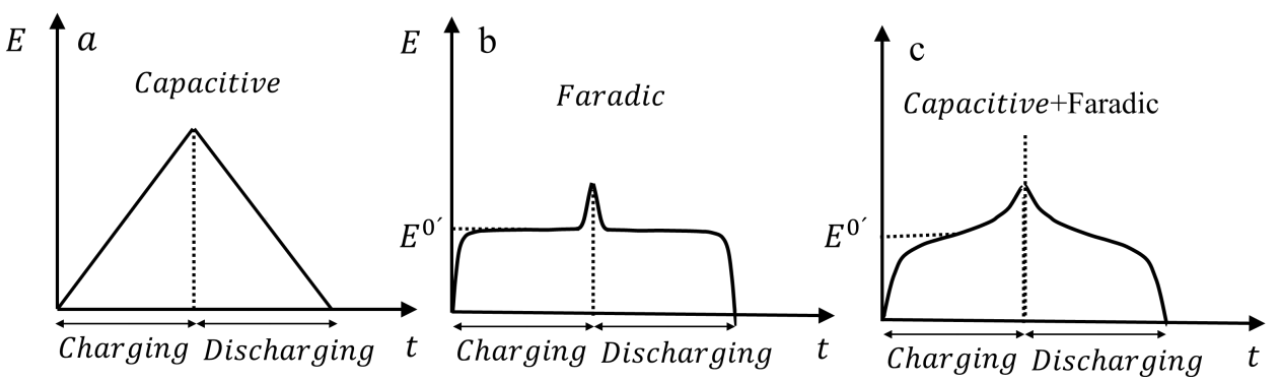

Figure 3.5. GCD measurements of different types of systems at constant current.

For a system involved pure capacitive process, the charge and discharge voltage are linear with time, Figure 3.5a, with the slope related to the constant capacitance C:

$$
\begin{gathered}
q=I d t=C \Delta E \\
\Delta E=\frac{1}{C} I d t
\end{gathered}
$$

$q$ is the charge at constant charging current $I$ in the time period of $d t, \Delta E$ is the potential difference caused by charging, $C$ is the differential capacitance. The total electrical energy stored $E_{n}$ is thus found by integration of the area under the galvanostatic curve. The total capacitance is then extracted from the relation between the $E_{n}$ and $C$ :

$$
\begin{gathered}
E n=I \int V d t \\
C=\frac{2 E n}{V^{2}}
\end{gathered}
$$

For a system comprising only faradaic process, the charge and discharge curve look like Figure $3.5 \mathrm{~b}$, as follows, in the deal case, from Nernst equation. In the case of a mixed capacitive and faradaic process, called also pseudo-capacitor, the charge and discharge follow the pattern of a combination of Figure $3.5 \mathrm{a}$ and $3.5 \mathrm{~b}$ (Figure $3.5 \mathrm{c}$ ) and capacitance can be also estimated from above equation. 


\subsubsection{Electrical Impedance Spectroscopy (EIS)}

Impedance is a generalization of electrical resistance for all alternative current, in the sense that it relates voltage and current in a most general case. The resistance, $R$, is defined as the coefficient of proportionality between voltage $E$ and current $I$,

$$
E=I R
$$

When AC voltage is applied to an arbitrary combination of resistors, capacitors or inductors, current that flows through will be in phase shifted with respect to voltage, and it will be also dependent on frequency. Impedance takes these factors into account.

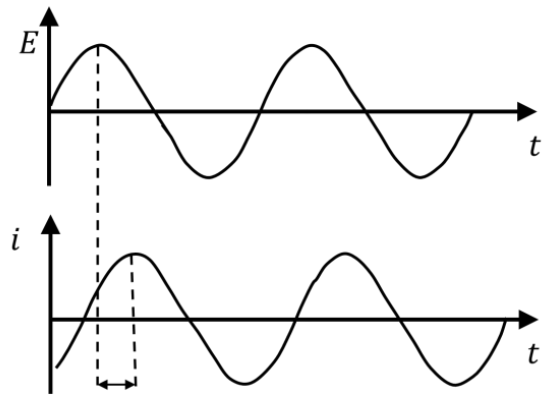

Figure 3.6. Sinusoidal current response in a linear system.

The electrical impedance is usually measured by using a small sinusoidal potential excitation signal to make the cell's response being pseudo-linear in linear system, the current response $i_{t}$, will be sinusoidal at the same frequency but shifted with a phase $\phi$, see in Figure 3.6.

$$
\begin{gathered}
E_{t}=E_{0} \sin (w t) \\
i_{t}=i_{0} \sin (w t+\phi)
\end{gathered}
$$

The impedance of the system, $Z$, can be calculated from an expression analogous to Ohlm's law and expressed in terms of magnitude, $Z_{0}$ and a phase shift $\phi$ :

$$
Z=\frac{E_{t}}{i_{t}}=\frac{E_{0} \sin (w t)}{i_{0} \sin (w t+\phi)}=Z_{0} \frac{\sin (w t)}{\sin (w t+\phi)}
$$

Impedance can also be expressed in a complex form: $Z=Z_{0}(\cos \phi+i \sin \phi)$, including a real and imaginary part. When the real and imaginary part are plotted on the $\mathrm{X}$-axis and $\mathrm{Y}$-axis, correspondingly, the plot is called Nyquist plot. Another way to present the data is called Bode plot, in which frequency is plot on $\mathrm{X}$-axis, both the absolute values of impedance $(/ Z /)$ and the phase shift are plot on the Y-axis. EIS can be analyzed by fitting the data to an equivalent circuit model with electrical elements connected in series or in parallel. The common electrical elements are resistor, inductor and capacitor as shown in Table 3.1. 
Table.3.1. Common electrical elements

\begin{tabular}{cccc}
\hline Component & I vs. E & Impedance & I, E Phase shift \\
\hline Resistor & $\mathrm{R}=\frac{E}{I}$ & $\mathrm{Z}=R$ & in phase \\
Inductor & $\mathrm{L}=\frac{E}{d I / d t}$ & $\mathrm{Z}=i \omega L$ & $90^{\circ}$ phase shift \\
Capacitor & $\mathrm{C}=\frac{I}{d E / d t}$ & $\mathrm{Z}=1 / i \omega C$ & $90^{\circ}$ phase shift \\
& & & \\
\hline
\end{tabular}
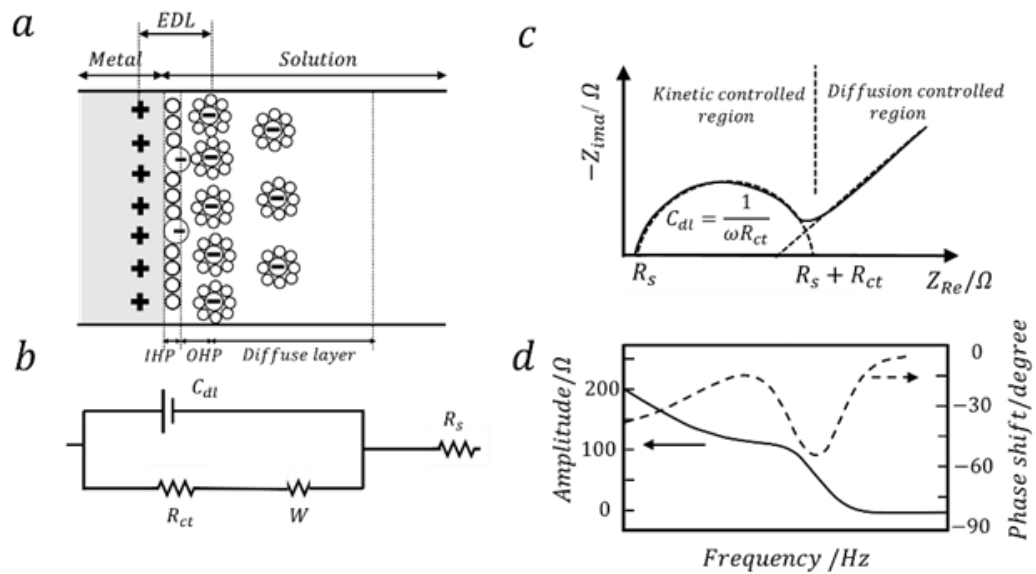

Figure 3.7. a) An electrical interface, b) Equivalent Circuit with Mixed Kinetic and ChargeTransfer Control, c) The corresponding Nyquist diagram and d) Bode diagram.

Electrical interface is usually modeled by an equivalent Randles circuit, which includes a double layer capacitor in parallel with a charge transfer resistor and a diffusion resistor (represented by Warburg impedance), connected in series with a solution resistor. This model as well as the corresponding Nyquist plot and Bode plot are shown in Figure 3.7.

\subsection{Electrical Conductivity}

Electrical conductivity or specific conductance, $\sigma(\mathrm{S} / \mathrm{m})$, represents the material's ability to transport electrical charge. It is defined as the ratio of current density $j$ to applied potential bias $E$ and it is the reciprocal of electrical resistivity $\rho$. It is very important property of conducting materials, therefore, two methods used to measure electrical conductivity, namely, the 4-probe and electrochemical in-situ measurement will be introduced. 


\subsubsection{4-probe Measurement}

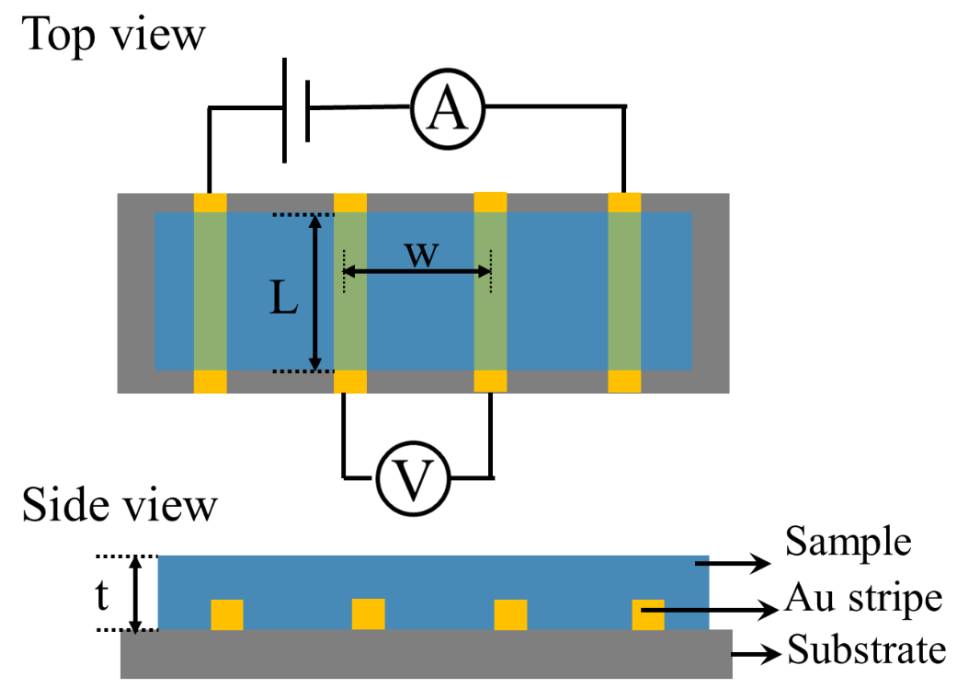

Figure 3.8. Electrical conductivity measurement by 4-probe.

Figure 3.8 shows the 4-probe technique for electrical conductivity measurement of thin films. The current supplying terminals are connected to two outer electrodes, while the voltage sensing terminals to the two inner electrodes. The resistance and conductivity of the film materials can be obtained from the current $I$ and voltage $V$ and the length $L$, width $w$ and thickness $t$ of the cuboid where the voltage is measured:

$$
\begin{gathered}
R=\frac{V}{I} \\
\sigma=\frac{L}{R w t}
\end{gathered}
$$

\subsubsection{In-situ Conductivity}

In-situ conductivity is to measure the conductivity of thin film sample in an electrochemical cell as shown in Figure 3.9. The film of interested is coated on to a very sensitive interdigitated array (IDA) electrodes ${ }^{[91]}$, both interdigitated electrodes (terminals) are connected as working electrodes controlled by bipotentiostat. A potential bias is applied between the two terminals resulting in a current flow $i_{p}$ through film.

According to Kirchhoff's first law for points at two terminals of $i_{p}$,

$$
i_{1}=i_{F 1}-i_{p}
$$


If zero bias is applied,

$$
\begin{gathered}
i_{2}=i_{p}+i_{F 2} \\
\Delta i=i_{2}-i_{1}=i_{F 2}-i_{F 1}+2 i_{p} \\
2 i_{p}=\Delta i-\Delta i_{F}
\end{gathered}
$$

$$
\begin{gathered}
\Delta E^{\prime}=0 \\
i_{p}{ }^{\prime}=0 \\
\Delta i^{\prime}=\Delta i_{F}{ }^{\prime}
\end{gathered}
$$

Therefore,

$$
\begin{aligned}
& i_{1}{ }^{\prime}=i_{\mathrm{F} 1}{ }^{\prime} \\
& i_{2}{ }^{\prime}=i_{\mathrm{F} 2}{ }^{\prime}
\end{aligned}
$$

If a non-zero bias is applied,

$$
\Delta E^{\prime \prime}=\Delta E \neq 0
$$

assume WE1 remains at the potential at zero bias,

At WE1,

$$
i_{\mathrm{F} 1}{ }^{\prime \prime}=i_{\mathrm{F} 1}{ }^{\prime}=i_{1}{ }^{\prime}
$$

At WE2, the current can be rewrite as:

$$
\begin{gathered}
i_{\mathrm{F} 2}{ }^{\prime \prime}=i_{2}{ }^{\prime}+\Delta i(\Delta E) \\
2 i_{p}{ }^{\prime \prime}=\Delta i^{\prime \prime}-\Delta i_{F}{ }^{\prime \prime}=\left(i_{2}{ }^{\prime \prime}-i_{1}^{\prime \prime}\right)-\left(i_{\mathrm{F} 2}{ }^{\prime \prime}-i_{\mathrm{F} 1}{ }^{\prime \prime}\right)=\left(i_{2}{ }^{\prime \prime}-i_{1}^{\prime \prime}\right)-\left(i_{2}^{\prime}-i_{1}^{\prime}\right)-\Delta i(\Delta E)
\end{gathered}
$$

Suppose $\Delta i(\Delta E)$ can be neglected, then,

$$
i_{p}{ }^{\prime \prime}=\left(\left(i_{2}{ }^{\prime \prime}-i_{1}{ }^{\prime \prime}\right)-\left(i_{2}{ }^{\prime}-i_{1}{ }^{\prime}\right)\right) / 2
$$

It indicates that the current passing across the film can be obtained by applying a zero and a non-zero bias potential, and recording the currents passing through the two working electrodes, respectively. The conductivity of the polymer $\sigma$ can then be calculated:

$$
\begin{aligned}
& R_{p}=\frac{\Delta E}{i_{p}} \\
& \sigma=\frac{1}{R_{p}} * \frac{d}{A}
\end{aligned}
$$

Where $d$ is the distance between the electrodes and $A$ is the cross section area which current flows through. 


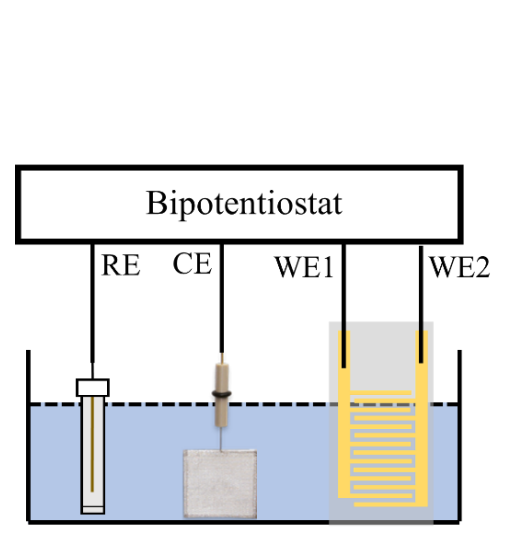

$a$

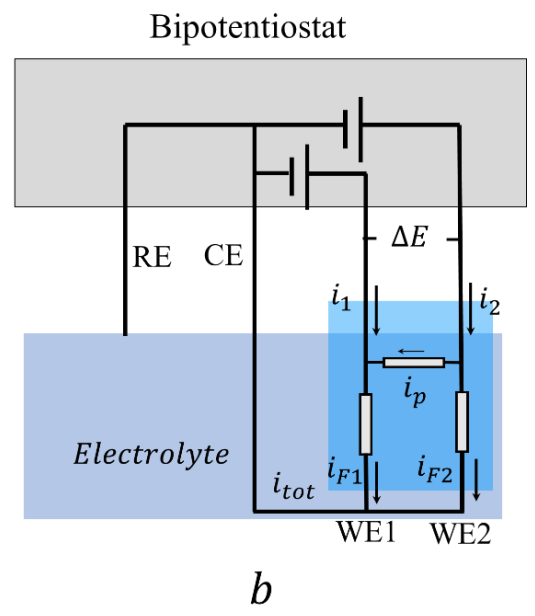

Figure 3.9. a) Electrochemical setup for in-situ electrical conductivity measurement, b) circuit diagram of the biopotentiostat setup with the two IDA electrodes. (Reprinted with permission from Ref 91. Copyright $\odot 2015$ Elsevier Ltd.)

\subsection{Quartz Crystal Microbalance}

\subsubsection{Introduction}

A quartz crystal microbalance (QCM) is a nanogram sensitive technology to measure mass by utilizing the acoustic wave generated by an oscillating piezoelectric quartz resonator. The method is sometimes also known as quartz microbalance (QMB) or quartz crystal nanobalance (QCN).

In 1880, the Curie brothers discovered the piezoelectrical effect on certain materials such as quartz: when mechanical stress applied to these materials, voltage is produced in proportional to the stress ${ }^{[92]}$. Later on, a German scientist, named Sauerbrey G, developed the theory and experiment quantitively related the frequency change of oscillating crystal to the mass of the extra layer on the crystal in $1959^{[93]}$, which boosted the use of quartz plate resonator as microbalance for thin, rigid films. The QCM technology was first used in vacuum and gas phase, while around 1980, T. Nomura and M. Okuhara measured the frequency change, $\Delta f$, of quartz crystal in organic solvents, and found it depends on the crystal and the density and viscosity of the solvents ${ }^{[94]}$, which prompted new approaches for soft adsorbents and expanded QCM technology dramatically in liquid phase application later.

The QCM technology was further developed to predict the physical properties of adhesion layers by analyzing the dissipation factor, D, (QCM-D) by Swedish scientists and became 
commercial by the company Q-sense in 1990s, and now it has been widely used to quantify surface interactions such as: adsorption/desorption, binding and reactions such as degradation, cross-linking, swelling/collapse, conformation changes, electrochemical reactions and so

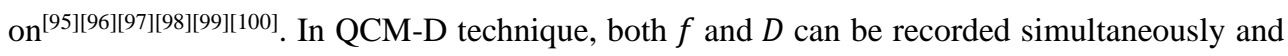
it measures $f$ and $D$ values at multiple harmonics in succession on the millisecond time scale. The probing of multiple harmonics permits the modelling of the experimental data with theory to extra parameters including mass, thickness, density, viscosity, sheer modulus. QCM-D is also more sensitive and accurate than QCM as more data points per second were measured and only changes occurring at the surface is recorded.

\subsubsection{Measurement Principle}

The quartz sensor consists of a quartz crystal disk sandwiched between a pair of electrodes as shown in Figure 3.10. The operation basis of QCM is related to the quartz's inherent piezoelectric property.

As shown in Figure 3.11(A), when the electrodes are connected to an oscillator and alternating current (AC current) is applied across the electrodes, the quartz disk starts to oscillate at its resonance frequency $\left(f_{0}\right)$ due to the piezoelectric effect. When the circuit is short circuited, then the sensor oscillation starts to decay exponentially. The decay rate is called dissipation factor $\left(\mathrm{D}_{0}\right)$, it reflects the energy losses in the system per oscillation cycle.

The angle of cutting out the quartz crystalline affect the inherent oscillation modes and its temperature property. The popular crystal cuts include the AT-cut, BT-cut, GT-cut, IT-cut, SCcut, XY-cut. The AT-cut quartz is most widely used in electronic instruments and it is cut an angle of $35^{\circ} 25^{\prime}$ to the $\mathrm{Z}$ axis, generating a frequency from $1 \mathrm{MHz}$ to several hundreds $\mathrm{MHz}$. The thickness of the quartz plate is also an important parameter to determine its oscillating frequency. Resonance occurs only when the thickness of the quartz plate is an odd integer of the half wavelengths of the induced wave. The resonant frequency $f$, is given by ${ }^{[101]}$ :

$$
\begin{gathered}
f=n \frac{v_{q}}{2 t_{q}}=n f_{0} \\
f_{0}=\sqrt{\frac{\mu_{q}}{\rho_{q}}} / 2 t_{q}=\frac{v_{q}}{2 t_{q}}
\end{gathered}
$$

The $f_{0}$ is defined as fundamental resonant frequency. $\mu_{q}$ is the sheer modulus, $\rho_{q}$ is the density of the quartz, $v_{q}$ is the wave velocity or sound speed in the quartz plate, $t_{q}$ is the thickness of the quartz plate, $n=3,5,7,9,11$ is the third, fifth, seventh, ninth and eleventh overtone and so on. 
In normal operation as a mass sensor, mass added to the crystal affects the effective thickness, while all other influencing variables remains the same. Thus, the changes in mass or extra thickness corresponds to a change in frequency. When extra molecules adsorb onto the quartz sensor, frequency changes from $f_{0}$ to $f_{i}, \Delta f\left(=f_{i}-f_{0}\right)$ is recorded in situ and real time; in the meantime, the energy loss $D$, or dissipation, which is related to the viscoelastic properties of the oscillating mass ${ }^{[100]}$ will also be recorded in situ and real-time as $\Delta D\left(=D_{i}-D_{0}\right)$, shown in Figure 3.11 (B\&C). The energy dissipation, D factor, indicates the energy loss in the whole system and is defined as ${ }^{[96]}$ :

$$
D=\frac{1}{Q}=\frac{E_{\text {dissipated }}}{2 \pi E_{\text {stored }}}
$$

$Q$ is the quality factor of the mechanical resonance, $E_{\text {dissipated }}$ is the energy loss during one period of oscillation when the driven current is turned off and $E_{\text {stored }}$ is the total mechanical energy in the oscillating system.

The D factor during a QCM-D experiment can be obtained from the decay time constant $\tau$ and the resonance frequency $f$ as:

$$
D=\frac{1}{\pi f \tau}
$$

The frequency changes as well as dissipation changes can be quantified by mathematical models in order to visualize the physical, chemical or biological state or process. These models will be introduced in the following section. In general, rigid adsorbents follow the crystal oscillation with little deformation and consequently gives low dissipation, while soft adsorbents give large dissipation. The mass sensitivity follows the vibration amplitude distribution, which decrease from the center to the edge.

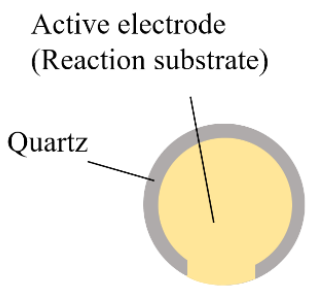

Top view

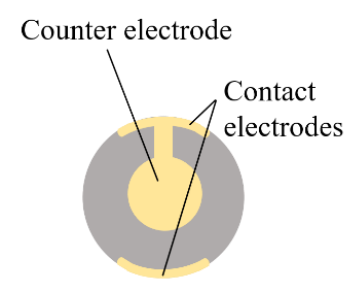

Bottom view

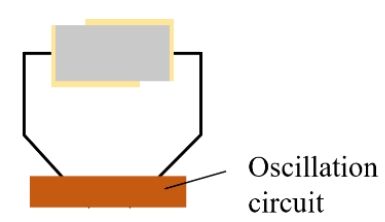

Cross view

Figure 3.10 Schematic illustrations of a quartz sensor used in QCM-D measurements. 
A)
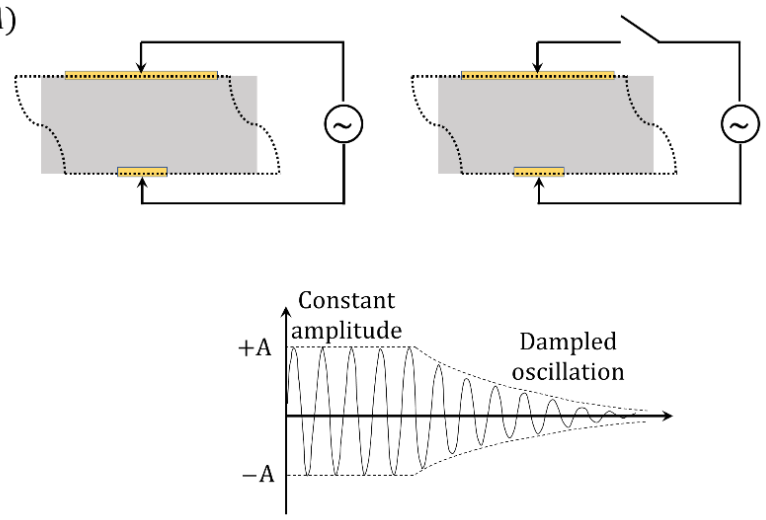

B)
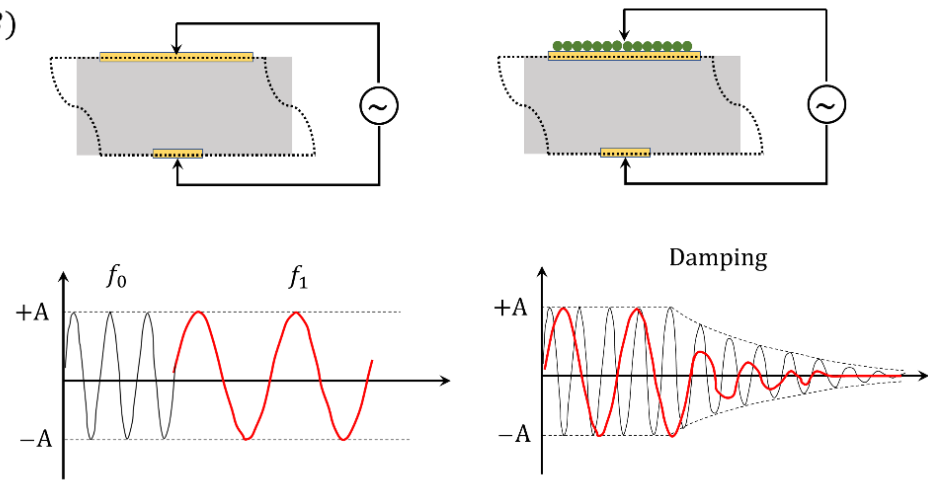

$\Delta f=f_{1}-f_{0}$,

$$
\Delta D=D_{1}-D_{0}
$$

C)

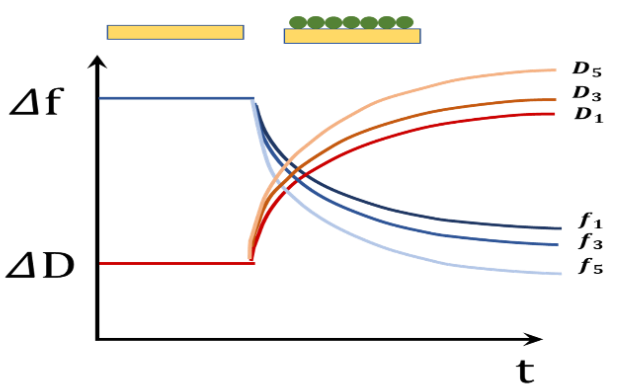

Figure 3.11 A diagram of the measurement principle ${ }^{[100][101]}$ : A) Maintained and damped oscillation of the quartz during application of an AC voltage; B) Changes of oscillating frequency and dissipation upon addition of an extra film layer; C) The $\Delta f, \Delta D$ recorded in situ and real time during measurement. 


\subsubsection{Data Interpretation}

There are mainly two models utilized to analyze QCM results for rigid and soft films, respectively. As mentioned in the 3.3.1, one is the Sauerbrey equation developed earlier for systems in vacuum and gas phase for thin, rigid deposits, and the viscoelastic model developed later for systems involving thicker, soft deposits or in contact with a liquid phase. These two models will be introduced with details in the following text.

\subsubsection{The Sauerbrey Model}

For rigid subjects such as metallic coatings, metal oxides, thin adsorbed layers, which do not dissipate any energy during oscillation, the adsorbed mass and frequency change $(\Delta \mathrm{f})$ are found to be proportional to each other, this relation is termed with Sauerbrey's name, the proportional constant is derived from the natural frequency of the quartz oscillator ${ }^{[93][100]}$,

$$
\Delta m=-\Delta f \frac{m_{q}}{f}=-\Delta f \frac{t_{q} \rho_{q}}{n f_{0}}=-\Delta f \frac{v_{q} \rho_{q}}{2 n f_{0}^{2}}=-\frac{C}{n} \Delta f
$$

where $\mathrm{n}$ is the overtones and $\mathrm{C}$ is the mass sensitivity constant,

$$
C=\frac{v_{q} \rho_{q}}{2 f_{0}^{2}}
$$

Here, $m_{q}$ is the mass per area of the crystal, $m_{q}=t_{q} \rho_{q}, t_{q}$ is the thickness of the quartz, and $\rho_{q}$ is the density of the quartz, for AT-cut quartz crystal, $\rho_{q}=2650 \mathrm{~kg} / \mathrm{m}^{3}, v_{q}$ is the speed of the sound, equals to $3400 \mathrm{~m} / \mathrm{s}$. $C$ equals about $17.7 \mathrm{ng} / \mathrm{cm}^{2} / \mathrm{Hz}$ for a $5-\mathrm{MHz}$ crystal.

In general, the Sauerbrey relation is valid only when if three requirements are fulfilled: (i) the adsorbed mass is relatively small to the quartz crystal; (ii) the adsorbent is rigid; (iii) the adsorbent is distributed evenly over the active area.

\subsubsection{Viscoelastic Model (the Voigt model)}

The Sauerbrey model was widely used for solid thin films in vacuum and gas phase in the early times. But for thick, soft films as well as in liquid environments, new modellings of the mass of deposits is needed as the viscous and elastic contributions is usually not negligible. In this model, energy loss, or the dissipation factor, needs to be taken into account.

Before going into the details, it is good to define "viscoelasticity". Viscoelasticity is the property of materials that exhibit both viscous and elastic characteristics when undergoing deformation. Viscous materials exhibit time-dependent behavior when a stress is 
applied to them. While under constant stress, they deform at a constant rate and then the material remains in the deformed state when the stress is removed. By contrast, elastic materials deform when stretched and return to their original state once the stress is removed ${ }^{[102]}$. Viscoelastic materials have elements of these two properties and exhibit time-dependent strain.

In 1990s, viscoelastic modelling for different cases, including for quartz immersed into a liquid, or quartz with viscoelastic overlayers in vacuum or gas, or quartz with overlayers in liquid was developed ${ }^{[100]}$. In those cases, both the energy dissipation, and the resonant frequency shifts are functions of the overlayer's viscosity, elasticity and density.

\section{For the case of quartz in contact with liquid directly:}

Nomura and Okuhara showed quartz could oscillate in a liquid ${ }^{[94]}$, then a quantitative relationship between the frequency shift and the density, sheer viscosity of the liquid was developed by Kanazawa and Gordon in $1985^{[103][104]}$,

$$
\Delta f \approx \mathrm{f}_{0}^{\frac{3}{2}}\left(\eta \rho / \pi \mu_{q} \rho_{q}\right)
$$

where $\rho_{q}, \mu_{q}$ are the density and shear modulus of quartz. $\rho, \eta$ are the density, viscosity of the liquid.

Krim and coworkers pioneered the use of the dissipation factor of the QCM technique to measure the friction between a molecular thin film and a solid surface ${ }^{[105][106][107]}$. In the nineties, M.Rodahl, F. Höök, B. Kasemo and their colleagues developed the methods further to use QCM for mass measurements of polymer films in contact with air or with liquid ${ }^{[05][97][99]}$. The viscoelastic materials were modelled as a Maxwell or a Voigt element or various combinations of them. The Maxwell model is typically applied to solutions, while the Voigt model, consisting of a spring and a dashpot in parallel, is applied to polymers. A shear viscosity coefficient $\eta$ and a shear elasticity modulus $\mu$ were introduced to interpret the mechanical properties of viscoelastic materials.

Under the assumption that a sheer stress is applied to the Voigt element, and "no slip" condition is considered, the shift in resonance frequency $\Delta f$ and the dissipation factor $\Delta D$ can be obtained:

\section{For the case of a viscoelastic layer in vacuum:}

For very small thicknesses,

$$
\Delta f \approx-\frac{f_{0}}{\rho_{q} t_{q}} \Delta m, \Delta m=\rho t, \Delta D=0 .
$$


Hence, the frequency shift can be well approximated by a linear function of the oscillating frequency and the mass of the adsorbed layer, which is the Sauerbrey relation discussed above; for sufficiently thin layers, there is a small correction to the Sauerbrey relation which can be hardly observed experimentally.

For thick films, the viscoelastic properties of the overlayer start to appear, leading to nonnegligible $\Delta D$. For these cases, $\Delta f$ and $\Delta D$ measured in QCM-D experiments would be functions of film viscoelasticity and satisfy:

$$
\begin{aligned}
& \Delta f \approx-\frac{1}{2 \pi \rho_{q} t_{q}}\left(\frac{\rho}{2}\right)^{\frac{1}{2}}\left\{\eta \omega\left(\frac{\left(\mu^{2}+\eta^{2} \omega^{2}\right)^{\frac{1}{2}}+\mu}{\mu^{2}+\eta^{2} \omega^{2}}\right)^{\frac{1}{2}}-\mu\left(\frac{\left(\mu^{2}+\eta^{2} \omega^{2}\right)^{\frac{1}{2}}-\mu}{\mu^{2}+\eta^{2} \omega^{2}}\right)^{\frac{1}{2}}\right\} \\
& \Delta D \approx \frac{1}{\pi f \rho_{q} t_{q}}\left(\frac{\rho}{2}\right)^{\frac{1}{2}}\left\{\eta \omega\left(\frac{\left(\mu^{2}+\eta^{2} \omega^{2}\right)^{\frac{1}{2}}-\mu}{\mu^{2}+\eta^{2} \omega^{2}}\right)^{\frac{1}{2}}+\mu\left(\frac{\left(\mu^{2}+\eta^{2} \omega^{2}\right)^{\frac{1}{2}}+\mu}{\mu^{2}+\eta^{2} \omega^{2}}\right)^{\frac{1}{2}}\right\}
\end{aligned}
$$

where $\omega$ is the angular frequency.

\section{For the case of two viscoelastic layers in a bulk liquid:}

Two thin viscoelastic layers of thickness $t_{j}(j=1,2)$ under a bulk Newtonian liquid (index “3”), the acoustic response will follow:

$$
\begin{gathered}
\Delta f \approx-\frac{1}{2 \pi \rho_{q} t_{q}}\left\{\frac{\eta_{3}}{\delta_{3}}+\sum_{j=1,2}\left[t_{j} \rho_{j} \omega-2 t_{j}\left(\frac{\eta_{3}}{\delta_{3}}\right)^{2} \frac{\eta_{j} \omega^{2}}{\mu_{j}^{2}+\eta_{j}^{2} \omega^{2}}\right]\right\} \\
\Delta D \approx \frac{1}{2 \pi f \rho_{q} t_{q}}\left\{\frac{\eta_{3}}{\delta_{3}}+\sum_{j=1,2}\left[2 t_{j}\left(\frac{\eta_{3}}{\delta_{3}}\right)^{2} \frac{\eta_{j} \omega}{\mu_{j}^{2}+\eta_{j}^{2} \omega^{2}}\right]\right\}
\end{gathered}
$$

where $\delta$ is the viscous penetration depth.

Based on above deduction, ultrathin films have a small contribution of the acoustic response in comparison with the bulk liquid acoustic response. Thus, $\Delta f \sim \frac{\eta_{3}}{\delta_{3}}, \Delta D \sim \frac{\eta_{3}}{\delta_{3}}$. But thin layers with finite thickness will demonstrate a different acoustic response depending on the ratio between viscosity and elasticity. 
Recently, Jiajie and others, have also derived a proportional relationship of the frequency and the film mass from above the voight model for the thin layers at the solid-liquid interfaces ${ }^{[108]}$, which is:

$$
\Delta f=\frac{m_{f}}{m_{q}} f\left(1-\frac{\rho_{b}}{\rho_{f}} \frac{\eta_{f} \mu_{f} w^{2}}{\mu_{f}^{2}+\eta_{f}^{2} w^{2}}\right), m_{f}=\rho_{f} t_{f}
$$

$\rho, \mathrm{t}, \eta$ and $\mu$ refers to the density, thickness, viscosity and sheer modulus, respectively. The subscripts $\mathrm{f}$ and $\mathrm{b}$ correspond to the film and the bulk newtonian liquid.

In general, those mathematical models are valid if the following conditions are met:

1) Each layer covers the whole active area of the QCM-D sensor;

2) Each layer has uniform thickness and is homogenous;

3) The viscoelastic properties for all layers are the same for all resonant frequencies used;

4) The medium in which the sensor is resonating is a bulk Newtonian fluid (like air or water);

5) All layers are stress free, i.e., the layers contain no internal stress.

The mathematical models are implemented in QCM-D data analysis softwares such as QTools, Qsoft404, enabling researchers to determine parameters for one or two viscoelastic layers, such as film thickness, viscosity, elasiticity, sheer modulus from the response in $\mathrm{f}$ and $\mathrm{D}$ (at any overtone). In this thesis, QCM-D was employed to estimate the mass of PEDOT:Tos films in air, and to study polymer-associated surface adsorption phenomena in aqueous solution. Specifically, Sauerbrey model was applied to estimate the mass of polymer films in air. And mirogravimetric studies during ion exchange processes taking place at the polymer-liquid interface was also examined using the Saurbrey model, as the dissipation changes (in 1E-6) during ion exchange were very small, less then $5 \%$ of the frequency change (in $\mathrm{Hz}$ ).

\subsubsection{QCM-D Instrument}

The instrument usually includes (i) Electronics Unit; (ii) Chamber Platform where mount measurement modules are mounted; (iii) Tubing and pump and (iv) the software. The Chamber Platform can mount 4 parallel flow modules at the same time for parallel experiments and are able to heat up to $60^{\circ} \mathrm{C}$. Other modules, such as flow module, electrochemistry module, humidity module, window module, ellipsometry modul etc., and the combinations of above modules can be combined with QCM-D. With the electrochemistry module, frequency, dissipation as well as electrochemical parameters can be measured. With the window module, 
the optical monitoring or light-induced reactions are enabled. With the ellipsometry module, ellipsometric angles delta and psi can be measured.

The flow module is the most common module, it has an inlet and outlet. Liquid or gas are pushed to flow through the inlet, pass through the perpentine channel which is designed to stabilize at the set temperature, then flow through the sensor, and coming out through the outlet. This module is designed for:

1) Exchange of solvents/buffers.

2) Flowing liquid or gas.

3) Adsorption/desorption from solution.

4) Flowing gas with varying humidity.

\subsection{Dynamic Light Scattering (DLS)}

DLS is a common technique to measure particle size in the nanometer range. During the measurement, a single frequency laser is directed to the sample contained in a curvette. The incident light gets scattered in all directions when there are particles in the sample. The scattered light is detected over time and used to determine the diffusion coefficient and the particles size. In general, compare to larger particles, small particles shows faster temporal fluctuations of the scattered light as well as faster decay of the correction function ${ }^{[109]}$.

\subsection{Atomic Force Microscopy (AFM)}

AFM is a high resolution scanning probe microscopy technique. It uses a flexible cantilever as a sort of spring, at the end of which a sharp tip is attached, which is used as a probe. When the tip comes in contact with the sample, the attractive or repulsive force between them result in a deflection of the cantilever towards or away from the sample. This deflection causes a change of reflection angle of the laser beam that is monitored and analyzied (see setup in Figure 3.12). 


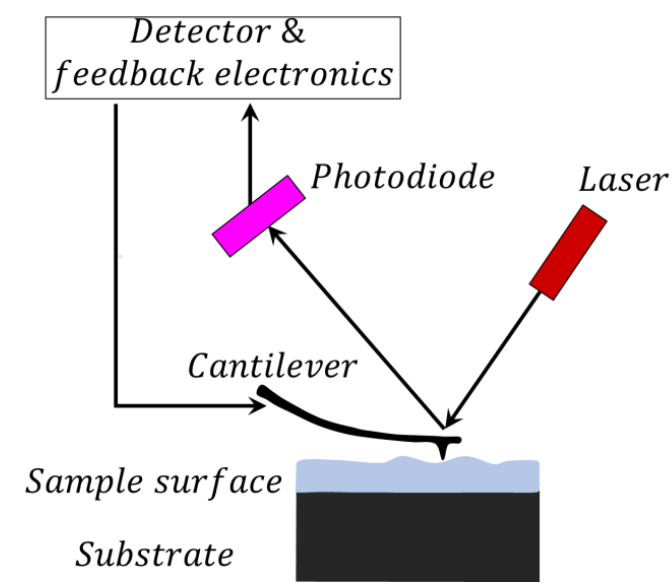

Figure 3.12. A diagram of the AFM using laser beam deflection detection, the enlarge picture shows the interaction between tip atom and the sample atoms ${ }^{[110]}$.

AFM has three major functions including force measurement, imaging and manipulation ${ }^{[111]}$, of which we are interested only in imaging. For imaging, the probe tip scans the sample surface a very close distance, a plot of the upward and downward motion ( $\mathrm{z}$ ) as a function of the tip $\mathrm{x}$ y position provides a high resolution topography image. However, in this simple "contact" mode, the surface of soft or fragile samples may be damaged in the course of imaging. To overcome this problem without sacrifying resolution, an other operation mode, "tapping"mode was invented. In this mode, the tip vibrates rapidly up and down at or near its resonance frequency, and only comes very close to the sample surface at the bottom of its oscillation cycle. The topography image is thus produced by monitorning the intermittent contacts of the tip with the sample surface. Besides, in tapping mode, the phase of the cantilever's oscillation with respect to the driving signal can be recorded, so the signal channel contains information about the energy dissipated by the cantilever in each oscillation cycle. Samples with varing stiffness or with different adhesion properties give a contrast in the signal channel, that can be extracted to form phase images ${ }^{[111]}$.

\subsection{UV-vis Spectroscopy}

UV-visible spectroscopy is the absorption spectroscopy or reflectance spectroscopy in part of the ultraviolet ( $\sim 190$ to $400 \mathrm{~nm}$ ) and the full visible light region (400 to $700 \mathrm{~nm}$ ). Since the energy levels of matters are quantized, light absorption occurs only when its energy can cause transitions from one level to another. The absorption of UV/visible light is associated with excitation of electrons in both atoms and molecules. Organic, conjuagated molecules contain 
with $\pi$ bonds or lone electronic pairs localized on specific atoms (such as oxygen, nitrogen or a halogen) display typically intense transitions even in the visible. Transition metal ions are typically having also intense transitions in the UV-Vis region and those are affected by their interaction with surrounding molecules, e.g. chlorophyl and other biological macromolecules ${ }^{[12]}$.

The location or wavelength of absorption peaks can be correlated with types of bonds and are valuable in determing functional groups within a molecule. The concentration of the absorbing species can be obtained quantitatively by Beer-Lambert law:

$$
A=\log _{10} \frac{I_{0}}{I}=\varepsilon C L
$$

where $A$ is the measured absorbance, $I_{0}$ is the intensity of the incident light at a given wavelength, $I$ is the transmitted intensity, $\varepsilon$ is the molar absorption coefficient, $L$ is the path length through the sample, and $C$ is the concentration of the absorbing species.

\subsection{Fuel Cell and Redox Flow Battery (RFB)}

\subsubsection{Fuel Cell}

Fuel cell is a device that produces electricity from the chemical reactions of a fuel with an oxidant without combustion. As one of the clean and green alternative energy harvesting techniques, it is becoming more and more important as the world has a limited amount of fossil energies (coal, gas, petrol) and the environement is suffering from green house gases emission emitted from the fossil fuel combustion in domestic and industrial application.

Fuel cells are similar to batteries and capacitors in structure, all of them consist of two electrodes in contact with an electrolyte solution. Both batteries and fuel cells involve the conversion of chemical energy into electricity via redox reactions. Fuel cells are open systems within which the electrodes are just charge transfer media and the active masses undergoing the redox reactions are delivered from outside; while batteries are closed systems within which the electrodes can be not only the charge transfer media but also active masses in the redox reations. Capacitors and supercapacitors, on the contrary, involve no conversion of chemical energy into electricity, i.e., no redox reactions, but it stores electricity and involves movements of ions in the dielectric seperator and electrons in the outer circuit. In comparison, batteries are the most well established and found the most applications in the markets by far, while capacitors as storage devices are inferior to batteries, and found rather niche markets as memory protection in electronic devices. Fuel cells are basically still in the development stage due to their high cost, insufficient durability and lifetime ${ }^{[113]}$. However, fuel cells have many advantages as they 
are systems of the highest energy capability (shown in Figure 3.13), and could provide electricity countinously as long as the fuel is fed in.

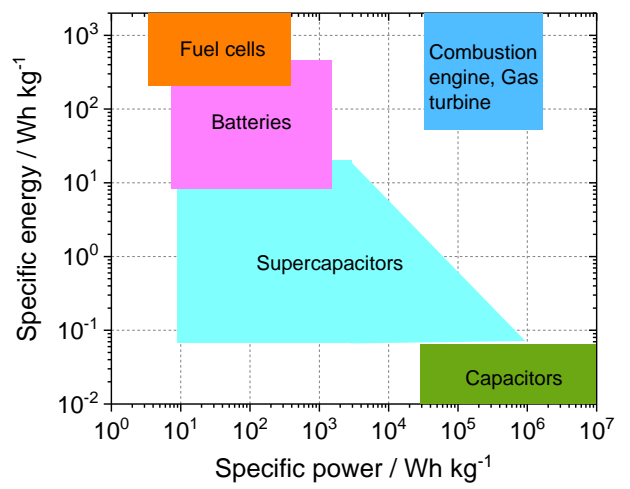

Figure 3.13. Simplified Ragone plot of the energy storage domains for the various electrochemical energy conversion systems ${ }^{[113]}$.

Fuel cells can be classiffied in different types according to the electrolyte employed, the main include Alkaline fuel cell (AFC), Polymer Electrolyte Membrane Fuel Cell (PEMFC), Direct Methanol Fuel Cell (DMFC), Phosphoric Acid Fuel Cell (PAFC), Molten Carbonate Fuel Cell (MCFC), Solid Oxide Fuel Cell (SOFC). According to the operating temperature, they can be divided into low temperature fuel cells $\left(<200^{\circ} \mathrm{C}\right)$ and high temperature fuel cells $\left(>450^{\circ} \mathrm{C}\right)$, all summarized in Figure 3.14. In general, hydrogen fuel cell is the most popular fuel cell due to the highest energy density in hydrogen and the readily avaliable oxygen in air and the clean product (water). But hydrogen is not readily availabe, because production and transportation of pure hydrogen imply economical and safety issues. Alcohols, hydrazine, ammonia, natural gas, and biomass are also popular fuel options in research. The electrodes in fuel cells are relatively complex compared to those in capacitors and batteries; they need to ensure a stable electrical interface between the reactants and the electrolyte, to catalyze the electrode reactions, and to conduct the electrons, in other words, they works as electrode as well as catalyst. The benchmark catalyst material is platinum, a precious metal which accounts for the major part of the cost. Efforts have been dedicated to reduce the amount of Pt or to look for its alternative materials, such as optimising the stucture by using nanoporous structured Pt or loading Pt with carbon nanotubes, less expensive metals such as $\mathrm{Ru}, \mathrm{Ni}$, Co etc. Recently, the electrocalysis by conducting polymers has also come into the eyes of researchers ${ }^{[22][114]}$.

In this thesis, we tried to demonstrate the possibility of ligno fuel in fuel cell devices with a conducting polymer being the catalyst electrode. We take hydroquinone as a model molecule 
as it has been well studied in literature, and compared the performance of hydroquinone-oxygen fuel cell using conducting polymer PEDOT as catalyst electrode without using Pt and glassy carbon.

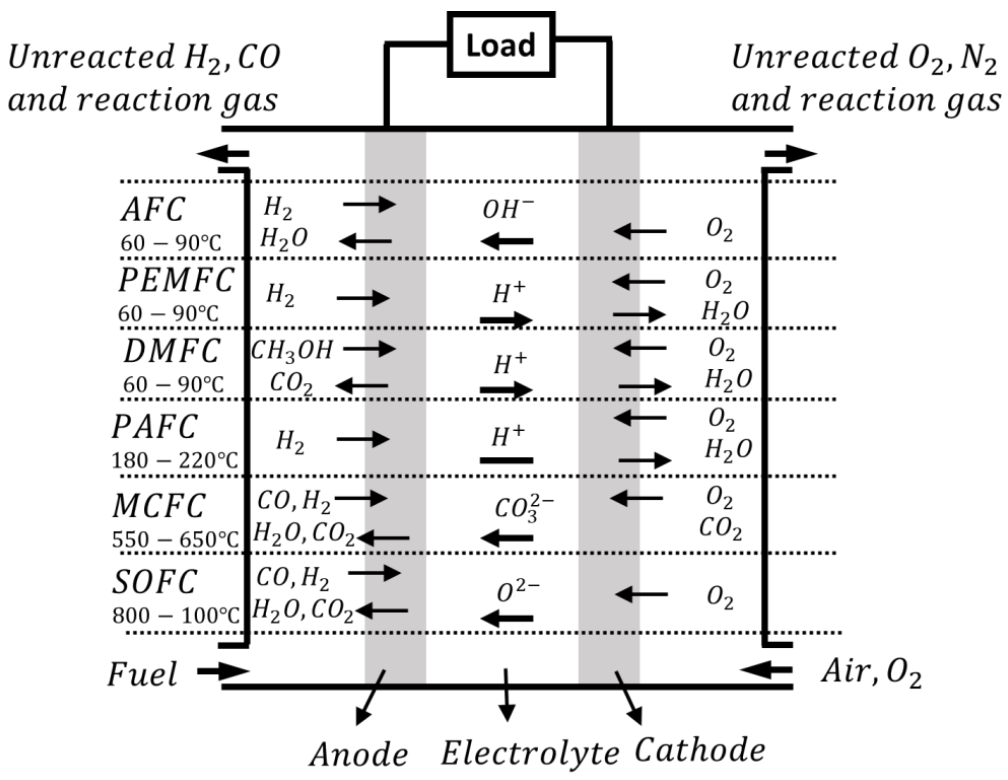

Figure 3.14. Summary of various fuel cell systems and their reactions, processes ${ }^{[113]}$. (Reprinted with permission from Ref 113. Copyright (C) 2004 American Chemical Society).

For a hydroquinone-oxygen fuel cell, the half cell and overall reactions and the corresponding standard electrode potential $\left(E^{0}\right)$ may be:

$$
\text { Cathode } \quad \frac{1}{2} \mathrm{O}_{2}(g)+2 \mathrm{H}^{+}+2 e \rightleftarrows \mathrm{H}_{2} \mathrm{O} \quad E^{0}=1.23 \mathrm{~V}
$$

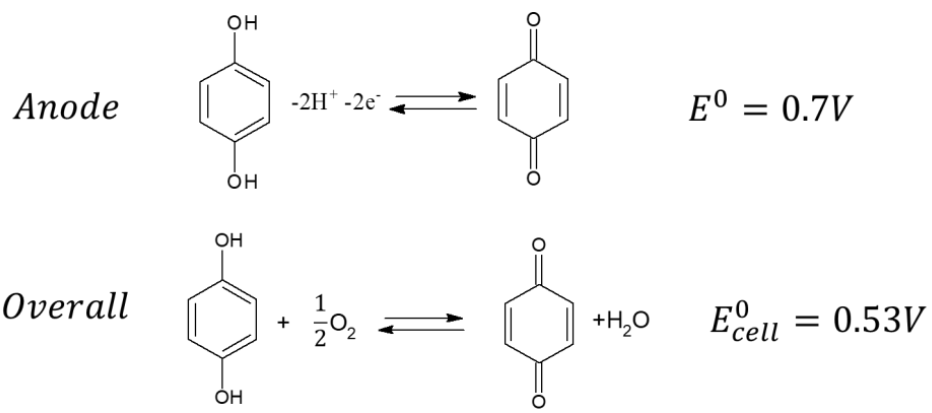

$E^{0}$ (in $\mathrm{V}$ ) is the standard reduction potential of the reactants, $E_{c e l l}^{0}$ (in V) is the standard cell potential. 


\subsubsection{Redox Flow Battery (RFB)}

The concept of redox flow batteries was first reported in 1976 by Thaller, and the first complete redox flow battery developed was based on $\mathrm{Fe}^{3+} / \mathrm{Fe}^{2+}-\mathrm{Cr}^{3+} / \mathrm{Cr}^{2+}$ by NASA-Lewis Research Center for space program ${ }^{[115]}$. A redox flow battery is a type of electrochemical cell where chemical energy is provided by two chemical components dissolved in liquids contained within the system and separated by a membrane, the solution is pumped thought the cell during charging and discharging ${ }^{[116]}$. The definition of a flow battery crosses that of a rechargeable battery and a fuel cell, and its operation has similarities to both. In discharge mode, the anolyte flows through one electrode and its electroactive component is oxidized at the electrodeeletrolyte interface, while the electroactive component of the catholyte is reduced on the other, which generates electricity. In charge mode, electricity is applied to convert the anolyte to its reduced state and catholyte to its oxidized state. The general reaction is shown in Table 3.2.

Table. 3.2. General reaction in redox flow battery ${ }^{[117]}$.

\begin{tabular}{cll}
\hline & Charge mode & Discharge mode: \\
Anode tank & $A^{n} \rightarrow A^{n+x}+x e^{-}$ & $A^{n} \leftarrow A^{n+x}+x e^{-}$ \\
Cathode tank & $C^{n+x}+x e^{-} \rightarrow C^{n}$ & $C^{n+x}+x e^{-} \leftarrow C^{n}$ \\
\hline
\end{tabular}

The energy capacity depends on the electrolyte volume, concentration of the active reactants, and the power depends on the surface area of the electrode, the number electrodes in a cell stack and the number of stacks in a system. The biggest advantage of flow batteries is that their energy density and power density can be scaled independently. Flow batteries are also superior in a long life cycle.

Redox flow batteries are categorized based on the anolyte and catholyte. Nowadays, many types of redox flow batteries have been studied intensively, as summarized in Table 3.3. At present, all-vanadium redox flow battery is the most developed one due to its high reversibility and relatively large power output ${ }^{[78]}$. Recently, organic active materials were proposed to be the electrolyte due to their abundance and renewable resources in order to further decrease the cost. Indeed, the electrolyte cost of even early-staged organic flow batteries $\left(35 \$(\mathrm{kWh})^{-1}\right.$ has been demonstrated to be lower than vanadium redox flow batteries electrolyte $\left(\left(80 \$(\mathrm{kWh})^{-1}\right)^{[78]}\right.$. Here, we turn our interest to aqueous organic redox flow battery based on quinone and antraquinone derivates by using conducting polymer PEDOT as electrode materials, for inexpensive, renewable energy storage devices. 
Table 3.3. Examples of Redox flow batteries and their advantages and disadvantages ${ }^{[17]}$.

\begin{tabular}{|c|c|c|c|}
\hline RFB types & $\begin{array}{c}\text { Reactions, } \\
E^{0} / V \text { vs . RHE }\end{array}$ & Advantages & Disadvantages \\
\hline Iron-chromium & $\begin{aligned} F e^{2+} \rightleftarrows & F e^{3+}+e^{-}, \\
& 0.77 \\
C^{2+} \rightleftarrows & C r^{3+}+e^{-}, \\
& -0.41\end{aligned}$ & high kinetics Fe redox & low kinetics $\mathrm{Cr}$ redox \\
\hline $\begin{array}{c}\text { Bromine/polysu } \\
\text { lfide }\end{array}$ & $\begin{aligned} 3 \mathrm{Br}^{-} \rightleftarrows & \mathrm{Br}_{3}^{-}+2 e^{-}, \\
& 1.09 \\
2{S_{2}}^{2-} \rightleftarrows S^{2-}+2 e^{-}, & \\
- & 0.265\end{aligned}$ & $\begin{array}{l}\text { abundant and cheap, } \\
\text { highly soluble in } \\
\text { aqueous electrolytes }\end{array}$ & $\begin{array}{l}\text { formation of } \mathrm{H}_{2} \mathrm{~S} \text { and } \\
\mathrm{Br}_{2} \text { due to crossover }\end{array}$ \\
\hline All-vanadium & $\begin{array}{c}V O^{2+}+H_{2} O \rightleftarrows V O_{2}^{+}+2 H^{+}+e^{-}, \\
1.00 \\
V^{2+} \rightleftarrows V^{3+}+e^{-}, \\
-0.26\end{array}$ & $\begin{array}{c}\text { two oxidation } \\
\text { states of the same } \\
\text { element }\end{array}$ & $\begin{array}{l}\text { low solubility of } \\
\text { vanadium }\end{array}$ \\
\hline $\begin{array}{c}\text { Vanadium/brom } \\
\text { ine }\end{array}$ & $\begin{array}{c}\mathrm{Br}^{-}+2 \mathrm{Cl}^{-} \rightleftarrows \mathrm{BrCl}_{2}^{-}+2 e^{-} \\
1.044 \\
\mathrm{VCl}_{2}+\mathrm{Cl}^{-} \rightleftarrows V C l_{3}+e^{-} \\
-0.26\end{array}$ & $\begin{array}{c}\text { increased solubity of } \\
\text { Vanadium by halide } \\
\text { ions }\end{array}$ & $\begin{array}{l}\text { toxic bromine-vapor } \\
\text { emissions }\end{array}$ \\
\hline $\begin{array}{l}\text { Zinc/bromine } \\
\text { (Hybrid) }\end{array}$ & $\begin{aligned} & B r_{2}+2 e^{-} \rightleftarrows 2 B r^{-} \\
& 1.087 \\
& Z n \rightleftarrows Z n^{2+}+2 e^{-}, \\
&-0.76\end{aligned}$ & $\begin{array}{l}\text { high concentrations } \\
\text { of } B r_{2}, B r^{-} \text {can be used }\end{array}$ & $\begin{array}{l}\text { toxicity of } \mathrm{Br}_{2} \text {, highly } \\
\text { corroding concentrated } \\
\mathrm{HBr}\end{array}$ \\
\hline $\begin{array}{l}\text { Soluble lead } \\
\text { acid } \\
\text { (Hybrid) }\end{array}$ & $\begin{array}{c}\mathrm{Pb}^{2+}+\mathrm{H}_{2} \mathrm{O} \rightleftarrows P b O_{2}+4 H^{+}+ \\
2 e^{-} \\
1.49 \\
P b \rightleftarrows P b^{2+}+2 e^{-} \\
-0.13\end{array}$ & $\begin{array}{l}\text { no risk of } \\
\text { crossover }\end{array}$ & $\begin{array}{l}\text { short-circuit due to } \\
\text { material detach/grow } \\
\text { across the } \\
\text { separator gap }\end{array}$ \\
\hline $\begin{array}{l}\text { All-iron } \\
\text { (Hybrid) }\end{array}$ & $\begin{aligned} F e^{2+} \rightleftarrows & F e^{3+}+e^{-}, \\
& 0.77 \\
F e \rightleftarrows F e^{2+}+e^{-} & \\
& 0.33\end{aligned}$ & $\begin{array}{l}\text { nonhazardous, } \\
\text { inexpensive. }\end{array}$ & $\begin{array}{c}\text { precise } \mathrm{pH} \text { control and } \\
\text { electrolyte }\end{array}$ \\
\hline Non-aqueous & & high cell potential & $\begin{array}{c}\text { low electrolyte } \\
\text { conductivity, stability } \\
\text { and high cost }\end{array}$ \\
\hline
\end{tabular}


For an Alizarin red S-Tiron redox flow battery, the half cell and overall reactions and the corresponding standard eletrode potential $\left(E^{0}\right)$ may be ${ }^{[15]}$ :

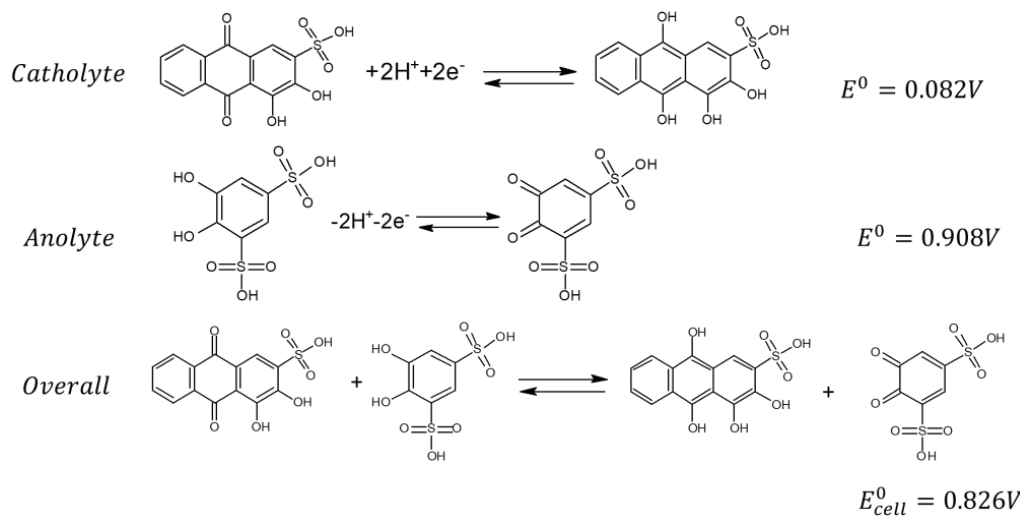

\subsubsection{Cell Performance}

The key performance of the fuel cells and redox flow batteries can be characterized by the voltage-current density curve and power density curve as illustrated in Figure 3.15. The biggest difference between the two is that there exists a charge process for a redox flow battery, and it can be charged and discharged many cycles. The measured voltage, E, equals to:

$$
E=E_{e q}-E_{L}-\eta_{a c t}-\eta_{i R}-\eta_{\text {diff }}
$$

$E_{e q}$ is the theoritical equilibrium potential expected from Nernstien voltage, $E_{L}$ is the voltage loss due to electrolyte crossover through the separator. $\eta_{a c t}, \eta_{i R}, \eta_{\text {diff }}$ are the three main types of voltage losses. $\eta_{a c t}$ is the acitivation overpotential due to the origin of sluggish electrode kinetics, even at low current densities, it represents the acivation barriers to start a reaction. When the voltage drop caused by activation loss is large $\geq 50-100 \mathrm{mV}$, the activation overpotential can be estimated by Tafel equation derivated from the Butler-Volmer equation:

$$
\eta_{a c t}=-\frac{R T}{\alpha n F} \ln j_{0}+\frac{R T}{\alpha n F} \ln j
$$

$\alpha$ is the electron transfer coefficient, $j_{0}$ is the exchange current density.

The activation loss can be decreased, for given reactants, by using a catalyst or improving the electrode microstructure.

$\eta_{i R}$ is the overpotential due to ohmic resistance. It is the sum of the total ohmic resistance in the cell including ionic resistance in the electrolyte and electrodes, electronic resistance in the 
electrodes, current collectors and interconnects as well as contact resistance. Ohmic losses follow Ohm`s law and dependes on the materials and temperature.

$\eta_{\text {diff }}$ is the overpotential due to mass diffusion limitation to the suply of fresh reactants and evacuation of the products. It can be given by the equation:

$$
\eta_{\text {diff }}=\frac{R T}{n F} \ln \frac{C_{s}}{C_{B}}=\frac{R T}{n F} \ln \left(1-\frac{i}{i_{L}}\right)
$$

$C_{S}$ is the surface concentration while $C_{B}$ is the bulk concentration; $i_{L}$ is the limiting current measured at the maximum rate when the surface concentration is zero. $\eta_{\text {diff }}$ becomes more significant at high current density, that is, at a high rate of the reactants' interconversion.

A)

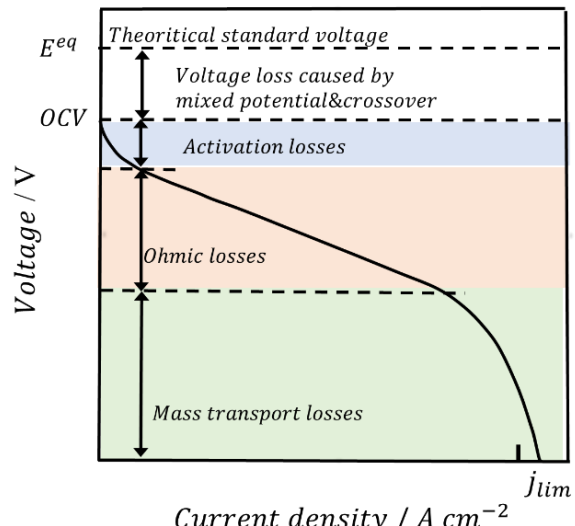

B)

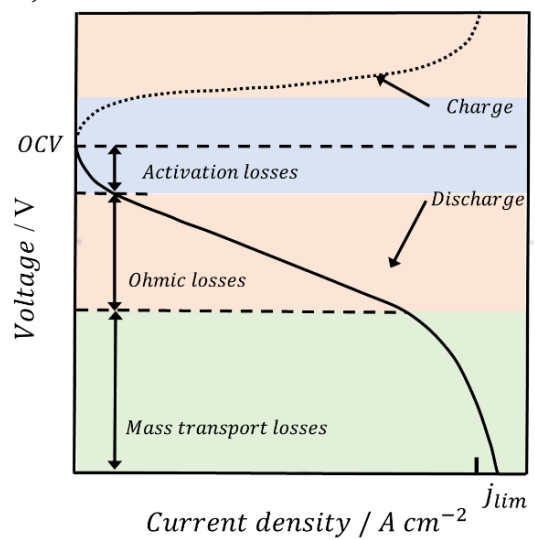

Figure 3.15. Voltage vs current density curve for A) fuel cell and B) redox flow battery ${ }^{[18]}$.

The power density of the cell is a function of the output voltage and current density as below. As voltage drops with the increase of current density, power density has maximum, which is the result of such a trade-off.

$$
\text { Power density }=V * J
$$

The figures of merit for efficiency of redox flow battery are coulombic efficiency $\left(\eta_{\text {coulombic }}\right)$, voltage efficiency $\left(\eta_{\text {Voltage }}\right)$ and energy efficiency $\left(\eta_{\text {energy }}\right) . \eta_{\text {coulombic }}$ is the ratio between the amount of electrical charge supplied during charging and recoveredd during discharging and it is affected by the side reactions and the crossover of the reactants species through the separator; $\eta_{V o l t a g e}$ is determined by the voltage ratio between charge and discharge and it is influenced by the electrical reveribility of the system; $\eta_{\text {energy }}$ is defined by the ratio of the 
energy that has been recovered during discharge and consumed during charge, it is the product of $\eta_{\text {coulombic }}$ and $\eta_{\text {Voltage }}$.

$$
\begin{gathered}
\eta_{\text {coulombic }}=\frac{Q_{\text {Discharge }}}{Q_{\text {Charge }}} * 100 \%, \mathrm{Q}=\mathrm{I} * \mathrm{t} \\
\eta_{\text {Voltage }}=\frac{V_{\text {Discharge }}}{V_{\text {Charge }}} * 100 \%, \\
\eta_{\text {energy }}=\eta_{\text {coulombic }} * \eta_{\text {Voltage }}=\frac{E_{\text {Discharge }}}{E_{\text {Charge }}} * 100 \%, \mathrm{E}=\mathrm{V} * \mathrm{I} * \mathrm{t}
\end{gathered}
$$

The stability is also an important aspect for redox flow battery performance and is characterized by charge and discharge of many cycles as shown in Figure 3.16.
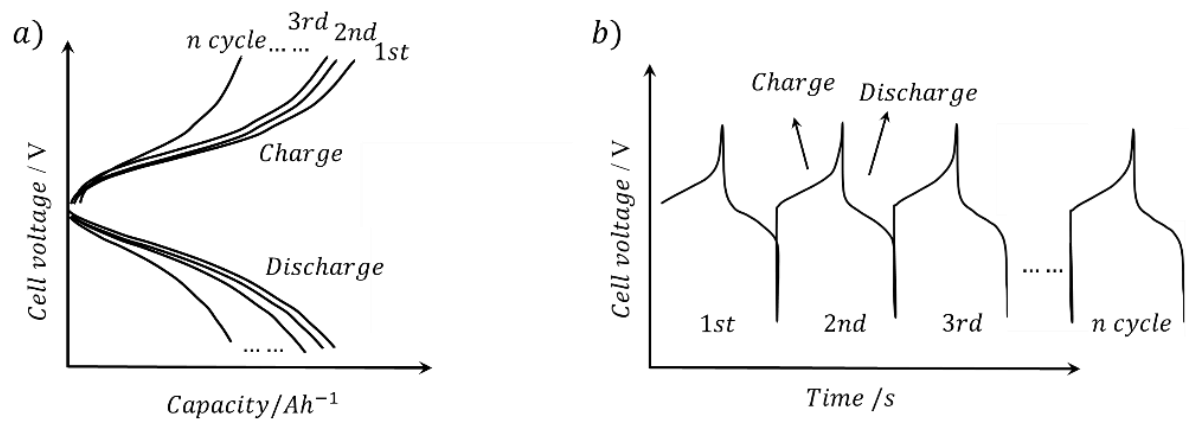

Figure 3.16. Typical charge and discharge profile of a redox flow battery, a) cell voltage vs charge capacity; b) cell voltage vs time. 


\section{Experimental}

This chapter introduces the experimental details, including the fabrication of PEDOT:PSS and PEDOT:Tos film electrodes on glass, quartz sensor and carbon paper; the synthesis of PEDOT and PEDOT: lignosulfonate nanoparticles; the substrate's pretreatment, and the fuel cell and redox flow battery assembly used throughout the thesis.

\subsection{PEDOT:Tos Film Electrodes}

PEDOT:Tos film electrodes were prepared by two approaches: chemical polymerization and vapor phase polymerizaation(VPP).

\subsubsection{Chemical Polymerization}

The chemical polymerization consists of four steps.

Step 1: Oxidant solution preparation. A stock of oxidant solution was prepared by mixing $5 \mathrm{ml}$ of $40 \mathrm{wt} \%$ iron(III) p-toluenesulfonate $\mathrm{Fe}(\mathrm{Tos})_{3}$ (CB40 V2, purchased form Heraeous) with $0.2 \mathrm{ml}$ of pyridine and stirring the blend for $1 \mathrm{~h}$. Note: in the later period of the project, CB40 V2 was out of supply, then $40 \mathrm{wt} \% \mathrm{Fe}(\mathrm{Tos})_{3}$ was prepared by diluting the $54 \mathrm{wt} \%\left(\mathrm{Fe}(\mathrm{Tos})_{3}\right)$ (C-B 54 V2, purchased from Heraeous) down with n-butanol firstly.

Step 2: Film casting. Prior to polymerization, EDOT monomer was fully mixed with the above oxidant solution in the volume ratio of oxidant solution: EDOT=20:1, and then a few drops of the mixture were spread on the clean glass substrate manually and followed by spin coating. 
Step 3: Polymerization, the substrates with the mixture were placed on hotplate at $100^{\circ} \mathrm{C}$, for $10 \mathrm{~min}$.

Step 4: The film electrodes thus obtained are rinsed gently with ethanol to remove the excess oxidant and dried by nitrogen gas flow before use.

\subsubsection{Vapor Phase Polymerization (VPP)}

Vapor phase polymerization of PEDOT:Tos was carried out in a chamber setup as shown in Figure 4.1.

The stock oxidant solution (same as above) was spin-coated onto the metal-modified glass and then heated up for 30 seconds at $60{ }^{\circ} \mathrm{C}$ before putting in the vacuum chamber. Few drops of EDOT monomer were added onto two glass slides and placed on the hotplate beside the sample. The polymerization was completed in low vacuum condition of $70 \mathrm{~mm} \mathrm{Hg}$ at $60{ }^{\circ} \mathrm{C}$ after 1 hour followed by heating for 2 minutes at $60{ }^{\circ} \mathrm{C}$ in air. The sample was gently rinsed in ethanol and dried by nitrogen gas flow before use.

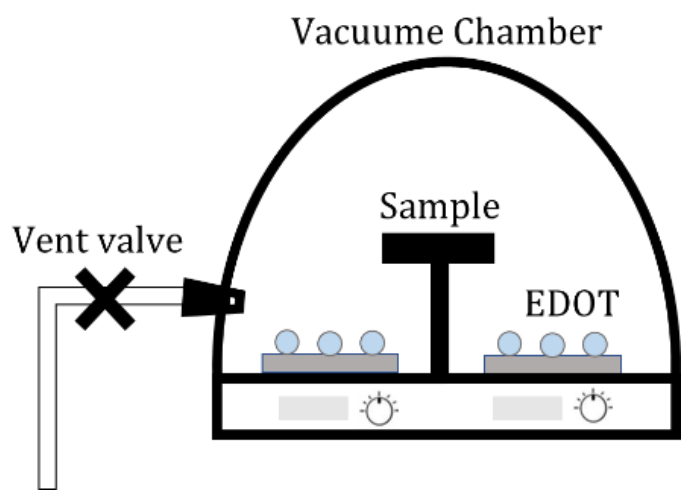

Figure 4.1. Schematic diagram of the VPP in vacuum chamber.

\subsection{PEDOT:PSS Film Electrode}

PEDOT:PSS film electrodes are prepared by the process shown in Figure 4.2. The blend comprising commercial PEDOT:PSS suspension PH1000 (solid content 1.3wt\%), and DMSO, $10 \mathrm{mM}$ glycerol, GOPS with the ratio of $94 \mathrm{wt} \%, 4 \mathrm{wt} \%, 1.5 \mathrm{wt} \%$, and $0.5 \mathrm{wt} \%$ was spin coated onto the metal modified glass substrates. The substrates were cleaned and treated with UVozone in Ozone cleaning device (Model: PSD-UV8) for $15 \mathrm{~min}$ before PEDOT:PSS film casting to improve the surface wettability and film quality. After spin coating, the slides were heated up to $140{ }^{\circ} \mathrm{C}$ for $30 \mathrm{~min}$ for thermal annealing. 


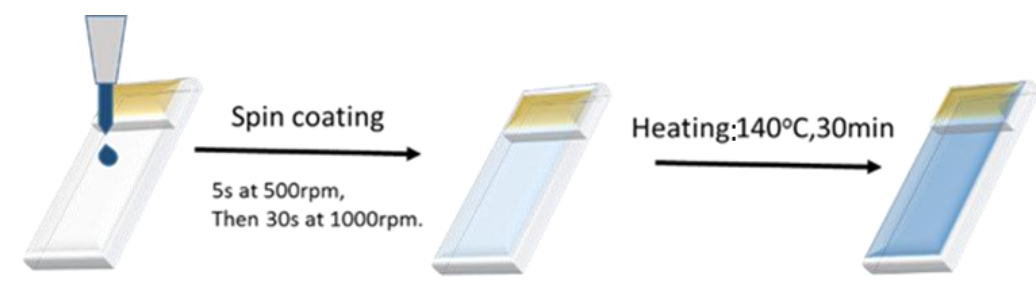

Glass slide

Figure 4.2. Diagram of the PEDOT:PSS synthesis on metal modified glass substrates.

\subsection{PEDOT and PEDOT: Lignosulfonate (PEDOT:LS) Nanoparticles}

As mentioned in 2.3, lignosulfonate (LS) is an energy rich as well as cheap biomass, incorporation of LS into PEDOT would be an economically good way to enhance the energy storage capacity. This section will introduce the aqueous synthesizing methods of PEDOT and composite of PEDOT:LS used in paper II. LS used throughout the thesis is LC30, MW 13 400, purchased from MeadWestvaCo. The common point of those synthesis routes (Figure 4.3) is that they are based on emulsion polymerization achieved by continuously stirring the waterinsoluble liquid monomer with an aqueous solution of reagents (oxidizer and catalyst).

Route 1: Oxidative chemical polymerization of EDOT was carried out using sodium persulfate $\left(\mathrm{Na}_{2} \mathrm{~S}_{2} \mathrm{O}_{8}\right)$ as oxidizing agent with 1.6 molar ratio with respect to EDOT and iron (III) chloride catalyst. The polymerization was carried out in aqueous media by stirring at room temperature (RT) for $24 \mathrm{~h}$. The polymerized product was collected by centrifugation and washed it with deionized water (DI) three times to remove any impurity or unreacted reactants.

Route 2: One pot synthesis of PEDOT:LS nano-composite suspension was synthesized by the oxidative chemical polymerization of the EDOT (as explained above in route 1) in the presence of LS ( $1 \mathrm{wt} \%$ in water) with mass ratio of LS to EDOT $1: 3^{[11]}$. The product of the polymerization was washed with deionized water (DI) in centrifuge 3 times to remove the unreacted reagents. Route 3: Two step synthesis of PEDOT:LS composite; LS added without washing to the polymerized PEDOT. EDOT was first polymerized via route 1 in aqueous media by stirring for 
$24 \mathrm{~h}$ at RT (step 1) after which LS (with 1:3 mass ratio with respect to EDOT) was added to the mixture and stirred for another $24 \mathrm{~h}$ continuously at RT (step two). DI water was used for washing the final product in centrifuge.

Route 4: Two-step synthesis of PEDOT:LS composite; LS was added after washing the polymerized PEDOT. This is similar to the Route 3 except for the cleaning of polymerized product of the step 1, with DI water before the addition of LS.

Route 1.

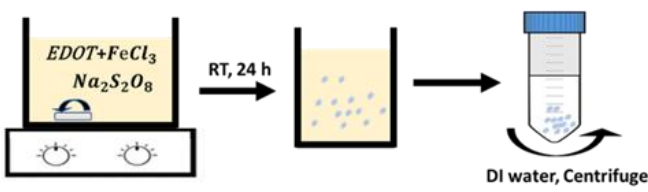

Route 2.
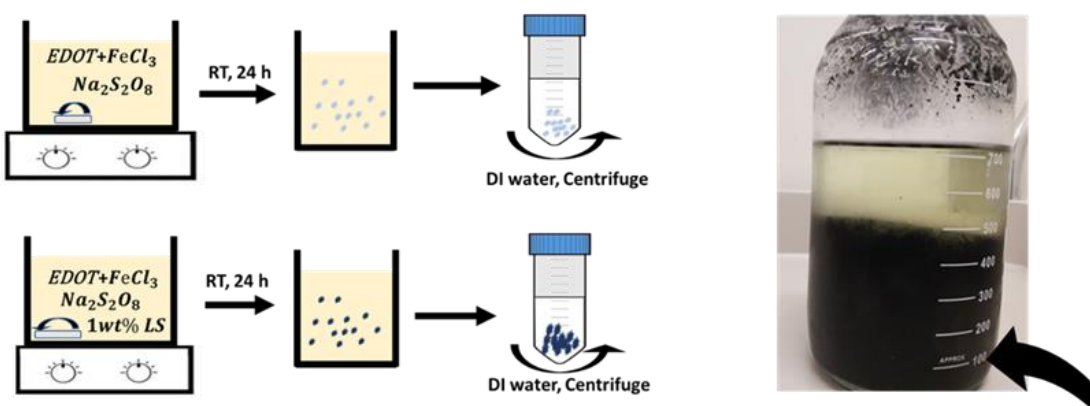

Route 3.

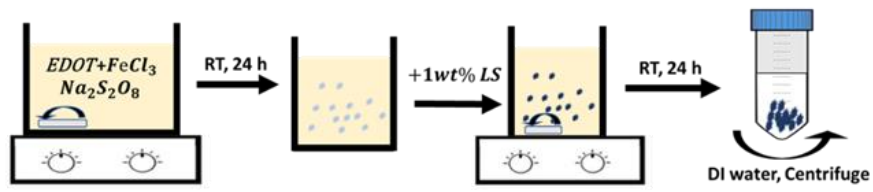

Route 4.

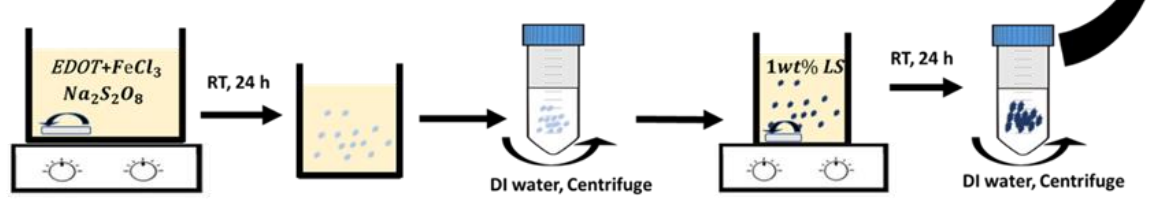

Figure 4.3 Diagram of the Chemical synthesis of PEDOT and PEDOT:LS composites in aqueous media ${ }^{[119]}$. (Reprinted with permission from Ref 119, Copyright $(0) 2019$ WILEY-VCH Verlag GmbH \& Co. KGaA, Weinheim). 


\subsection{Substrates}

\subsubsection{Metal Modified Glass}

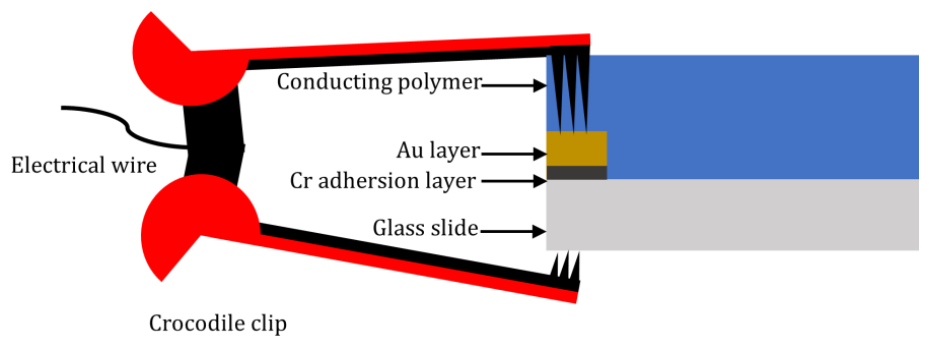

Figure 4.4. A diagram of conducting polymer film on a metal modified glass substrate connected by a crocodile clip.

In three-electrodes electrochemistry, we always deposited the conducting polymers on metal modified glass substrate. Glass is used as solid insulating support with no disturbance to the electrical measurement. However, the films are generally thin and may easily break under the crocodile clip in the circuit connection, resulting in poor electrical contact. Metal layers, to be specific, as shown in Figure 4.4, a layer of gold of $50 \mathrm{~nm}$ with an adhesion layer of chromium $10 \mathrm{~nm}$ is deposited on the glass, to ensure a good electrical contact with crocodile during the measurements. The metal-modified glass slides were always cleaned with soap and rinsed with acetone, distilled water, and isopropanol before polymer film loading.

\subsubsection{Quartz Sensors}

During the Quartz Crystal Microbalance with dissipation (QCM-D) experiments, the quartz sensors (quartz sandwiched by thin Au layers with Ti adhesion layers, No.QS338) were cleaned with a heated $\left(75^{\circ} \mathrm{C}\right)$ mixture $(5: 1: 1)$ of water, ammonia $(25 \mathrm{wt} \%)$ and hydrogen peroxide (30 $\mathrm{wt} \%$ ) for 5 minutes followed by rinsing with water, drying with nitrogen and UV/ozone treatment for 10 minutes. Then the sensor was covered using a mask with a hole (diameter=10 $\mathrm{mm}$ ) to define the exposed film area. PEDOT:Tos films synthesized via VPP as mentioned in 4.1.2 were peeled off carefully in ethanol (70\%), and transferred to cover the quartz sensor with a mask followed by drying in nitrogen and mask removing. 


\subsubsection{Rotating Disk Electrode}

The glassy carbon disk (diameter=5 mm) modified with PEDOT:PSS films was prepared by drop-casting the blend followed by the heating $\left(60{ }^{\circ} \mathrm{C}\right.$ for 30 minutes); while in the case of PEDOT:Tos, it was firstly synthesized via VPP, and then cut and transferred to cover the disk in water.

\subsubsection{Carbon Papers}

In the redox flow battery, carbon papers (Toray carbon paper 060, FuelCellStore, USA) of diameter $5 \mathrm{~cm} * 5 \mathrm{~cm}$ were used as substrates for PEDOT loading. In those cases, PEDOT:Tos loading layer was prepared by drop casting the above oxidation solution and EDOT mixture in a volume ratio of $20: 1$, and then annealing at $100{ }^{\circ} \mathrm{C}$ for $10 \mathrm{~min}$, the weight of the PEDOT:Tos loading on each Toray paper was about $0.0134 \mathrm{~g}$. The PEDOT:PSS loading layer was prepared by pouring the suspension into a petri dish of diameter $12 \mathrm{~cm} * 12 \mathrm{~cm}$, and then placed it into the oven at $50{ }^{\circ} \mathrm{C}$ for overnight to dry, PEDOT:PSS paper of diameter $5 \mathrm{~cm} * 5 \mathrm{~cm}$ was cut and loaded on Toray paper. The dry weight of PEDOT:PSS loading was $0.141 \mathrm{~g}$.

\subsection{Hydroquinone-Oxygen Fuel Cell and ARS-Tiron Redox Flow Battery}

\subsubsection{Hydroquinone-Oxygen Fuel Cell}

The hydroquinone-oxygen fuel cell set up used to demonstrate the concept is shown in Figure 4.5. It is based on a standard H-cell separated by a porous glass frit. On the anodic side, $5 \mathrm{mM}$ hydroquinone was dissolved in $0.1 \mathrm{M} \mathrm{H}_{2} \mathrm{SO}_{4}$, nitrogen gas was pumped into the solution to remove oxygen, Pt, glassy carbon (GC), and GC loaded PEDOT:PSS, GC loaded PEDOT:Tos are used as catalyst, respectively in this side. While on the cathodic side, oxygen was pumped into $0.1 \mathrm{M} \mathrm{H}_{2} \mathrm{SO}_{4}$ to act as the oxidizer, platinum is the catalyst. A resistor box with tunable range $1 \Omega$ to $1 \mathrm{M} \Omega$ was used as external load. A nanovoltmeter (Keithley Instruments, Inc., model $1282 \mathrm{~A}$ ) was used to record the steady-state values of voltage across the load.

Blank GC ( $3 \mathrm{~mm}$ diameter) was polished on 0.3 and $0.1 \mu \mathrm{m}$ alumina powders and rinsed with Milli-Q water. PEDOT:PSS and PEDOT:Tos films loaded on GC were prepared by drop casting followed by thermal annealling at $60^{\circ} \mathrm{C}$ for $30 \mathrm{~min}$ (Extra step For PEDOT:Tos, cleanning in ethanol). 


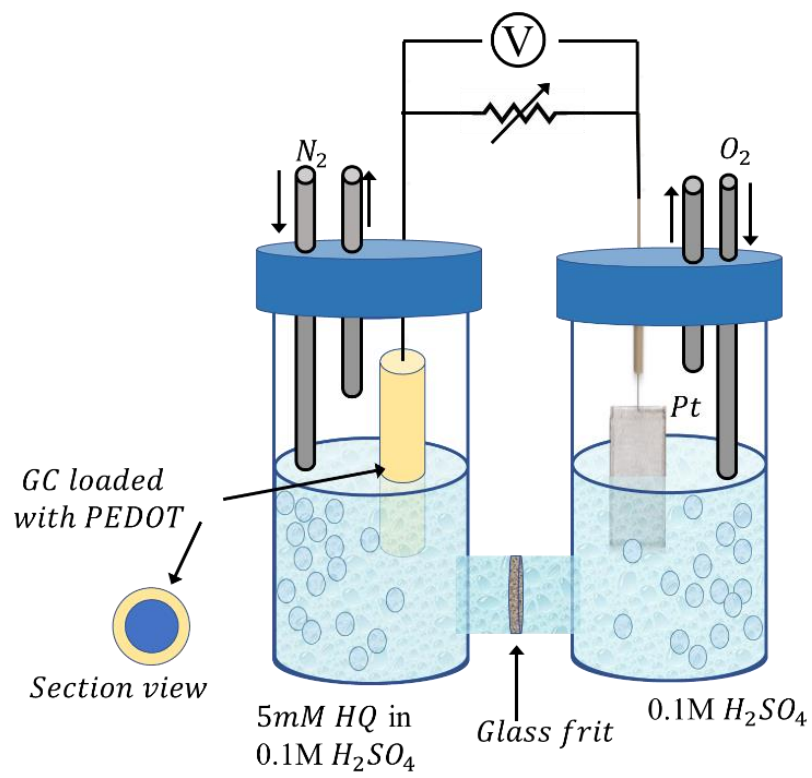

Figure 4.5. A schematic diagram of the hydroquinone-oxygen fuel cell, the right double ring picture is a diagram of the bottom view of the glassy carbon electrode loaded with conducting polymer in the center.

\subsubsection{ARS-Tiron Redox Flow Battery}

The structure of the redox flow battery used throughout the thesis is shown in Figure 4.6. It consists of an external anolyte tank and an external catholyte tank, the electrolytes were pumped through the cell separated by a membrane during the operation, power are generated in discharge, while load is applied in charge mode. The symmetric cell includes brass and graphite current collector, flow distribution frame, graphite diffusion layer, carbon paper electrode, membrane gasket, and an ion selective membrane.

Specifically, an acid lab scale RFB was assembled with ARS as the negolyte and Tiron as the posolyte active components. The cell hardware with active area of $25 \mathrm{~cm}^{2}$ was purchased from C-flow Tech. Plain carbon papers (AvCarb® MGL 190, $190 \mu \mathrm{m}$ thickness) were obtained from FuelCellStore (TX, USA) and Nafion perfluorinated membranes (Nafion® 115, thickness 0.005 in) were purchased from Sigma Aldrich. The structure of the RFB used graphite felt as diffusion layers and carbon paper load with or without PEDOT:Tos as electrodes, as shown in Figure 5.5. To increase their wettability, prior to use in the cell the graphite felts were immersed in a concentrated $\mathrm{H}_{2} \mathrm{SO}_{4}$ solution for about 5 seconds and then immersed and stored in DI water. 
The positive reservoir contained $30 \mathrm{ml} 0.05 \mathrm{M}$ Tiron in $1 \mathrm{M} \mathrm{H}_{2} \mathrm{SO}_{4}$ and the negative reservoir $30 \mathrm{ml} 0.05 \mathrm{M}$ ARS in $1 \mathrm{M} \mathrm{H}_{2} \mathrm{SO}_{4}$.

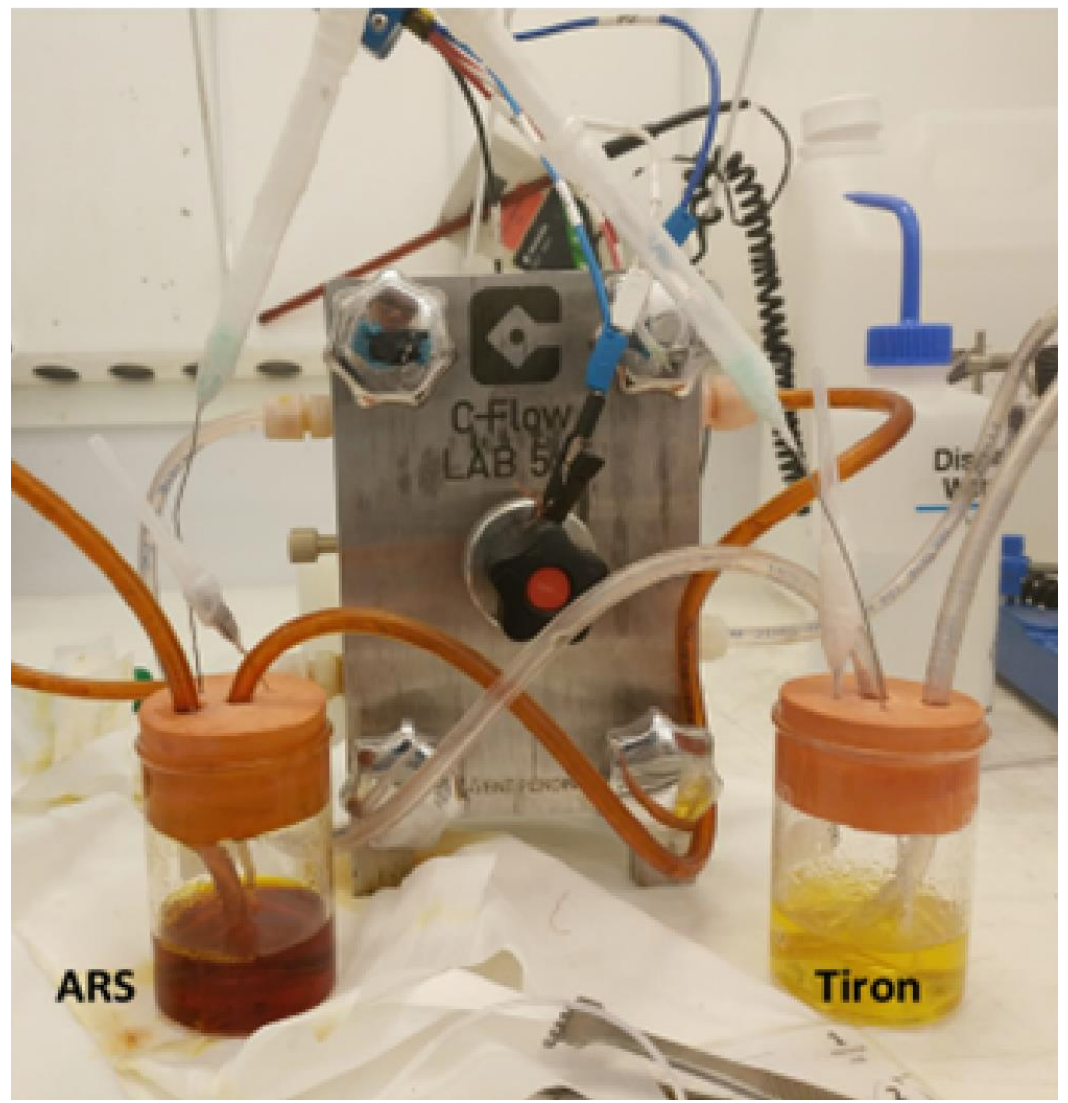




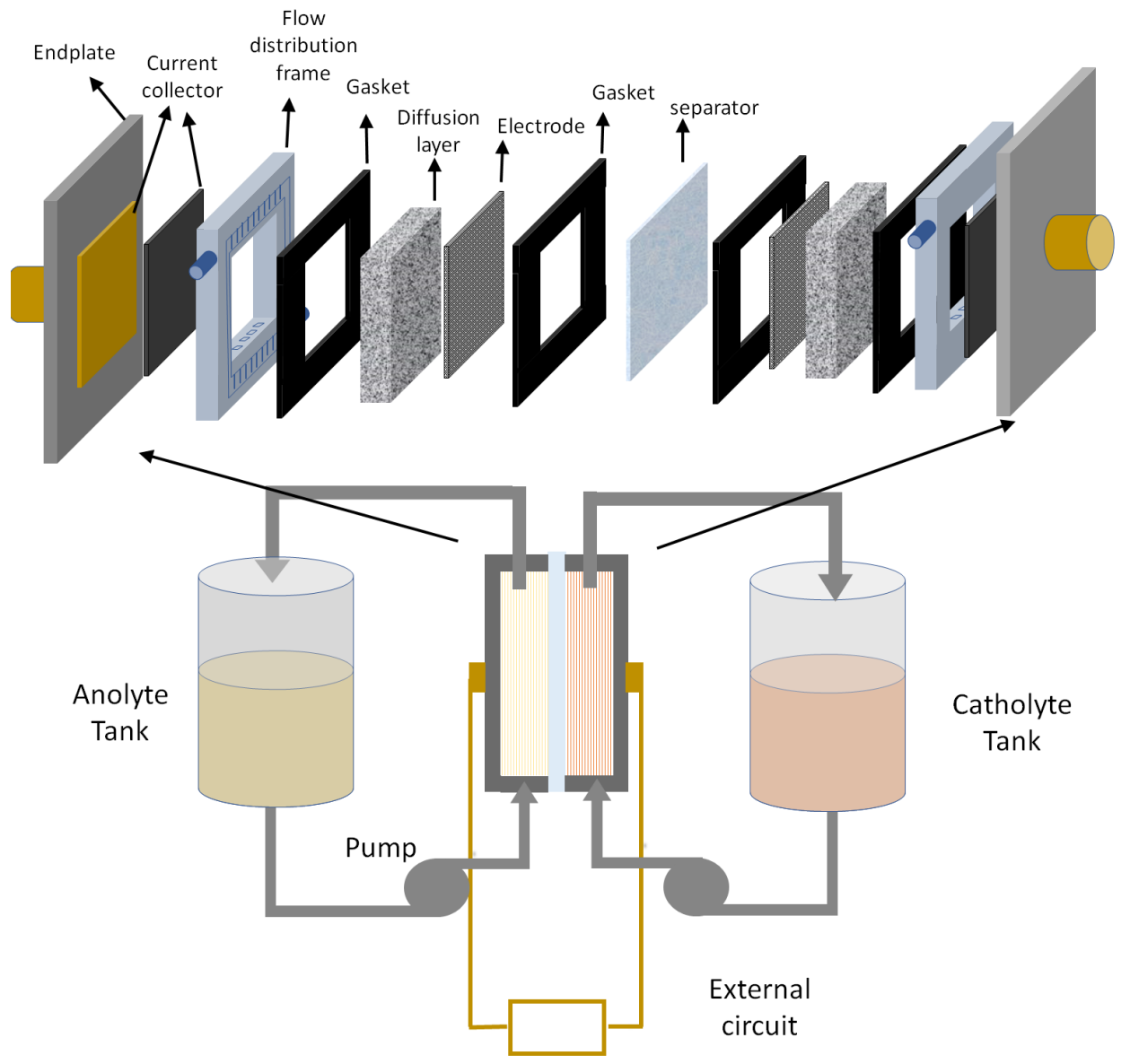

Power or Load

Figure 4.6. A practical redox flow battery setup and a schematic diagram of redox flow battery structure utilized. 


\section{Conclusion and outlook}

In this thesis, we studied the redox reactions of benzendiols, such as hydroquinone, catechol, Tiron and Alizarin Red S, on conducting polymer PEDOT with two different anions as primary dopants, namely tosylate and poly(styrenesulfonate), for their applications in electrochemical technologies such as fuel cells or redox flow batteries and implantable devices. In particular, the unique microenvironment in conducting polymers created by various dopants has a strong effect on the rate of the proton-coupled electron transfers with above quinone. This was analysized by electrochemical techniques in aqueous solutions of high and low buffer capacities in a wide $\mathrm{pH}$ range. We also investigated the strategies of twinning macromolecule lignosulfonate via ion exchange as a strategy for scaling up the chemical synthesis of lignosulfonate-PEDOT blends designed for large scale electrical storage. After studying the interplay between the polymer electrodes and the chemical nature of the quinones, we have identified the best combination for fast reversible electrochemical transformation; which were then demonstrated in quinones-based energy devices including fuel cell and redox flow battery. The outcomes of this scientific work and a outlook of future work is briefly commented as below.

\subsection{Conclusion}

Paper 1 deals with the electrocatalysis of hydroquinone/benzoquinone reactions on different PEDOTs. For the proton-asscociated redox process, maintenance of efficient ionic and electronic transports is important. An outstanding performance of benzenediol redox interconversion was observed on the PEDOT:PSS in comparison with PEDOT:Tos, glassy carbon and platinum, revealing the key effect of the polyelectrolyte dopant in ionic-electronic mixed conductor in promoting of both electron and proton transfer as well as reactant diffusion. 
The electrocatalysis on PEDOT:PSS in hydroquinone/benzequinone redox systems opens pathway towards the sustainable electrical energy storage and generation based on forest products.

Based on this, in Paper II, we studied the direct interaction between intact biopolymer, lignosulfonate and PEDOTs. It was figured out that the lignosulfonate incorporate into PEDOT matrix via counter ion exchange. The equilibrated incorporation resulted in an maximized access to the quinone redox moieties by electrical paths introduced by the PEDOT chains, which led to the enhanced stability and the increase of the electrical charge storage capacity. The effect of $\mathrm{pH}$, ionic strength as well as lignosulfonate concentration on the redox polymer incoporation have been studied. The several water-based synthetic routes towards PEDOT:biopolymer composites are presented and evaluated for up-scaling application in electrical energy storage.

Under the inspiration of the aforementioned data, we investigated the effects of counter ions, as well as the charge of the reactants on the kinetics of redox processes at the polymer electrode in Paper III. The concept of the ion-selective eletrocatalysis (ISEC) has been proposed. Indeed, the congruence in the ionic and reactant transports gains the significant increase in the rate of the redox reaction. This helped to enhance the performance of quinone/antraquinone-based organic redox flow battery. Indeed, the redox flow battery composed of Tiron as posolyte and Alizarin Red S (an antraquinone) as negolyte, showed the higher charge capacity and smaller voltage loss in the conditions of ISEC in comparison with bare electrodes.

Finally, the effect of proton transport on the PEDOTs eletrodes were studied in wide region of $\mathrm{pH}$ values of high and low buffer capacity media (Paper IV). The detailed analysis reveals an effects of ISEC on both coupling of PEDOT environment with outer electrolyte as well as on the proton transfers kinetics.

\subsection{Outlook}

Future investigations could be focused on a few aspects inspired by this thesis. (1) The redox processes on intact redox biopolymers are still far from fully understood. The market potential of utilizing redox biopolymers in electrical charge storage should motivate the technological attempts to this research area. Indeed, Nature is a reserve of redox organic quinones such as those found in lignin in wood as well as humic and fulvic acids, soil, coal and turf. Moreover, the mechanistic evaluation of corresponding redox processes would be interesing to study. In particular, the methodology utilized in Papers 3 and 4 could be applied for intact biopolymers. 
Another aspect of future research inspired by this thesis is (2) the functional evaluation of implantable interfaces. It would be very interesting to evaluate the existing implant technologies and devices for the buffer capacity and coupling with the outer media such as host tissues. In this respect it would be highly useful to develop strategies to overcome the aforementioned challenges of interface decoupling and the interfacial effect on host tissue homeostasis.

Another aspect on investigations inspired by this thesis could be (3) the use of PEDOT electrocatalysis for highly soluble redox compounds. Here, the existing state-of-the-art in the inorganic and organic redox systems developed for redox flow batteries might be investigated. Moreover, the intact redox biopolymers could be evaluated for the electrical energy storage by bulk redox interconversion. 


\section{References}

[1] S. R. James, Curr. Anthropol. 1989, 30, 1.

[2] G. Mongkhonsiri, R. Gani, P. Malakul, S. Assabumrungrat, Integration of the Biorefinery Concept for the Development of Sustainable Processes for Pulp and Paper Industry, Elsevier Masson SAS, 2018.

[3] I. B. E. Workshop, in IEA Bioenergy Summ. Conclusions, 2007, pp. 1-10.

[4] T. Wilke, M. Schneider, K. Kleinermanns, Open J. Phys. Chem. 2013, 3, 97.

[5] C. Che, M. Vagin, K. Wijeratne, D. Zhao, M. Warczak, M. P. Jonsson, X. Crispin, Adv. Sustain. Syst. 2018, 1800021, 1.

[6] S. Nawar, B. Huskinson, M. Aziz, Mater. Res. Soc. Symp. Proc. 2013, 1491, 1.

[7] B. Huskinson, M. P. Marshak, C. Suh, S. Er, M. R. Gerhardt, C. J. Galvin, X. Chen, A. Aspuru-Guzik, R. G. Gordon, M. J. Aziz, Nature 2014, 505, 195.

[8] K. Lin, Q. Chen, M. R. Gerhardt, L. Tong, S. B. Kim, L. Eisenach, A. W. Valle, D. Hardee, R. G. Gordon, M. J. Aziz, M. P. Marshak, Sicence 2015, 349, 1529.

[9] B. Yang, L. Hoober-burkhardt, F. Wang, G. K. S. Prakash, S. R. Narayanan, J. ofThe Electrochem. Soc. 2014, 161, A1371.

[10] G. Lota, G. Milczarek, Electrochem. commun. 2011, 13, 470.

[11] F. N. Ajjan, N. Casado, T. Rębiś, A. Elfwing, N. Solin, D. Mecerreyes, O. Inganäs, J. Mater. Chem. A 2016, 4, 1838.

[12] J. Edberg, I. E. and M. B. Olle Ingan, J. Mater. Chem. A 2018, 6, 145.

[13] M. A. Ghanem, Electrochem. commun. 2007, 9, 2501.

[14] Z. Yang, L. Tong, D. P. Tabor, E. S. Beh, M. Goulet, D. De Porcellinis, A. Aspuruguzik, R. G. Gordon, M. J. Aziz, Adv. Energy Mater. 2018, 1702056, 1.

[15] S. Zhang, X. Li, D. Chu, Electrochim. Acta 2016, 190, 737. 
[16] B. Yang, L. Hoober-Burkhardt, S. Krishnamoorthy, A. Murali, G. K. S. Prakash, S. R. Narayanan, J. Electrochem. Soc. 2016, 163, A1442.

[17] S. K. Lunsford, H. Choi, J. Stinson, A. Yeary, D. D. Dionysiou, Talanta 2007, 73, 172.

[18] H. Qi, C. Zhang, Electroanalysis 2005, 17, 832.

[19] C. Guo, L. Zhou, J. Lv, Polym. Polym. Compos. 2013, 21, 449.

[20] L. Y. Chang, Y. Y. Li, C. T. Li, C. P. Lee, M. S. Fan, R. Vittal, K. C. Ho, J. J. Lin, Electrochim. Acta 2014, 146, 697.

[21] C. T. Li, C. P. Lee, Y. Y. Li, M. H. Yeh, K. C. Ho, J. Mater. Chem. A 2013, 1, 14888.

[22] J. Ma, X. Wang, X. Jiao, Int. J. Electrochem. Sci. 2012, 7, 1556.

[23] E. Tamburri, V. Guglielmotti, S. Orlanducci, M. L. Terranova, Inorganica Chim. Acta 2011, 377, 170.

[24] G. Milczarek, I. Olle, Science. 2012, 335, 1468.

[25] D. H. Nagaraju, T. Rebis, R. Gabrielsson, A. Elfwing, Adv. Energy Mater 2014, 4, 1.

[26] E. Büttner, R. Holze, J. Electroanal. Chem. 2001, 508, 150.

[27] L. Duic, S. Grigic, Electrochim. Acta 2001, 46, 2795.

[28] G. Inzelt, Conducting Polymers, Springer-Velag Berlin Heidelberg, 2008.

[29] H. Shirakawa, E. Louis, A. MacDiarmid, C. Chiang, J. Heeger, J. Chem. Soc. Chem. Commun. 1977, 13, 578.

[30] C. K. Chiang, C. B. Fincher, Y. W. P. Jr., A. J. Heeger, Phys. Rev. Lett. 1977, 39, 1098.

[31] M. H. Harun, E. Saion, A. Kassim, N. Yahya, E. Mahmud, UCSI Acad. J. J. Adv. Sci. Arts 2007, 2, 63.

[32] L. Yongfang, Conducting Polymers, Organic Optoelectronic Materials, 2015.

[33] A. Elschner, S. Kirchmeyer, W. Lövenich, U. Merker, K. Reuter, PEDOT: Principles and Applications of an Intrinsically Conductive Polymer, CRC Press, Taylor \& Francis Group, LLC, Boca Raton, 2010.

[34] W. R. Salaneck, R. H. Friend, J. L. Brédas, Phys. Rep. 1999, 319, 231. 
[35] E. Said, Electrolyte-Semiconductor Combinations for Organic Electronic Devices, Linköping University, 2009.

[36] T. H. Le, Y. Kim, H. Yoon, Polymers (Basel). 2017, 9, 150.

[37] J. Zhao, D. Tan, G. Chen, J. Mater. Chem. C 2017, 5, 47.

[38] J. Bredas, B. Themans, J. ANDRE, Syhnthetic Met. 1984, 9, 265.

[39] N. Massonnet, A. Carella, O. Jaudouin, P. Rannou, G. Laval, C. Celle, J. P. Simonato, J. Mater. Chem. C 2014, 2, 1278.

[40] I. Zozoulenko, A. Singh, S. K. Singh, V. Gueskine, X. Crispin, M. Berggren, ACS Appl. Polym. Mater. 2019, 1, 83.

[41] K. Jeuris, L. Groenendaal, H. Verheyen, F. Louwet, F. C. De Schryver, Synth. Met. 2003, 132, 289.

[42] C. M. Palumbiny, F. Liu, T. P. Russell, A. Hexemer, C. Wang, P. Müller-Buschbaum, Adv. Mater. 2015, 27, 3391.

[43] I. Petsagkourakis, N. Kim, K. Tybrandt, I. Zozoulenko, X. Crispin, Adv. Electron. Mater. 2019, 1800918, DOI 10.1002/aelm.201800918.

[44] A. F. Diaz, J. I. Castillo, J. A. Logan, W. Lee, J. Electroanal. Chem. 1981, 129, 115.

[45] P. Audebert, P. Hapiot, Synth. Met. 1995, 75, 95.

[46] J. Heinze, B. A. Frontana-Uribe, S. Ludwigs, Chem. Rev. 2010, 110, 4724.

[47] J. H. P. Utley, J. Gruber, J. Mater. Chem. 2002, 12, 1613.

[48] T. Yeu, K. M. Yin, J. Carbajal, R. E. White, J. Electrochem. Soc. 1991, 138, 2869.

[49] D. Kim, I. Zozoulenko, J. Phys. Chem. B 2019, 123, 5160.

[50] Y. Xia, K. Sun, J. Ouyang, Adv. Mater. 2012, 24, 2436.

[51] N. Kim, S. Kee, S. H. Lee, B. H. Lee, Y. H. Kahng, Y. R. Jo, B. J. Kim, K. Lee, Adv. Mater. 2014, 26, 2268.

[52] D. Alemu, H. Y. Wei, K. C. Ho, C. W. Chu, Energy Environ. Sci. 2012, 5, 9662.

[53] O. P. Dimitriev, D. A. Grinko, Y. V. Noskov, N. A. Ogurtsov, A. A. Pud, Synth. Met. 2009, 159, 2237. 
[54] R. Po, C. Carbonera, A. Bernardi, F. Tinti, N. Camaioni, Sol. Energy Mater. Sol. Cells 2012, 100, 97.

[55] A. Håkansson, S. Han, S. Wang, J. Lu, S. Braun, M. Fahlman, M. Berggren, X. Crispin, S. Fabiano, J. Polym. Sci. Part B Polym. Phys. 2017, 55, 814.

[56] A. Malti, J. Edberg, H. Granberg, Z. U. Khan, J. W. Andreasen, X. Liu, D. Zhao, H. Zhang, Y. Yao, J. W. Brill, I. Engquist, M. Fahlman, L. Wågberg, X. Crispin, M. Berggren, Adv. Sci. 2015, 3, 1.

[57] R. Kroon, D. A. Mengistie, D. Kiefer, J. Hynynen, J. D. Ryan, L. Yu, C. Müller, Chem. Soc. Rev. 2016, 45, 6147.

[58] D. Evans, M. Fabretto, M. Mueller, K. Zuber, R. Short, P. Murphy, J. Mater. Chem. 2012, 22, 14889.

[59] L. Su, R. M. Darling, K. G. Gallagher, W. Xie, J. L. Thelen, A. F. Badel, J. L. Barton, K. J. Cheng, N. P. Balsara, J. S. Moore, F. R. Brushett, J. Electrochem. Soc. 2016, 163, A5253.

[60] W. J. Baucher, J. Ralph, M. Baucher, Annu. Rev. Plant Biol 2003, 54, 519.

[61] V. Nyman, G. Rose, J. Ralston, Colloids and Surfaces 1986, 21, 125.

[62] G. Milczarek, Langmuir 2009, 25, 10345.

[63] G. Milczarek, Electroanalysis 2007, 19, 1411.

[64] N. Mohammed Modawe Alshik Edris, J. Abdullah, S. Kamaruzaman, Y. Sulaiman, Microchim. Acta 2019, 186, DOI 10.1007/s00604-019-3376-y.

[65] M. M. Walczak, D. a Dryer, D. D. Jacobson, M. G. Foss, N. T. Flynn, J. Chem. Educ. 1997, 74, 1195.

[66] H. Yin, Q. Zhang, Y. Zhou, Q. Ma, T. Liu, L. Zhu, S. Ai, Electrochim. Acta 2011, 56, 2748.

[67] C. A. Bishop, L. K. J. Tong, J. Am. Chem. Soc. 1965, 87, 501.

[68] S. Steenken, P. Neta, J. Phys. Chem. 1979, 83, 1134.

[69] R. A. Binstead, B. A. Moyer, G. J. Samuels, T. J. Meyer, J. Am. Chem. Soc. 1981, 103, 2897. 
[70] C. Costentin, Chem. Rev. 2008, 108, 2145.

[71] M. H. V. Huynh, T. J. Meyer, Chem. Rev. 2007, 107, 5004.

[72] C. Costentin, D. H. Evans, M. Robert, J.-M. Savéant, P. S. Singh, J. Am. Chem. Soc. 2005, 127, 12490.

[73] M. Y. Okamura, M. L. Paddock, M. S. Graige, G. Feher, Biochim. Biophys. Acta Bioenerg. 2000, 1458, 148.

[74] D. R. Weinberg, C. J. Gagliardi, J. F. Hull, C. Fecenko, Chem. Rev. 2012, 112, 4016.

[75] J. J. Warren, T. a Tronic, J. M. Mayer, Chem. Rev. 2010, 110, 6961.

[76] K. J. Lee, J. L. Dempsey, ACS Energy Lett. 2018, 3, 2477.

[77] S. I. Bailey, I. M. Ritchie, F. R. Hewgill, J. Chem. Soc. Perkin Trans. 2 1983, 645.

[78] P. Leung, A. A. Shah, L. Sanz, C. Flox, J. R. Morante, Q. Xu, M. R. Mohamed, C. Ponce de León, F. C. Walsh, J. Power Sources 2017, 360, 243.

[79] Q. Lin, Q. Li, C. Batchelor-Mcauley, R. G. Compton, J. Phys. Chem. C 2015, 119, 1489

[80] E. Laviron, J. Electroanal. Chem. 1984, 164, 213.

[81] M. Quan, D. Sanchez, M. F. Wasylkiw, D. K. Smith, J. Am. Chem. Soc. 2007, 129, 12847.

[82] M. R. Deakin, P. M. Kovach, K. J. Stutts, R. M. Wightman, Anal. Chem. 1986, 58, 1474.

[83] J. Wang, L. Wang, Y. Wang, W. Yang, L. Jiang, E. Wang, J. Electroanal. Chem. 2007, 601,107

[84] L. R. B. Allen J., Faulkner, Electrochemical Methods: Fundamentals and Applications, Wiley Textbooks, 2000.

[85] A. M. O. B. Christopher M. A. Brett, Electrochemistry: Principles, Methods, and Applications, Oxford University Press, 1993.

[86] Allen J. Bard; Larry R., Fundamentals and Applications, 2001.

[87] A. D. McNaught, A. Wilkinson, in IUPAC. Compend. Chem. Terminol., Blackwell 
Scientific Publications, Oxford, 1997, p. 1491.

[88] R. Guidelli, R. G. Compton, J. M. Feliu, E. Gileadi, J. Lipkowski, W. Schmickler, S. Trasatti, Pure Appl. Chem. 2014, 86, 245.

[89] R. Guidelli, R. G. Compton, J. M. Feliu, E. Gileadi, J. Lipkowski, W. Schmickler, S. Trasatti, Pure Appl. Chem. 2014, 86, 259.

[90] W. Joseph, Analytical Electrochemistry, 2002.

[91] C. Karlsson, H. Huang, M. Strømme, A. Gogoll, M. Sjödin, Electrochim. Acta 2015, $179,336$.

[92] J. Curie, P. Curie, Rendu 1880, 91, 294.

[93] G. Sauerbrey, Zeitschrift fiir Phys. 1959, 155, 206.

[94] T. Nomura, M. Okuahara, Anal. Chem. Acta 1982, 142, 281.

[95] M. Rodahl, F. Höök, A. Krozer, P. Brzezinski, B. Kasemo, Rev. Sci. Instrum. 1995, 66, 3924.

[96] M. Rodahl, B. Kasemo, Rev. Sci. Instrum. 1996, 67, 3238.

[97] M. Rodahl, B. Kasemo, Sensors Actuators, A Phys. 1996, 54, 448.

[98] M. V. Voinova, M. Jonson, B. Kasemo, J. Phys. Condens. Matter 1997, 9, 7799.

[99] M. V. Voinova, M. Rodahl, M. Jonson, B. Kasemo, Phys. Scr. 1999, 59, 391.

[100] M. C. Dixon, J. Biomol. Tech. 2008, 19, 151.

[101] Y. T. and M. Takai, in Compend. Surf. Interface Anal. (Ed.: Manabu Kiguchi), Springer Nature Singapore Pte Ltd, 2018, pp. 509-520.

[102] G. C. Papanicolaou, S. P. Zaoutsos, in Creep Fatigue Polym. Matrix Compos., Woodhead Publishing Limited, 2011, pp. 3-47.

[103] K. K. Kanazawa, J. G. Gordon, Anal. Chem. 1985, 57, 1770.

[104] M. Rodahl, B. Kasemo, Sensors Actuators, B Chem. 1996, 37, 111.

[105] A. Widom, J. Krim, Phys. Rev. B. 1986, 34, 1403.

[106] E. T. Watts, J. Krim, A. Widom, Phys. Rev. B. 1990, 41, 3466. 
[107] J. Krim, R. Chiarello, J. Vac. Sci. Technol. B 1991, 9, 1343.

[108] X. Du, J. Fang, D. M. Zhu, Analyst 2018, 143, 3209.

[109] “The principles of dynamic light scattering," can be found under https://wiki.antonpaar.com/en/the-principles-of-dynamic-light-scattering/, n.d.

[110] "Atomic force microscopy," can be found under https://en.wikipedia.org/wiki/Atomic_force_microscopy, n.d.

[111] "Atomic force miscroscopy," can be found under https://en.wikipedia.org/wiki/Atomic_force_microscopy, n.d.

[112] "Ultraviolet-visible spectroscopy," can be found under https://en.wikipedia.org/wiki/Ultraviolet-visible_spectroscopy, n.d.

[113] M. Winter, R. J. Brodd, Chem. Rev. 2004, 104, 4245.

[114] L. Y. Chang, Y. Y. Li, C. T. Li, C. P. Lee, M. S. Fan, R. Vittal, K. C. Ho, J. J. Lin, Electrochim. Acta 2014, 146, 697.

[115] Z. Dapeng, L. Qinghua, L. Yongdan, in React. Process Des. Sustain. Energy Technol. (Ed.: F. Shi), Elsevier, 2014, pp. 61-97.

[116] "Flow battery," can be found under https://en.wikipedia.org/wiki/Flow_battery, n.d.

[117] A. Z. Weber, M. M. Mench, J. P. Meyers, P. N. Ross, J. T. Gostick, Q. Liu, J. Appl. Electrochem. 2011, 41, 1137.

[118] S. M. Haile, Acta Mater. 2003, 51, 5981.

[119] C. Che, M. Vagin, U. Ail, V. Gueskine, J. Phopase, R. Brooke, R. Gabrielsson, M. P. Jonsson, W. C. Mak, M. Berggren, X. Crispin, Adv. Sustain. Syst. 2019, 1900039. 


\section{Papers}

The papers associated with this thesis have been removed for copyright reasons. For more details about these see:

http://urn.kb.se/resolve?urn=urn:nbn:se:liu:diva-161645 


\section{FACULTY OF SCIENCE AND ENGINEERING}

Linköping Studies in Science and Technology, Dissertation No. 2033, 2019 Department of Science and Technology

Linköping University

SE-581 83 Linköping, Sweden

wWw.liu.se 